UCRL-50007-82

Distribution Category UC-41

UCRL- $-50007-82$

DE83 015598

\title{
Hazards Control Department Annual Technology Review 1982
}

\author{
Scientific Editor: R. V. Griffith
}

Manuscript date; June 15, 1983

\author{
DISCLAIMER
}

\begin{abstract}
This report was prepared as an account of work spbisored by an agency of the United Slates Governinent. Neither the United States Government not any agency therenf, sos any of their employes, makes any warranty, express or implierl, of assumes any legal liability or responsibility for the accuracy, completeness, or usefulness of any information, appazatus, product, of procuss disclosed, or represetts that its use would not infringe privately owned rights. Referenct herein to any specific commeteial producl, process, or service by trade name, tradematk, mantuacturer, or otherwise does nol necessarily constitute or imply its endorsemenl, recommendation, or favoring by the United States Government or any agency thereof. The views and opinions of authors expressed herein do not necessarily state or serfect those of the United States Government of any agency thereor.
\end{abstract}

\section{LAWRENCE LIVERMORE NATIONAL LABORATORY \\ Univeristy of California - Livermore, California - 94550}




\section{Foreword}

This report, which covers the period from October 1981 to September 1982, is divided into three major sections. The first section, Progress Reports, covers the status of activities undertaken or continuing during the period; additional reports or separate publications will cover the final results of these activities. The second section, Technical Notes, contains reports on interesting activities of a more limited scope on which further reporting is not anticipated. The third section lists recent publications.

Readers who are interested in more detail may contact the authors of the reports. 


\section{Contents}

\section{PROGRESS REPORTS}

Industrial Hygiene

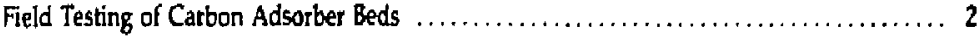

Instrument Development

A Real-Time Monitor for Tritium in Waste Water $\ldots \ldots \ldots \ldots \ldots \ldots \ldots \ldots \ldots \ldots, 5$

Environmental Protection

Adding ân On-Line X-Ray Fluorescence Analyzer for Metals

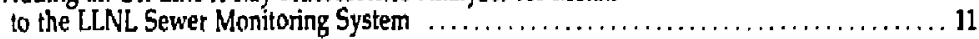

Radiation Protection

Progress in Multi-Target TRAX Development .............................. 13

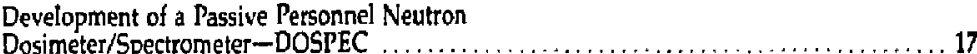

Fire Safaty

Effectiveness of Standard and Alcohol-Resistarit

Aqueous-Film-Forming Foam (AFFF) on A.lcohol Fires ...................... 25

\section{TECHNICAL NOTES}

Industrial Hygiene

Detemination of Explesives Using High-Performance

Liquid Chromatography ............................................ 29

Self-Contained-Breathing-Apparatus Protection at

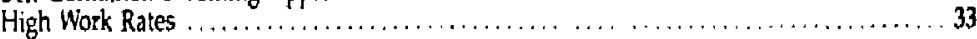

Radjatjon Protection

Neutron and Gamma-Ray Measurements at the LANL

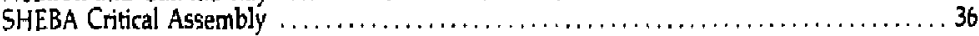

Additional Calibrations of the PTB Beta Sources $\ldots \ldots \ldots \ldots \ldots \ldots \ldots \ldots \ldots \ldots \ldots . \ldots \ldots$

Probability of Interaction and Energy Deposition of

Neutron-Induced Recoil Protons in a Cell Plasma Membrane $\ldots \ldots \ldots \ldots \ldots \ldots \ldots \ldots, 47$

Calibration of the PNR-4 Neutron Remmeter for

Weapons-Like Spectra .............................................50

A Single. Calculation Comparison of MORSE76 $\mathrm{L}$ and ANISN $\ldots \ldots \ldots \ldots \ldots \ldots \ldots \ldots, 52$

Effective Absorption Thickness of the ${ }^{7} \mathrm{Li}$ TLD

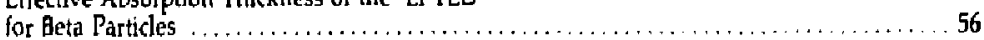

Fire Safely

Evaluation of the Fire Properties and Potential Safery

Hazard of Building 431's Exterior Wall Patiels . ............................... 59

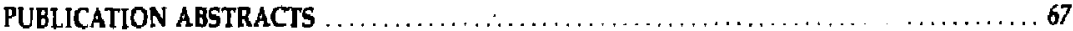




\section{Progress Reports}




\title{
Field Testing of Carbon Adsorber Beds
}

\author{
P. M. Siltarengen 1. S. fohmsim, R. A. do Ruan, and C. A. Harder
}

Activated carbon adsorbers are used in air cleaning systems at LLNL to remove hazardous gases or vapors. The Safety Science Group has been working on an in-place field test procedure to measure the residual adsorption capacity (RAC) of large-bed activated carbon adsorbers. The effects of humidity and organic vapor load on testing for RAC have been studied. A parallel-flow sampling manifold for an in-place field test is near completion and will soon be installed; laboratory experiments have been performed that will guide testing of the cartridges from the sampling manifold. Finally, a portable field trat instrument is being prepared for testing carbon beds at LLNL.

\section{Experimental}

Previous work has indicated that a chromatographic theory can be used to provide a measurement of the residual adsorption capacity (RAC) of carbon adsorbers. ${ }^{1.2}$ Recent work done in the Safety Science Group at LLNL has also shown that pulse testing with methane or ethane gas can indicate the RAC of a carbon bed. ${ }^{3}$ in this case, activated carbon cartidges (cylindrical, 2 in in diameter by 4 in. long) were loaded with varying amounts of toluene. The carbor was then tested with a $5-\mathrm{ml}$ pulse of ethane. Typical data are shown in Table 1. As the RAC decreases, the retention time (RT) for ethan: on the adsorber also decreases; RT of the test gas is thus proportiona] to RAC. When data from a series of such experi. ments are compiled, andytical-łype curves can be derived. Such an analysis is shown in Fig. 1.

Although adsorber testing with a weakly adsorbed gas like ethane can provide information on the condition of the bed, our work has also show a limitation of this type of test. From Fig. 1, it is apparent that above $50 \%$ relative humidity $(\mathrm{RH})$, a pulse test will provide no information about the RAC of an adsurber bed. The humidity of the air in the system containing the adsorber bed is thus a critical prameter. It should be noted that in these laboratory experiments, the carbon was sub. jected to a 24-h equilibration period in the humidity conditions chosen for testing. The purpose of the equilibration was to maintain the amount of water on the carbon and in the air stream as nearly constant as possible during testing.
Evidence to show that the amount of water on carbon has an effect on the RT of the test gas is shown in Table 2. The data presented were of. tained under experimental conditions identical to those shown in Table 1. The first column shows the $\mathrm{RH}$ conditions during equilibration and testing. The second column shows the RT observed for ethane at the start of the test, before any toluene

Table 1. Results of pulse-testing' a carbon cartridge $^{b}$ with ethane gas.

\begin{tabular}{ccc}
$\begin{array}{c}\text { Exposure time } \\
\text { (h) }\end{array}$ & $\begin{array}{c}\text { RT } \\
(\mathrm{min})\end{array}$ & $\begin{array}{c}\text { RAC } \\
(7)\end{array}$ \\
\hline 0 & 2.50 & 300 \\
0.40 & 1.70 & 90 \\
0.72 & 1.50 & 83 \\
1.02 & 1.25 & 76 \\
1.40 & 1.00 & 67 \\
1.52 & 0.85 & 64 \\
1.74 & 0.71 & 58 \\
2.10 & 0.49 & 50 \\
2.31 & 0.35 & 45 \\
2.50 & 0.22 & 40 \\
3.04 & 0.14 & 27 \\
\hline
\end{tabular}

- Flow velocity of ethane $=8.2 \mathrm{~cm} / \mathrm{s}$.

'Sureliffe Speakman $2089 \mathrm{C}$ carbon loaded with 3000 ppm toluene in air flow of to liters/min lair at 40 ? RH. 25. C). 


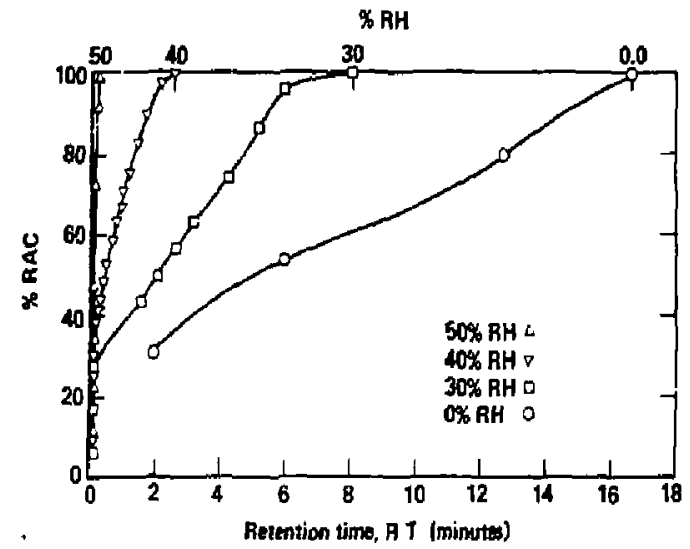

Figure 1. RAC of carbon cartridges pulse-tested wilh ethane, at various relative humidities of air.

was loaded on the carbon. The RT for ethane decreases as the RH increases. Eventually, RT derases to the condition described above, where no information on RAC is provided.

Two other phenomena pertaining to carbon were revealed during this investigation. First, at $\mathrm{RH}$ values greater than $50 \%$, the $\mathrm{RAC}$ of the carbon is still quite hight. As shown in the fourth column of Table 2, nearly the same mass of toluene can be removed from the air stream at high $\mathrm{RH}$ conditions as at low. Adjsorbed water can apparently affect the carbon surface so that the weakly adsorbed ethane is barely retained, causing the pulse test to fail. The more strongly adsorbed toluene, however, is still retained by carbon even in the presence of signijicant quantities of water.

A second important phenomenon is desorption, A carbon cartridge completely saturated with toluene was left in the flow system and expcsed to humid air containing no toluene; the downstream air was monitored and the toluene was observed to desorb from the carbon. With time, the RAC of the carbon increased and returned to a level near that of the new material. This was medsured by a steady increase in the ?T for ethane (pulse tested) as desorption proceeded. In the case of carbon tested at humidities of $40 \%$ or lower (where the ethane pulse test is a good indicator of RAC), the RT values returned to their originil (preloading) values. In the higher- $\mathrm{RH}$ cases, the carbon was found to have renewed its capacity for toluene. When we again challenged the bed with an air flow containing $3000 \mathrm{ppm}$ toluene, the carbon cleaned the air as it did before saturation.

Table 2. Effect of relative humidily on the RT of ethane.

\begin{tabular}{|c|c|c|c|c|}
\hline$\approx \mathrm{RH}$ & $\begin{array}{l}\text { RT of ethane } \\
\text { at start of } \\
\text { test (min) }\end{array}$ & $\begin{array}{l}\text { Weight of } \\
\text { carbon in } \\
\text { adsorber bed } \\
\text { (g) }\end{array}$ & $\begin{array}{l}\text { Keight of } \\
\text { tolatne } \\
\text { (g) }\end{array}$ & $\begin{array}{l}\text { Wieight of water } \\
\text { atter } 24-h \\
\text { equilibration } \\
\text { (g) }\end{array}$ \\
\hline$<3$ & 36.4 & 109.4 & 35.5 & - \\
\hline 30 & 8,0 & 111.9 & 26.3 & 8.3 \\
\hline 40 & 2.5 & 113.7 & 24.8 & 14.6 \\
\hline 50 & 0.31 & 109.8 & 21.8 & 33.9 \\
\hline 60 & 0.16 & 111.9 & 21.8 & 34.9 \\
\hline 70 & 0.13 & 110.8 & 24.0 & 36.3 \\
\hline
\end{tabular}




\section{Discussion}

The desorption of toluene that we observed raised several questions. First, what are the general trends of desorption on compounds of interest to industrial hygienists at LLNE? Second, what desorption trends are observed when shemicals are compared by physical constants such as boiling point, vapor pressure, molecular size, and functional groups (polarity) on the molecule? Finally, can a "retentivity index" for organic molecules be derived that would be of functional value to the industrial hygiene community?

\section{Future Work}

An instrument is currently being modified that will allow in-place field testing of existing adsorber beds. In contrast to the fixed-manifold system for in-place testing, this approach employs a portable instrument. $A$ gas chromatograph is being fitted with a pump and a gas-sampling valve (GSV); the CSV has two sampling loops that al- low alternate measurement of the air stream above and below the carbon bed. Testing can then be conducted according to American Association for Contamination Control Standard CS-8. By this standard, a commercial freon is released into the air stream upstream from the carbon bed; the challenge concentration must be at least 10,000 times greater than the minimum sensitivity of the detection system. Al least three upstream and three downstream determinations are then made at intervals of one minute, and there must be no downstream indication of the challenge gas. We expect the modified gas chromatograph to allow us to canty out this type of testing.

\section{References}

1. W. F. Klading, A. H. Weiss, and L. A. Jonas, Carbon 18, 31 (1980).

2. A. H. Weiss, T. Freund, and E. Biron, Chem. Eng. 4, 213 (1980).

3. P. M. Swearengen, J. S. Johnson, R. A. da Roza, and C. A. Harder, paper No, 70 in Proceedings of the AIHA Conf.. Cimcinnati, Olio. June 1970 . 


\title{
INSTRUMENT DEVELOPMENT
}

\section{A Real-Time Monitor for Tritium in Waste Water}

\author{
C. J. Huntzinger, D. E. Hankins, J. L. Cate, Jr, M. Dreicer, and A. A. Odell
}

We are developing an automatic on-line tritium monitoring system for a combined industrial and sanitary waste water stream. it will allow early detection and mitigation of either chronic or acute tritium spills to the sewer. Two major tasks were identified: to provide a means of obtaining relatively pure and representative samples, and to develop a reliable low-level tritium detector. This article reviews the highlights of our progress during the past year in solving these two tasks.

\section{History}

Since it was formed 30 years ago, LLNL has maintained a constant environmental surveillance program to ensure that concentrations of potentially hazardous materials in its effluents are well below existing guidelines. One of these effluents is the combined flow of sanitary and industrial waste water. Initially, sampling consisted of taking monthly sludge samples from the Livermore Water Reclamation Plant and a 24-h composite sample as the waste water left the Laboratory boundary. About 13 years ago the waste water monitoring capabilities were improved vastly with the addition of on-line low- and high-energy-photon detectors and a pH monitor.' We are continuing to improve our monitoring capabilities by adding an on-line $x$-ray fluorescence analyzer (XRFA' for metals (described in the next article), and by developing this tritium waste water monitor.

\section{System Specifications}

The monitoring system has two subunits: sample collection and radiation detection. It must be:

- Sensitive enough to detect $1-20 \mathrm{pCi}$ $\mathrm{HTO} / \mathrm{ml}(2,2-44.1 \mathrm{dpm} \mathrm{HTO} / \mathrm{ml})$. basis.

- Economical to operate on a continuous

- Rugged enough to operate at a remote environmental sannpling station.

- Easy to maintain on a routine basis.

- Simple for a casual user to opetate.
- Capable of being connected to the existing microcomputer alarm system.

- Capable of obtaining a representative and particulate-free liquid sample.

\section{Investigations}

\section{Sample Collection}

Osborne and his colleagues ar Atomic Energy of Canada, Ltd., have vasi experience collecting tritiated water vapor with bubblers ${ }^{2}$ and their studies prove that this approach to collecting a clean sample works. In our application, a dry gas would be bubbled through a representative waste water stream, leaving behind suspended particulates and dissolved chemicals. The vapor along with any HTO present would be collected from the gas stream. We constructed an experimental bubbler (Fig. 1). The collected sample vapor remained clean even when the starting solution had various combinations of chemicals, such as potassium permanganate, food colorings, light motor oil, and detergents. We also found we could transfer sufficient sample vapor for our counting requirements at room temperature.

Two major difficulties became apparent. It would take a large number of vapor flow meters, relative humidity indicators, level sensors, and valves to accurately control the rate of vapor transfer. There was also a question as to how we would introduce the vapor into the liquid scintillator cacktail. About this time a new plastic product called Nafion, developed by Du Pont to dry process-gas streams, came to our attention. It is a 


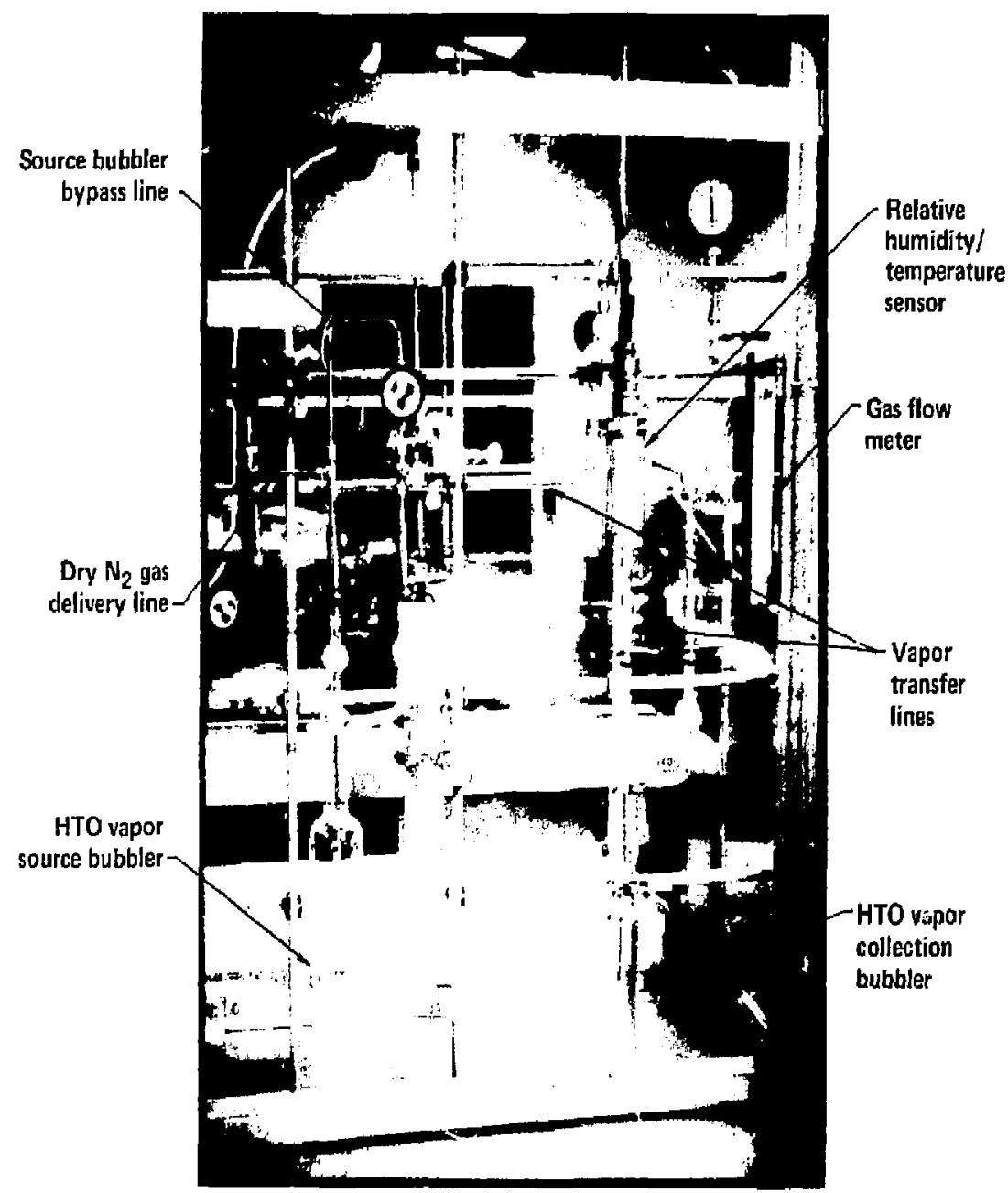

Figure 1. Experimental HTO vapor bubbler.

semipermeable membrane, similas to solid sulfuric acid, that is permeable to water only. It appeared that we could solve these two problems by passing the liquid scintillator through the center of the Nafion tubing, with the vapor sample around the exterior of the tubing, and have the vapor diffuse directly into the scintillator. We obtained three samples of tubirg, ranging in size from $0.625-\mathrm{mm}$ i.d. by $0.875-\mathrm{mm}$ o.d. to $2.75-\mathrm{mm}$ i.d. by $3.125-\mathrm{mm}$ o.d. Our studies showed that tritiated water vapor diffused into the liguid scintil- lation cocktail, but the largest concentration ratio we measured between scintillator and starting sample water was 0.0078 , which was disappointingly low-the goal being to achieve the largest decimal up to a maximum of one, which would represent the same concentration of HTO in the scintillator as in the sample water.

At this point we decided that the benefits of a simpler sampling method would more than compensate for a decrease in counting efficiency due to chemicals in the purified sample. Recently, a 
new type of filter media called cross-flow filters or tangential flow filters has been developed, primarily to concentrate biological cell colonies. They differ from conventional "dead-end" filters in that the sample stream continuously washes the filter face, greatly extending its useful life.

The Acroflux capsule cross-flow filter made by Gelman seened to be the leading candidate because of its modular design, low cost, and ease of disposal. We acquired a 1.2- $\mu \mathrm{m}$ pore size unit and installed it at the monitoring station for a trial run. It was downstream from the macerator, a mechanical device that reduces all particulates to a size of $100 \mu \mathrm{m}$ or less. The sample waste water stream was flowing at approximately $3 \mathrm{gal} / \mathrm{min}$. Unfortunately, the capsule operated for approximately 10 min before its flow was ocduded with a fibrous matrix. This matrix resisted attempts to clean it by backwashing.

The principles of cross-fow filtration are relatively straightforward so we decided to design our own prototype unit. After numerous modifications, we settled on the configuration shown in Fig. 2. The waste water stream flows down the XRFA chute over the face of the 49-mm-diam filter disk. The disk is placed on the expanded metal filter support, sealed to the back of the chute with an $\mathrm{O}$-ring, and held in place with a screw-on retainer ring.
A variety of pore sizes of filter disks have been tried, ranging in size from $10 \mu \mathrm{m}$ down to 0.5 $\mu \mathrm{m}$. (For reference, $1.2 \mu \mathrm{m}$ is considered general filtration and $0.2 \mu \mathrm{m}$ is considered sterilization.) The most inportant quality seems to be the macroscopic surface texture. Smooth-surface filters have lasted approximately 10 times longer than rough-surface filters of comparable pore size. A $1-\mu \mathrm{m}$ Teflon filter disk, wetted with ethanol, has lasted the longest-approximately 10 days at a filtrate flow tate of $0.23 \mathrm{ml} / \mathrm{min}$.

\section{Radiation Detection}

Numerous methods are available for the detection of tritiated water but few meet our sensitivity requirement of $1-20 \mathrm{pCj} \mathrm{HTO} / \mathrm{ml}$. We considered these methods:

- Sample enrichment followed by a less sensitive detection method.

- Conversion of sample to a courting gas for intemal proportional counting.

- Mixing sample vapor with a counting gas for internal proportioral counting.

- Counting sample vapor through a largevolume ion chamber.

- Passing condensed sample through a solid scintillator array.

- Continuous batch processing af condensed sample in a liquid scintillation counter.

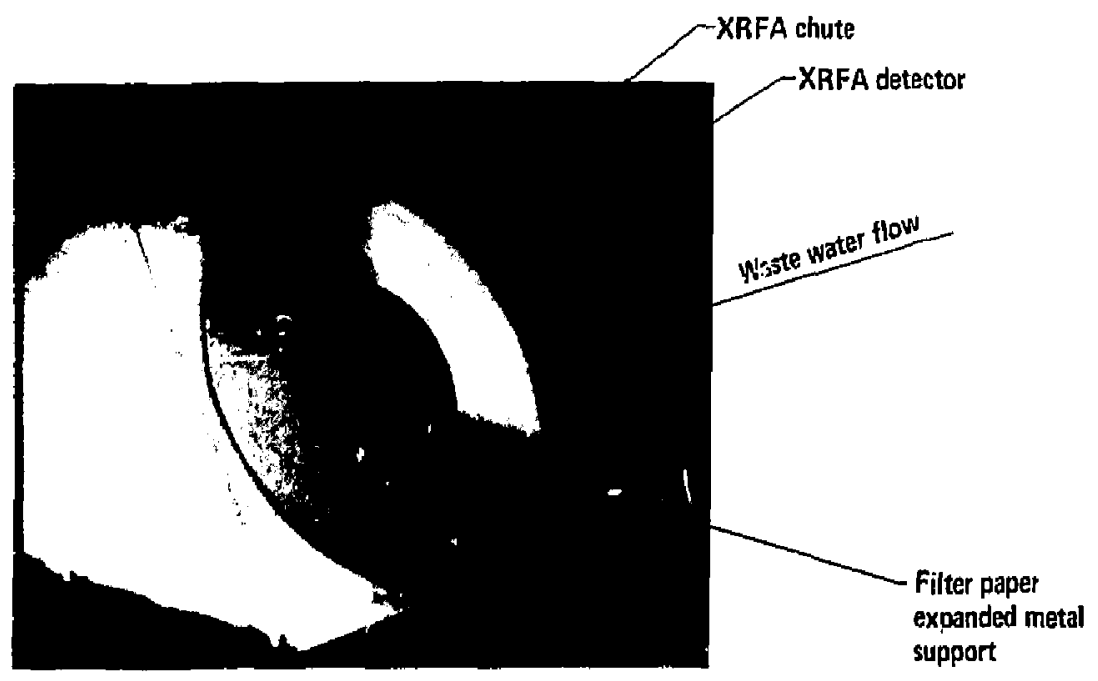

Figure 2. Prototype cross-flow filtration init mounted in XRFA monitor flume. 
- Passing condensed sample through a liquid-scintillation-counter flow cell.

The first two methods were discarded because they involve coriplicated chemical processes not easily done on a continuous basis and the enrichment process would take days to complete. The next two shethods involving counting the sample vapor in the gaseous phase were discarded because they did not have adequate sensitivity. For example, at $70^{\circ} \mathrm{F}$ and $80 \%$ relative humidity, $10 \mathrm{pCi} \mathrm{HTO} / \mathrm{ml}$ of liquid (a middle value for our sensitivity requirement) corresponds to $0.15 \times 10^{-15} \mathrm{Ci} \mathrm{HTO} / \mathrm{mil}$ of vapor. This is a small fraction of one disintegration per minute per milliliter of vapor. It could not be detected because the background count rate is Jarge and there are potential electrical instabilities and loss of sensitivity as the vapor content of the counting; gas increases. The last three methods utilize scintillation counting. A solid scintillator array was preferred because of tts simplicity, but it was discarded because it has low sensitivity due to the short range of tritium betas ( $6 \mu \mathrm{m}$ in water), possible chemical reactions between the waste water and fluor, and chronic loss of sensitivity due to biofouling (we have loosely defined biofouling as the unwanted growth of microscopic, opaque colonies of micro- organism'.). Liquid scintillation counting in a continuous batch mode (counting one discrete vin] while another is being collected) would have provided the greatest sensitivity, but requires a prohibitively elaborate system of flowmeters, valves, level sensors, and moving parts.

Liquid scintillation counting with a continuats flow cell appeared to be an optimum compromise between sensitivity and simplicity. $\mathrm{Th}_{\text {, con- }}$ densed sample stream would be mixed i. h a precise amount of liquid scintillation cocktail before being pumped through a flow cell detector. The major drawback to this method was the expense of using liquid scintillation cocktail continuously. We decided to design the detector to limit cocktail consumption to 1 gal per week $(0.4 \mathrm{ml} / \mathrm{min})$, which seemed to be the best compromise between sensitivity and cocktail expense.

There are a number of simple liquid scinillation flow cell detectors on the market. Most of them were designed to monitor high-specificactivity effluents from High Performance Liquid Chromatography (HPLC) columns. We were able to acquire a Radiomatic Instruments and Chemical Co., Inc.r Model HP on long-term loan (see Fig. 3). The detector element is a thin-wall Teflon tube coiled flat and sandwiched between two

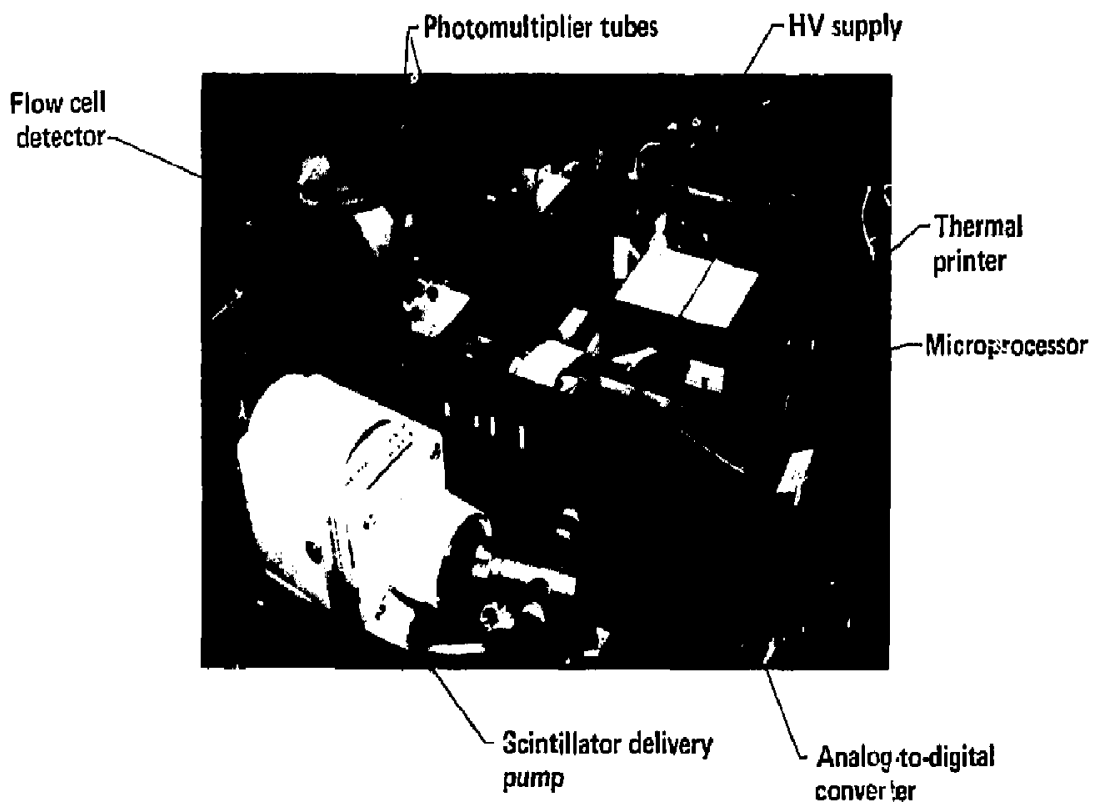

Figure 3. Radiomatic Instruments and Chemical Co. Model HP radioactive flow detector (top cover open). 


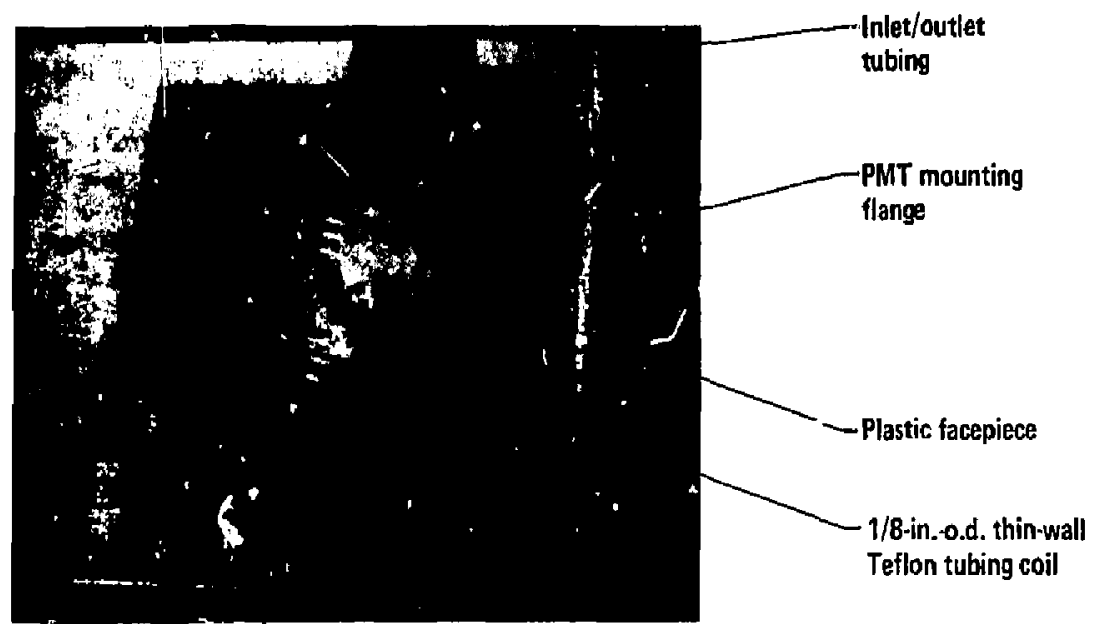

Figure 4. Scintillation flow cell.

matched photomultiplier (PM) tubes. The usable cell volume is $2 \mathrm{ml}$ (see Fig. 4).

We haracterized the performance of the unit as follows:

- The optimum ratio of scintillator to sample was between $3.5 / 1$ and $4 / 1$, depending on the scincillator used. At ratios of $3 / 1$ and below, the mixture went into an unstable two phase state and at ratios of $1.3 / 1$ and beiow it became a viscous gel.

- The maximum counting efficiency for trituum was measured at $22.6 \%$.

- The mirimum detectable activity (MDA) was calculated using the method of Tritium Measurement Techniques. ${ }^{3}$ It was $34 \mathrm{pCi} / \mathrm{ml}$ with "nown" (stable) background and $47 \mathrm{pCi} / \mathrm{ml}$ with "ur..known" (unstable) background.

- The two available electronic windows were used to establish a quench correction curve by the internal channel ratio (ICR) method. As the quench of the solution increases the entire spectrum is shifted down in energy. The ratio of the count rate in the two ovellapping windows gives an indication of how far the spectrum has been shifted. Using a sist of standard quench solutions, it is fairly easy to develop a curve that shows the amount of quench present for any unknown channel ratio.

We believe one of the largest potential maintenance problems is biofouling within the tritium monitor tubing and scintillation tubing. To avoid this we recently installed an Ultra Dynamics
Model 500 ultraviolet flow sterilizer. While the dissolved chemicals and turbidity in the waste water have prevented us from achieving the $16,000-\mu \mathrm{W}-\mathrm{s} / \mathrm{cm}^{2}$ dose racommended by the U.S. Public Health Service for sterilization of drinking water supplies, we have vibserved a reduction in the particulate hangup within the XRFA chute and associated tubing. An additonol benefit has been a reduction in the olfactory index of the 24-h composite sample.

\section{Future Investigations}

In the near future, we plan to operate the model HP flow cell detector in conjunction with the cross-flow filter disk. Initially this will be for short-term attended runs, and if successful for long-term unattended runs. When these runs are completed and we are satisfied the combined system will meet our expectations, we will begin to design and construct our own flow cell detector. It will probably include the following design features:

- A flat, spiral-wound coil of thin-wall Teflon tubing sandwiched between the two matched PM tubes, similar to the flow cell developed by Schram and Lombaert. The light-transmission properties of the cell will be improved by filling all voids with water or silicon oil, coupling the cell to the PM tubes with optical grease, and placing reflectors around the perineter of the cell. 
- The two PM tubes will be used in the coincidence counting mode.

- The flow cell and PM tubes will be placed in a layered metal shield.

- An external standard source will be used as an indicator for quench correction. The extemal source should provide statistically more signifcarit results than thi internal channel ratios (ICR) method. The source will be actuated by a simple mechanical system automatically for a 1-min count to determine the quench present, then removed so the sample alone can be counted.

- Standard NIM high-voltage and signalprocessing modules.

- Electronic connection to a multichannel analyzer and the alarm system LSI-11. They will be used to calculate the necessary quench correction using the Extemal Spectral Index of Sample method (ESIS), in which the spectrum is divided between numerous adjacent electronic windows rather than two large overlayping windows as in the ICR method. The ESIS spectrum is similar to what might $\mathrm{t}$ seen with a multichannel analyzer. The counts in each charnel are used to calculate the first moment of the spectra. A set of known quench standards is used to develop a curve that relates the first moment of a sample to the necessary quench correction. This method is more sensitive than the externat standard channel ratio method because the numerous small channels allow smal] changes of quench to be detected more readily.

- A single-pump motor with two heads to deliver the sample and liquid scintillator streams.
- Combination of the two streams in a mixing tee or packed-bed reactor. This will avoid the need for a mechanical stirring cell.

The tritium monitor may be utilized to detect ather dissolved isotopes in the waste water. Occasionally, a Lab employee has a nuclear medicine scan off site; if he returns to work later that day, there is a good chance he will void some of the remaining diagnostic isotope. The high- and lowenergy-photon detectors at the monitoring station easily detect trace quantities of these diagnostic isotopes. The tritium monitor might allow us to rapidly determine if a high photon count rate was caused by a nuclear medicine diagnostic isotope; we would add additional electronic windows that would be set specifically to s.tonitor for the lowenergy photons or beta particles from common ai agnostic isotopes.

\section{References}

1. J. L. Cate, Jr. and T. O. Hoeger, "A Radioisotope Monitoring System for Sewage Effluent," American Industrial Hygiene) Iurnal (October 1972).

2. R. V. Osborne, Monitoring Reactor Effluents for Tritium: Problems and Possibilities, Atomic Energy of Canada Lid, Chalk River, Ontario, Report AECL-4054 (1971).

3. National Council on Radiation Protection and Measurements, Tritium Measuremen! Techmiques, NCRP Report No. 47 (1976).

4. E. Schram and R. Lombaert, Anal. Biochem, 3, 68 (1962). 


\section{ENVIRONMENTAL PROTEC:ION}

\section{Adding an On-Line $X$-Ray Fluorescence Analyzer for Metals to the LLNL Sewer Monitoring System}

\section{L. Cale, D. W. Rueppel, assd C. I. Huntzinger}

About 13 years ago, we built a montioring system for the LLNL sanitary sewage effluent. This system monitored for radioactive materials and excursions in $\mathrm{pH}$ and has, with some modernization, served the lab faithfully. ${ }^{1.2}$ We later recognized a need to monitor certain toxic materials-namely, chromium, nickel, copper, and zinc-not so much for environmental reasons, but to protect the microbial digesters at the Livermore Water Reclamation Plant against upset caused by these elements. Over the last several years we have developed a system based on isotope-excited $x$-ray fluorescence analysis that can detect these four elements at or below our effluent concentration limits; it also monjors the levels of manganese, iron, cobalt, arsenic, bromine, mercury' and lead.

\section{Components}

The system consists of an exciter/detector unit and a data processing unit. The exciter fa 20$100 \cdot \mathrm{mCi} i^{109} \mathrm{Cd}$ source) and detector (a xenon-filled proportional counter) are arranged in a carefully optimized geometry over a sampling flume (Fig. 1). A continuous sewage sample passes through a macerator, which reduces solids to particles $<100 \mu \mathrm{m}$ in diameter, and then flows as a thin sheet down the flume where it is inadiated by the source. Chardctenstic $x$ rays from trace elements in the sewage are detected by the proportional counter and the signals routed to the data processing unit. This device, a DEC LI!-1]/2 microcomputer, acts both as a pulse-height analyzer generating a 256-channel $x$-rays spectrum and as a data reduction computer. In this latter role, it contains software which converts any detected $x$-ray internsities to elemental concentrations, compares these to preset limits and, if required, generates an alarm signal (see Table 1).

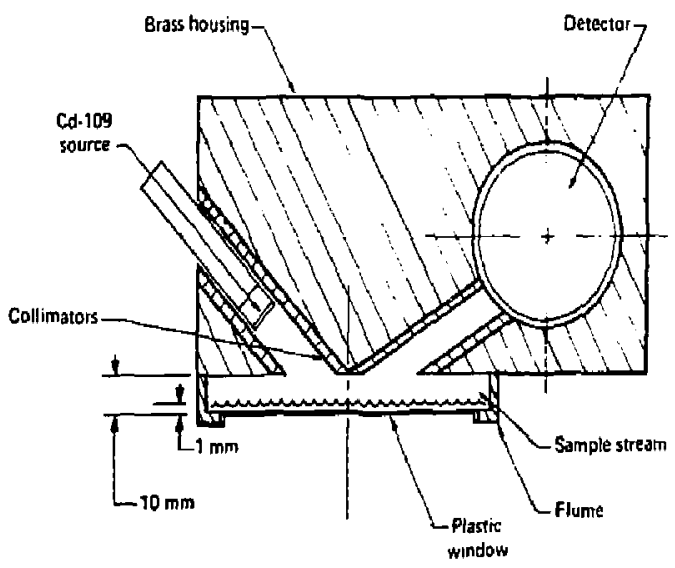

Figuse 1. Cross section of the exciter/detector geometry. 
Table 1. LLNL unaximum permissible metal discharge limits and XRFA alarm levels.

\begin{tabular}{cccc}
\hline Single mets ${ }^{4}$ & LLNL limit (ppm) & \multicolumn{2}{c}{ XRFA alarm level (ppmis } \\
$\mathrm{Cr}$ & 100 & 119 & 37 \\
$\mathrm{Cu}$ & 10 & 16 & 5 \\
$\mathrm{Zn}$ & 50 & 11 & 4 \\
$\mathrm{Ni}$ & 10 & 21 & 7
\end{tabular}

'Combinalions: total concentratior. to be less than $100 \mathrm{ppm}$.

"The alarm levels vary so:newhat, depending on the age of the exciting spurce. These are typical values.

\section{Status}

The computer has also assumed from the original sewer monitor the functic ns of moritoring radiation, $\mathrm{pH}$. and how. The system has undergone extensive testing and debugging while operating in parallel with the old monitor and is now ready to be connected to the alam sustem and assume the whole monitoring responsibility. (The sustem has been described in much greater detail in other publications. ${ }^{-i}$ )

\section{References}

1. J. L. Cate, jr. and T. O. Hogeger, "A Monitoring System for Sewage Effluents," Hazards Control Progress Report. No. 34, Lawsence Livermore National Laboratory, Livemrore, CA, UCRL50007-69-2 (1969).
2. J. L. Cate, Ir. and T. O. Hoeger, "A Radioisotope Monitoring System for Sewage Effluent," Am. Ind. Hyg. Assn. lournal (October 1972).

3. J. L. Cate, M. A. Matthew's, and D. W. Rueppel, "A Protutype On-Line X-Ray Fluorescence Analyzer for Detection of Metals in Sewage," Proc. 3tth ind. Waste Conf., Purduc Univ., 1979 (Ann Arbor Science, 1980).

4. J. L. Cate, Jr, On-Lime Monitnring for Metals in the Sewer and at Ponts Upstream Using X-Ray Fluoriscence Anali, i. Institute for Interconnecting and Packag og Electronic Circults, ICT.P-297 (1980).

5 M. Al.yong, J. L. Cate, and D. W. Rueppel, OnLine Monitoring of Toxic Materials in Sewage of the Laurence Livermore Laboratory, Lawrence Livermore National Laboratory, Livermore, CA, UCRL-83664 (1980). 


\title{
RADIATION PROTECTION
}

\section{Progress in Multi-Target TRAX Development}

\author{
J. L. Cate and C. J. Huntzinger
}

The transmission anode $x$-ray tube (TRAX) is a device for prod acing nearly monoenergetic $x$ rays by seif-filtration in the target. We have developed a teries of such tubes for use in our dosimery and calibration laboratory, which have been described earlier in this report series. ${ }^{1-8}$ Successful operation of the last of this series;-a uranium target tube-culminated our effort to provide the widest possible range of $x$-ray energies. However, since the last several iterations in design development had been modifications of one existing system, we now had only the uranium, neodymium, silve:; and copper tubes in operation. Thus, we weie faced with the prospect of building additional devices to round out our inventory of necessary targets. This approach not only required physical redundancy of vacuum systems, electron guns, power supplies, etc., but meent. disruption of experimental setups in order to change erieggies. We had long wanted to cevelop a tube with multiple targets: this secmed an opportune time-both experimentally and fiscallyto do so.

\section{Design Criteria}

We established several basic design criteria. First, we should have at least three target materials: tungsten, gold and uranium. Second, there should be little physical distuption of an experiment in progress associated with a change of energy. Third, the new design should incorporate as much of the existing hardware as possible.

\section{Target Selection}

Under these constraints, we considered means of selection of the desired target. Two genexal schemes exist: either leave the targets stationary and somehow selectively move the electron leam to strike the desired material, or have a statinnary electron beam and moye the desired target in front of it.

In the first category, an elegant solution is to have a single electron gun, and to steer the electron beam to the desired target by electrostatic or magnetic deflection as in a cathode ray tube. A less sophisticated approach might be to simply have three electron guns and tum on only the appropriate one for the desired larget. Several drawbacks to such systems were identified. They would utilize little of the existing hardware, one required development of a technology with which we had no experience (electron sallistics control), and, most importantly, they in terently had the targets in different physical locetions when used. Thus, the beam for each energ: would emanate from a different spot, presenting: problems in positioning and aligning dosimeter; and instruments for calibration. The ultimate us 'rs of the faclity viewed this as highly undesirabie.

The use of moving targets with a fixed beam avoids the last problem and we concentrated our efforts in this area.

\section{Target Array}

Again, two approaches can be identified. In one, the targets are arranged along the circumference of a circle, and the holder is rotated to select the desired materjal. The other configuration is a linear array of targets, requiring a linear motion for selection.

The rotary selection arrangement has some advantages and has been used by other workers in the field." However, the previous work involved lower-atomic-number targets, allowing 
much lower accele ating voltages. This, in tum, allows one to have the targets at ground potential. We were committed to a "double-ended" design where the electron gun is floated at roughly half the required voltage below ground, and the target is at about the same voltage above ground, $A$ rota. $y$ target holder design would require both being insulated to hold off $60-80 \mathrm{kV}$, and providing a means of dissipating some $50-100 \mathrm{~W}$ of heat, all while allowing the assembly to be rotated from outside the vacuum system. These formidable engineering problems led us tc abandon this initially attractive method in favor of a linear array.

The design problems associated with the linear amay again centered around providing vacuum sealing for the moving target array while maintaining a heat-dissipation path and highvoltage insulatior: Our solutions to these prob. lems utilized a balanced pair of stainless steel bellows to provide sealing and an adaptation of our old insulating and heat-rejection methods. The arrangement is shown in Fig. 1. A 3/4-in.-diam copper rod has the three foil targets brazed into it. One end of the rod penetrates into a heat exchanger via a Macor insulator and one of the bellows seals. The heat exchanger is filled with a flu. orocaroon liquid' which has a low $\left(\sim 80^{\circ} \mathrm{C}\right)$ bolling point and excellent insulative properties. thus allowing the necessary heat rejection while maintaining the necessary voltage standoff. Highvoltage cornection is made by a simple sliding contact between the end of the HV cable and the copper anode support. The HV cable enters the fluid-filled chamber through a common plastic tube fitting. The othes end of the rod is supported by another Macor insulator which, vie the other bellows seals (at ground potential) reaches the outside of the x-ray tube. There, three precision detents and a knob permit accurate manual selection of the desired target. The electron gun assem-

\footnotetext{
- 3 M Co. FC. 85 Fluorinert Electronic Liquid.
}

bly, exit window, and main housing remain unchanged from the previous design. The tube is actively pumped by an ion pump through a port not shown in the diagram.

Several interesting engineering problems arose during constmetion, Perhaps the most unusual one involved the brazing of the three target foils and the bellows to the target rod. Each joint needed a special brazing alloy and technique; the orchestration of the conflicting requirements was skillfully nandled by D. Berger of the Vacuum Services Lahoratory and is the subject of another paper. ${ }^{10}$ Arnother problem concerned the alignment of the target foils with the electron beams. We developed an alignment fixture that keyed on the conical collimators machined for each target. Then we epoxied the final location point (the joint between the anode support insulator and its bellows) After assembling the anode inside the tube body and inserting the alignment tod.

\section{Testing}

Initial yacuum testing was successful and we proceeded to high-voltage testing. To sum up a frustrating process, we found that while the insulators would hold of the necessary $140 \mathrm{kV}$ under static conditions, with any usable beam current the arcing rate became excessive. Several changes to the intemal insulators followed rith some improvement noted, but no real success. We have now added junction shields to the insulators, follouring criteria developed by Finke." These shields reduce the electric field strength at the junction between insulator and charged conductor. These highly stressed junctions have been identi:ied as potent sources of field emission electrons, and may thu. lead to electrical breakdown. We are now reading the tube for further testing. Other facets of the tube's operation have been successful; it appears that when we can overcome the arcing problem, the tube will be operational. 


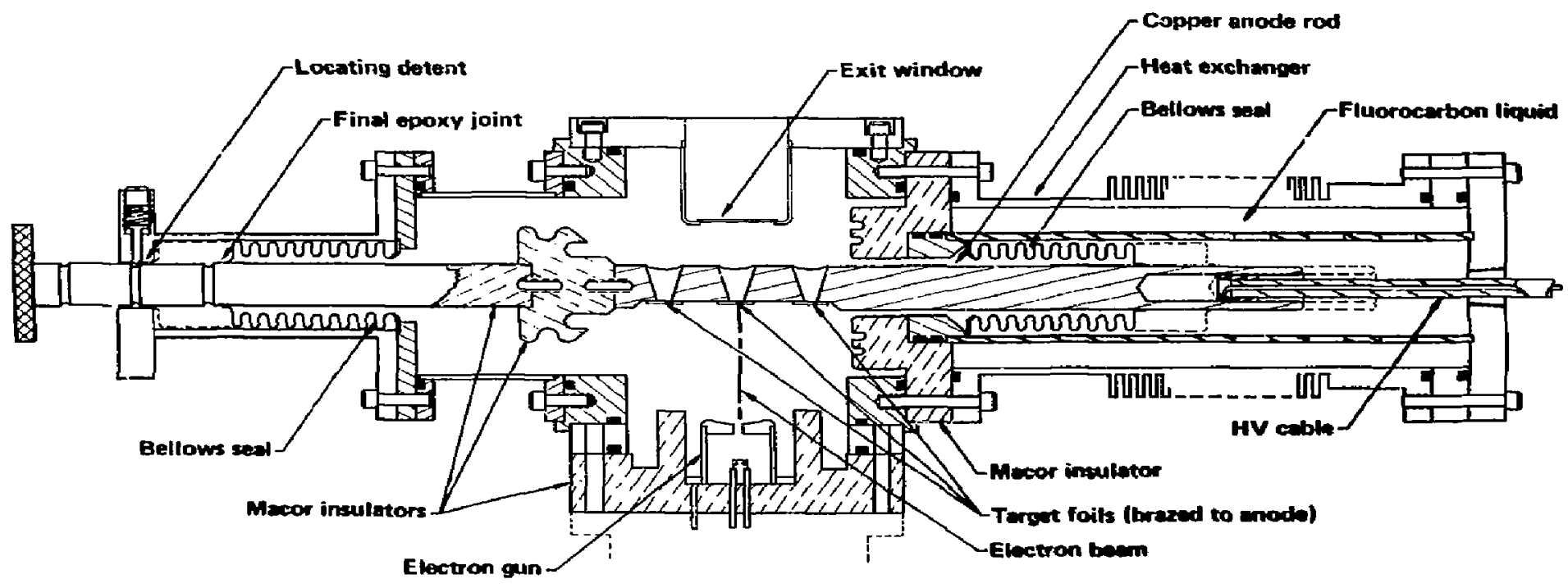

Figure 1. Diagram of the transmission anode x-ray tube. 


\section{References}

1. I. L. Cate and W. L. Pickles, "Safeguards: Measurements of $U$ and Pv Content in Dis. solved Fuel Rods," in Hazards Control Proģress Report .'vo. 44. Lawrence Livermore National Laboratory, Livermore, CA, UCRL50007-72-3 (1973).

2 II. L. Pickles, J L. Cate, and R. D. Taylor, "T-Rav Fluorescence Analysis for Nuclear Marerials Security," in Hazards Control Priprise Report dio. 47, Lawrence Livermore National Laboratory, Livermore, CA, UCRL$50007-33-3$ (1974).

3. Vi. L. Pickles and J. L. Cate, "Quantitative Non-Dispersive $X$-Ray Fluorescence Analysis of Highly Radioactive Samples of Uranium and Plutonium," in Adzances in X-Ray Anal4:15, Vol 17, C. L. Grant, C. S. Barrett, J. B. Newikitk, and C. O. Rutud, Eds. (Plentum Press, New York, 1973).

4. I. L. Cate and S. W. Campbell, Transmission Annde X-Ray Tubes: An Alternate Source of Monoenergetic X Rays, Lawrence Livemore National Laboratory, Livemore, CA. UCRL. 77673 (1974).

5. I. L. Cate, "Transmission Arade X-Ray Tube Development," in Hazards Control Progress Report No. 52, Lawrence Livermore National Laboratory, Livermore, CA, UCRL-50007. 76-1 (1976).
6. J. L. Cate "Transmission Anode X-Ray Tube Development," in Hazards Control Progress Report No. 53, Lawrence Livermore National Laboratory, Livermore, CA, UCRL-50007$76-2(1977)$.

7. J. L. Cate, Jr., "TRAX.II: A New Generation of Monoenergetic Transmission Anode X-Ray Tubes," in Hazards Control Progress Report No. 56, Lawrence Livermore National Laboratory, Livermore, CA, CRL-50007-78-1 (1978).

8. J. L. Cate, Jr. and K. J. Davidson, "TRAX-II-U: A Uranium Transmission Anode X-Ray Tube," in Hazards Control Progress Repori 5980. Lawrence Livermore National Laboratory, Livermore, CA, UCRL-50007-80 (1980).

9. V. V. Berdikov, et al., "Low-Powered Transmission $X$-Ray Tube for Exciting X-Ray Fluorescence," trans. from Pribory i Tekhyika Eksperimenta 1, 207-209, (Gan-Feb 10\%6\%.

10. D. Berger, "Step Ë̈̈zing a Multi-iărget IRAX," in press.

11. R. C. Finke, "A Study of Parameters Affecting the Maximum Voltage Capabilities of Shielded Negative Dielectric Junction Vacuum Insulators," Second International Symposium on Insulation of High Voltages in Vacuam, (Massachusetts Institute of Technology, 1966). 


\title{
Development of a Passive Personnel Neutron Dosimeter/Spectrometer-DOSPEC
}

\author{
R. V. Griffith and T. A. McMahon
}

Each of the two most widely used personnel netutron dosimeters-NTA (neutron track type: A) film and TLD (thernuluminescence dosimieter) albedo detectors-has significant practical limitations, NTA film is notorious for tading, particularly under adverse environmental conditions (high temperature and h dmidity). Moreover, since its practical detection limit is about 50 mrem it has a marginal sensitivity, and evaluation requires tedious optical counting with a high-magnification microscope. Albedo dosimeters do not have these limitations, but their energy response is so poor that it is almost the inverse of the neutron-fluence-to-dose-equivalent conversion factor curve (Fig. 1). As a result, neither of these, nor the radioactive fission track detectors, can be considered a generaily satisfactory personrtel neutron dosimeter. We have developed a prototype composite dosimeter that uses track detectors to augment an albedo detectol.

\section{Introduction}

This composite dosimeter combines the advantages of the albedo detector (excellent sensitiv. ity and ease of automation) with the fast neutron energy response of plastic etch track detectors. Three track detectors with different fast neulron response (CR-39, polycarbonate, and LR-115 cellulose nitrate) are included in the cadmium box used for the albedo dosimeter. The response of these detectors depends on the intherent properties of the plastic, and does not involve a ission foil radjator. Moreover, because the TLD is used as a screening tool, only the track foils from those dosimeters that appear to have been exposed to 50 mrem or more need to be etched and counted.

We have developed two versions of a dosimeter that embody the albedo detector-track foil conrept DOSPEC I includes a TLD component, plus CR-39, polycarbonate, and LR-115 (Fig. 2). In practice, one or more of the track foils can be and usually is omitted from 'he badge. If, for example, the contribution from reutrons above $10 \mathrm{MeV}$ is 5mall, the LR-115 is not used. The second version -DOSPEC II-is a combined albedo-CR-39 dosimeter that uses only track detrction. The albedo response is provided by a ${ }^{6} \mathrm{Li}$ or ${ }^{10} \mathrm{~B}(\mathrm{n}, \mathrm{alph}$ ) radiator. The shape of the etch-track albedo energy response is the same as the TLD albedo response. However, DOSPEC II is gamma-insensitive and the n,alpha radiator concentration and processing parameters are adjusted so that the overall albedo

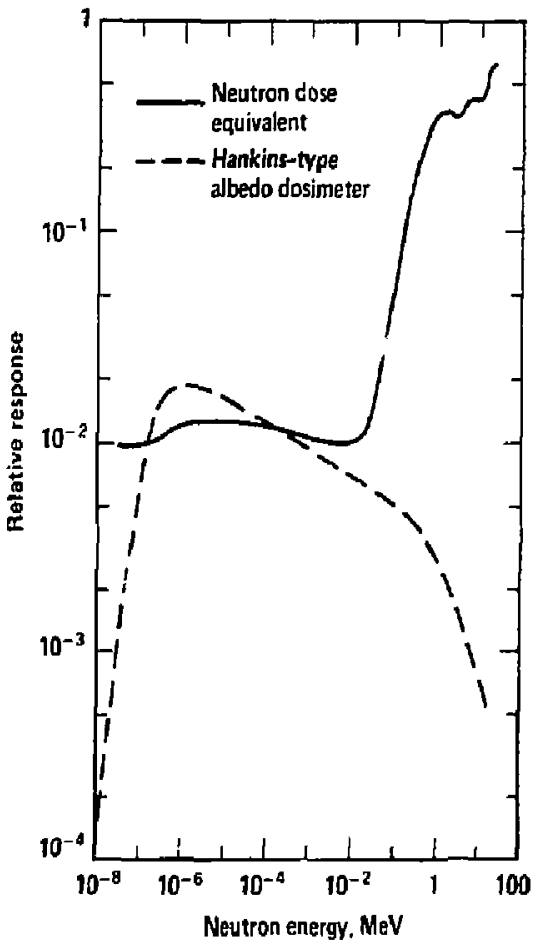

Figure 1. Comparison of the response of a Hankins-typa albedo dosimeter with the ICRP dose-equivalent conversion. 


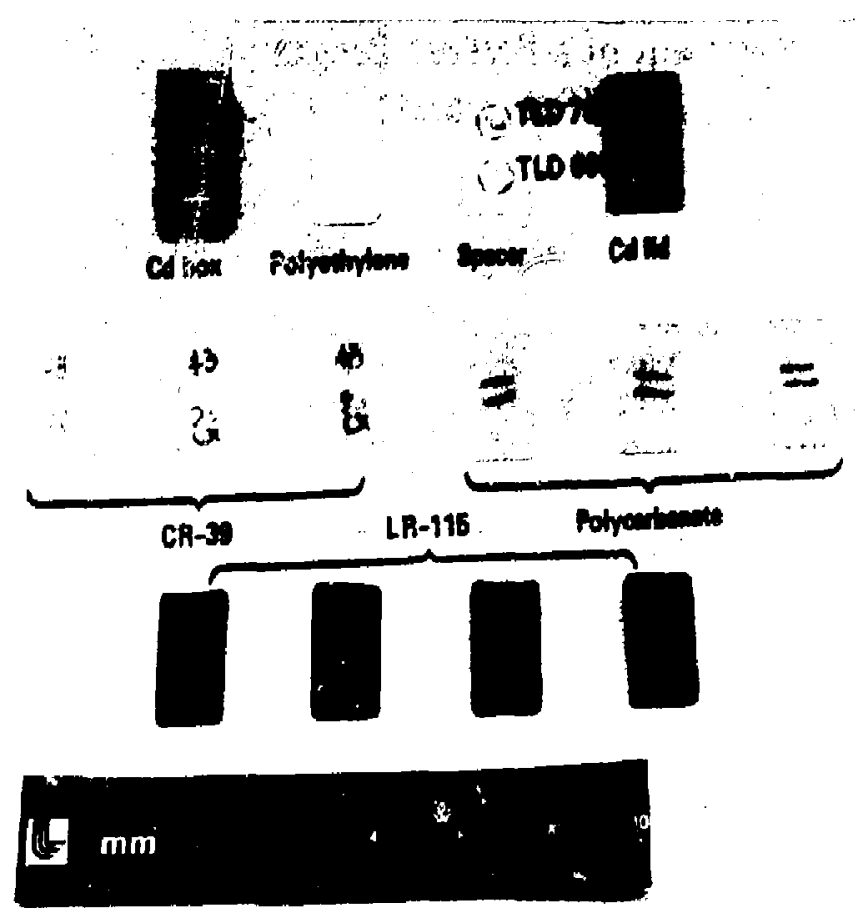

Figure 2. Components of DOSPEC I dosimeter/spectrometer.

plus $C R-39$ fast neutron response matches the fluence-to-dose-equivalent response as closcly as possible.

\section{DOSPEC I}

The energy response of the track detectors depends to some degree on the processing parameters. Although, for example, CR-39 is capable of detecting recoil protons while polycarbonate is not, the specific response function shape depends on a number of fact $\mathrm{Ts}$ :

- Thickness and composition of the covering or radiator. (ECE).

- Chemical vs electrochemical etching

- Pre-etch treatment.

- Temperature and concentration of etchant.
- Voltage gradient and frequency of ECE.

- Specific composition of plastics.

The conditions used for processing are presented in Table 1. (The TLDs in DOSPEC I are evaluated using conventional thermoluminescence dosimetry techniques.) The etch-track components are counted semi-automatically using a commercial bacterial colony counter coupled by a TV camera to an optical microscope (Fig. 3). The colony counter provides a simple pattem recognition and counting capability. Therefore, as long as the etch-track images meet the size and contrast requirements of the colony counter, counting is done efficiently and reproducibly. The colony counter can evaluate either dark tracks on a light background ar light tracks on a dark background. The format is switch selectable, so we can count either the black electrochemical-etch tracks in CR-39 and polycarbonate, or the light holes in the 
Table 1. DOSPEC component processing parameters.

\begin{tabular}{|c|c|c|c|}
\hline & CR-39 & Polycurbonate & $2 R-115$ \\
\hline Radiators & $0.06 \mathrm{~mm} \mathrm{CH}_{2}$ & $0.025 \mathrm{~mm} \mathrm{CH}$ & $0.013 \mathrm{~mm}$ cellulose nitrate \\
\hline Pre-trealineal & $\begin{array}{l}\text { 3-hour chemical } \\
\text { etch al } 60^{\circ} \mathrm{C} \text { in } \\
6 \mathrm{~N} \mathrm{KOH}\end{array}$ & $\begin{array}{l}\text { 1-hour exposure } \\
\text { to UV }\end{array}$ & None \\
\hline Etth parumeter & $\begin{array}{l}5 \text {-hour ECE of } \\
\text { incident side } \\
\text { at } 22^{\circ} \mathrm{C} \text { in } 5 \mathrm{NOH} \text {; } \\
31.5 \mathrm{kV} / \mathrm{cm} \text {. } \\
2 \mathrm{kHz}\end{array}$ & $\begin{array}{l}\text { 5-hour ECE of } \\
\text { both sides at } \\
22^{\circ} \mathrm{C} \text { in } 5 N \mathrm{KOH} ; \\
31.5 \mathrm{kV} / \mathrm{cm} \text {. } \\
2 \mathrm{kHz}\end{array}$ & $\begin{array}{l}\text { 35-bod } \\
\text { chemical etch at } \\
69^{\circ} \mathrm{C} \text { id } 10^{2}, \mathrm{NaOH}\end{array}$ \\
\hline
\end{tabular}

red LR-115 film. A blue filter is used when counting LR-115 to enhance contrast. The colony counter can also be inferfaced easily to a small computer for a greater degree of dosimetry system automation.

The relative energy responses of the four dosimeter components are shown in Fig. 4. These data are used as the basis of a four-group mainix that can be used to unfold a crude spectrum from the dosimeter component responses. We have assigned lower energy bounds of thermal, $0.1 \mathrm{MeV}$, $1.5 \mathrm{MeV}$, and $5.0 \mathrm{MeV}$ to the energy bins used in this matrix. A spectrum-weighted average has been calculated for each detector and each bin to

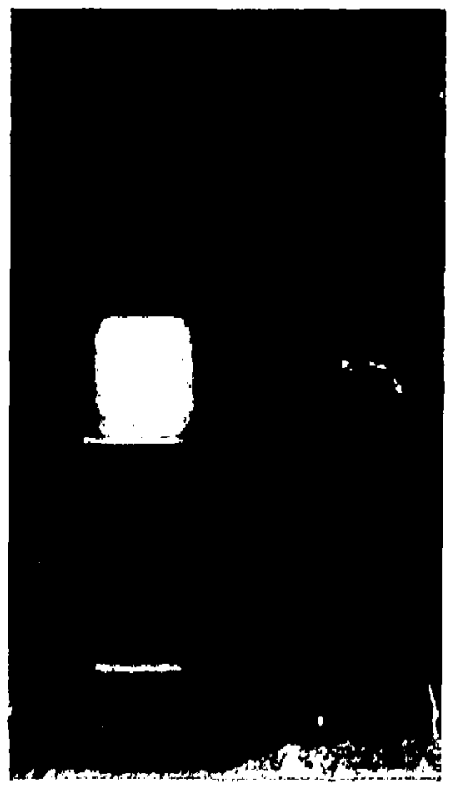

Figure 3. Commercial bacterial cojony counter and microscope used for measurement of track densities in DOSPEC elch track deteclons. create the final matrix (actually, three matrices have been created for different detector selections; see Fig. 5), We have found, for example, that the use of LR-115 has little practical value for the opexational conditions at our Laboratory. Therefore, the dosimeters as issued normally include only the other components.

We have incorporated these matrices into a processing code on a programmable calculator (Hewlett-Packard 41CV, with printer). The code performs the calculations by tollowing a simple sequence of steps:

1. Specify plot option, yes or no.

2. Sperify n: six dimension.

3. Spedfy neuiron source used to normatize response of dosimeter components (none, $\mathrm{Cl}$ or PuBe),

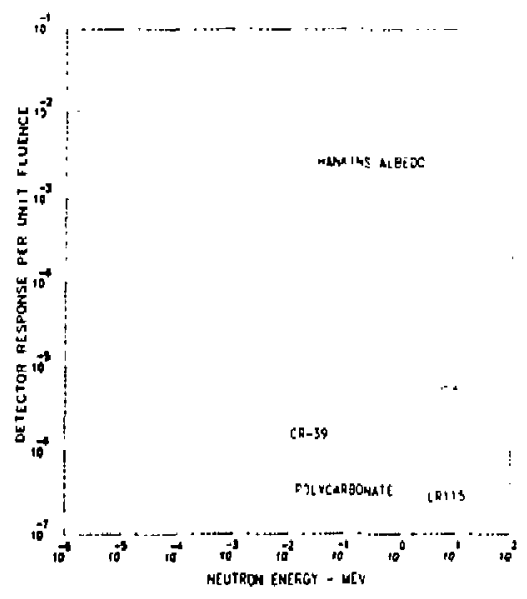

Figure 4. Relative neutron responses for the four DOSPEC I components. (Albedo response is in relative light units, so the absolute magnitude canaot be compared with etch-track responses in tracks per neutron.) 


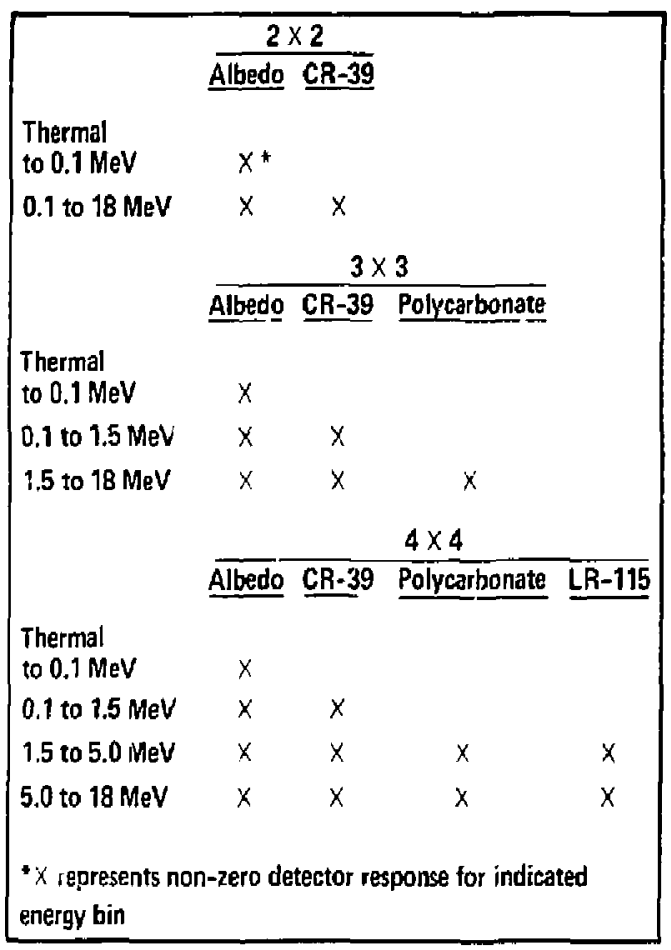

Figure 5. Matrices for varicas detector selections in DOSPEC I, used for determining spectra and calculating dose equivalents.

4. Input responses of dosimeter components for calibration dosimeters, if $\mathrm{Cf}$ or $\mathrm{PuBe}$, to normalize matrix responses.

5. Enter dosimeter identification.

6. Calculate furnce in each energy bin.

7. If Nuence in any bin is negative, recalculate using modified matrix.

8. If fluence remains negative, set to zero and calculate remaining fluences.

9. Use bin fluence data to calculate bin dose equivale:it values. summary:

10. Print spectrum and dose equivalent

11. Plot, if option requested.

12. Repeat steps 5 through 11.

A. sample of the output is presented in Table 2.

In April of this year, we submitted both DOSPEC I and DOSPEC II to the CEC-ORNL Personnel Dosimetry intercomparison study. Dr. simeters were sent to the Oak Ridge National Laboratory. Some were exposed to distributed- energy neutrons from the Health Physics Research Reactor (HPRR), while others were sent to the PTB and GSF laboratories in West Germany for mono-energetic exposures $(0.57,1.2,5.3$, and $15.0 \mathrm{MeV}$ ) plus irradiation by ${ }^{252} \mathrm{Cf}$ in a $15-\mathrm{cm}$ radius $\mathrm{D}_{2} \mathrm{O}$-filled sphere. The dose-equivalent evaluations for both DOSPEC I and II are presented in Table 3, along with the reference values. The DOSPEC I spactsal results are presented as fractions normalized to a total fluence in Table 4. LR-115 was not evaluated for these dosimeters, so there are only three energy bins shown.

\section{DOSPEC II}

The key to the success of the DOSPEC Il concept is obtaining a balanced response so that the fast neutron response of the CR-39 plus the track density contributed by the $n$,alpha radiator albedo response results in a full energy response that matches the fluence-to-dose-equivalent conver- 
Table 2 Example of the output spectrum and dose equivalent.

DOSPEC

DO YOU HAHT PLDTS?

EHTER I=YES, $\theta=F$ HO

$$
\text { COMPONENTS? } 1 . \text { ** }
$$

CALIBRATIOH SOURCE USED? MOSE $=9, C F=1$ OR PUBEE=?

EHTER CF252 ALBISO RESTIDE 754, 686. ** EHTER CF252 CR39 RES/DE 1.739. *\#* ERTER CF252 P.C. RES/DE 63. 4*4 ERTER CF252 LRI15 RES/DE 19. *** IDSPEC ID?

T. MC MAHOH

IHPUT ALBDO IRTA $3.91+85$ \#

IHPUT CQ39 IATA $1.36+83 \quad \$$

IHPUT P,C, DATA $5.34+81 \quad$ \$**

IHPUT LRLI5 DATA $8.84+80$
RESULTS

THERH T3.1 MEY

FH -

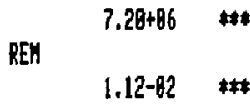

.1 MEY TO 1,5NEY

FH -

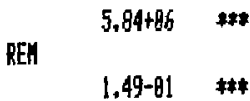

1.5NEY TO 5. MEY

$\mathrm{FH}$ -

REAH $\begin{array}{ll}1.28+67 & \text { *** } \\ 4.45-91 \quad * * *\end{array}$

ABOYE 5. MEY

FH -

REY $\begin{array}{rr}2.22+86 \quad \text { *** } \\ 9.36-82 \quad * * *\end{array}$

TOTAL- FN -

TOTAL- REN

$2.72+87 \%$

6.99-81 ***

\section{RELAT I VE} FLUENCE

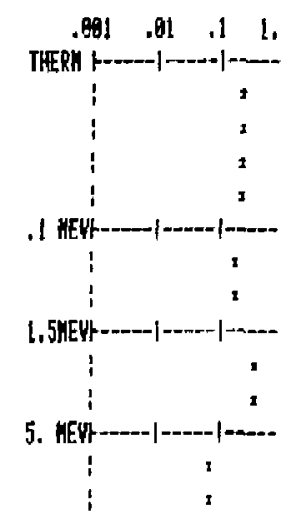

\section{RELAT IVE} DOSE EQUIV.

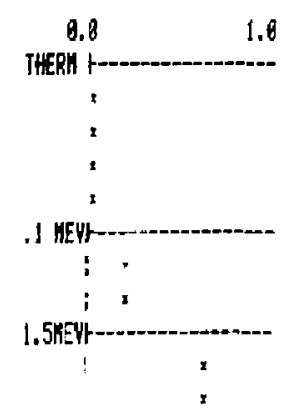

5. MEVt-- 
Table 3. CEC-ORNL personsel neutson dosimetsy inlescomparison summary.

\begin{tabular}{|c|c|c|c|c|}
\hline \multirow[b]{2}{*}{ Spectrum } & \multirow{2}{*}{$\begin{array}{c}\text { Referentce dost } \\
\text { equivalent } \\
\text { (mSS) }\end{array}$} & \multirow{2}{*}{$\begin{array}{c}\text { DOSPEC I } \\
\text { dose equivalent } \\
\text { (mSv) }\end{array}$} & \multicolumn{2}{|c|}{$\begin{array}{c}\text { DOSPEC II } \\
\text { dose equivalent }\end{array}$} \\
\hline & & & $(m S v)^{4}$ & $(\mathrm{mSv})^{\mathrm{b}}$ \\
\hline \multirow[t]{2}{*}{ Bare HPRR } & 0.62 & 0.67 & 1.20 & 0.75 \\
\hline & 11.13 & 9.30 & 12.10 & 11.6 \\
\hline \multirow[t]{2}{*}{ HPRR with $13 \mathrm{cno}$ steel } & 0.64 & 0.51 & 0.97 & 0.52 \\
\hline & 10.99 & 8.01 & 8.02 & 7.57 \\
\hline \multirow{2}{*}{ HPRR with $20 \mathrm{~cm}$ concrete } & 0.48 & 0.43 & 0.82 & 0.37 \\
\hline & 9.43 & 7,38 & 10.70 & 30.2 \\
\hline \multirow[t]{2}{*}{ HPRR with $12 \mathrm{~cm}$ lucite } & 0.59 & 1.32 & 1.25 & 0.80 \\
\hline & 10.96 & 11.80 & 13.00 & 12.6 \\
\hline \multirow[t]{4}{*}{$0.57 \mathrm{MeV}$} & 0.70 & 0.98 & - & - \\
\hline & 8.37 & 6.68 & - & - \\
\hline & 0.81 & - & 1.63 & 1.18 \\
\hline & 8.37 & $\cdot$ & 9.46 & 9.01 \\
\hline \multirow[t]{4}{*}{$1.2 \mathrm{MeV}$} & 6.00 & 6.56 & - & - \\
\hline & 1.50 & 2.17 & - & - \\
\hline & 7.01 & - & 9.14 & 8.79 \\
\hline & 2.50 & + & 4,29 & 3.84 \\
\hline \multirow[t]{4}{*}{$5.3 \mathrm{MeV}$} & 6.50 & 7.33 & $\cdot$ & $\cdot$ \\
\hline & 3.99 & 5.10 & - & - \\
\hline & 9.49 & $=$ & 13.4 & 13.0 \\
\hline & 2.99 & - & 5.55 & 5.10 \\
\hline \multirow[t]{3}{*}{$15.0 \mathrm{MeV}$} & 13.13 & 18.2 & 14.40 & 14.0 \\
\hline & 1.05 & 1.31 & - & - \\
\hline & 0.89 & $=$ & 0.93 & 0.48 \\
\hline \multirow[t]{3}{*}{${ }^{252} \mathrm{Cf}$ in $15 \mathrm{~cm} \mathrm{D}_{2} \mathrm{O}$} & 10.97 & 11.6 & 11.9 & 11.4 \\
\hline & 1.20 & 1.91 & - & - \\
\hline & 3.61 & - & 4.02 & 3.57 \\
\hline
\end{tabular}

- Values reported for the CEC-ORNL intercomparison.

"Values adjusted for error in background.

sion factor curve as closely as possible. A mathematical synthesis of the response is illustrated in Fig. 6. Two of the key variables are concentration of ${ }^{6} \mathrm{Li}$ and/or ${ }^{10} \mathrm{~B}$ in the n,aipha radiator, and the degree of etching performed. The $n, a$ lpha track response is quite sensitive to the etch parameters, primarily because of the short range of the alphas, and other reaction products.
For uniformity in dosimeter processing, we began by testing the etch parameters used for CR39 in UOSPEC I (with the protective polyethylene uncovered to permit registration of the alphas). We tested two commercially avaiable materials as radiators $-\mathrm{CN} 85$ (a plastic sheet covered with natural lithium tetraborate) and BNI (an ester-based plastic coating with naturai boron nitride). The

Table 4. Results of the spectral evaluation of DOSPEC I in the CEC.ORNL intercomparison.

\begin{tabular}{|c|c|c|c|}
\hline \multirow[b]{2}{*}{ Spectrum } & \multicolumn{3}{|c|}{ Energy bin fraction $\left(\mathrm{n} / \mathrm{cm}^{2}\right)$} \\
\hline & Thermal to $0.1 \mathrm{MeV}$ & 0.1 to $1.5 \mathrm{MeV}$ & Above $\mathrm{J.5} \mathrm{MeV}$ \\
\hline Bare HPRR & 0.295 & 0.459 & 0.246 \\
\hline HPRR with $13 \mathrm{~cm}$ sleel & 0.478 & 0.388 & 0.132 \\
\hline HPRR with $20 \mathrm{~cm}$ concrete & 0.718 & 0.181 & 0.101 \\
\hline HPRR wilh $12 \mathrm{~cm}$ lucile & 0.686 & 0.193 & 0.126 \\
\hline $0.57 \mathrm{MeV}$ & 0.000 & 1.000 & 0,000 \\
\hline $1.2 \mathrm{MeV}$ & 0.000 & 0,952 & 0.098 \\
\hline $5.3 \mathrm{MeV}$ & 0.00 & 0.314 & 0.682 \\
\hline $15.0 \mathrm{MeV}$ & 0.102 & 0.000 & 0.898 \\
\hline${ }^{251} \mathrm{Cl}$ in $15 \mathrm{~cm} \mathrm{D} \mathrm{D}_{2} \mathrm{O}$ & 0.807 & 0.117 & 0.076 \\
\hline
\end{tabular}




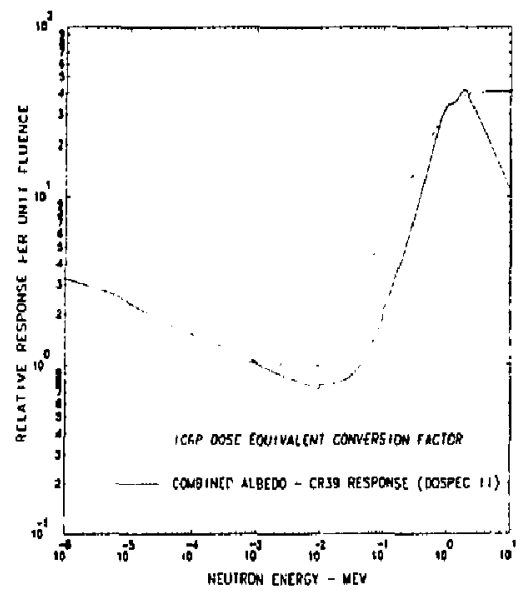

Figure 6. Calculated optimum response function for DOSPEC II.

BN1 has tumed out to be superior, which is fortunate because CN85 is no longer commercially available.

Four pjeces of CR-39 and four BN1 radiators are used in the version of the dosimeter tested at Oak Ridge (Fig. 7). The components are arranged as two pairs of radiator-detector combinations. In each pair, the radiators are sandwiched between two pieces of CR-39. The sensitive surfaces of the CR-39 face inward in each pair. An additional benefit accrues from this configuration-orientatiors dependence. The reutron direction can be determined because the upstream track aetector in each pair has a higher track density than those on the downstream side. This can be very useful for establishing body-orientation corrections.

The DOSPEC II results from the CEC-ORNL intercomparison are presented in Table 3. A problem devejoped in interpretation of the low dos. ( $<100$ mrem) dosimeters. Because of a limite: supply of BN1 radiators, we used CN85 for t ie background controls. However, the backgrounds turned out to be significantly elevated-to the point that they indicated doses on the order of 100 mrem. Whether this was due to alpha contaminetion of the lithium tetraborate or other causes, these backgrounds were unusable. On the other hand, doses evaluated using DOSPEC II CR-39 background values were uniformly abo'st 45 mrem higher than the reference dose-c quivalent values (Table 3 . col. 4). If we assume this value should be added to the background, the DOSPEC I results are uniformly quite close to the reference values and, in general, are even better than the DOSPEC I results.

\section{Summary}

The tests of the prototype are encouraging and demonstrate the validity of the bisic premises of the DOSPEC concepts. Additional work is needed to refine the evaluation process and test the dosimeteis rnori extensively. More effort needs to be directed at proper correction for orientation effects. Finall $;$, the CR-39 used does not represent dosimeter-grade material; "uch plastic is now becoming available and, after proper test and evaluation, should contribute to improved dosimeter performance. 


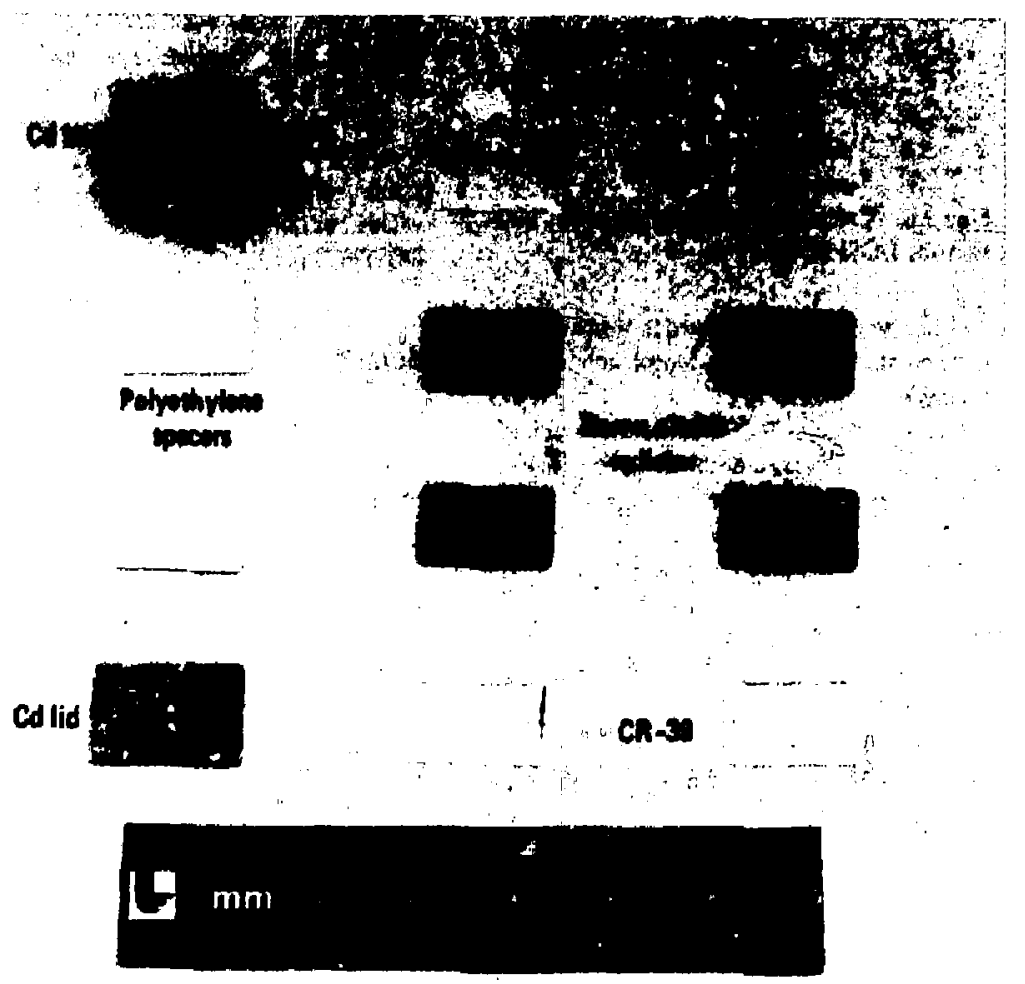

Figure 7. DOSPEC II tomponents. 


\title{
Effectiveness of Standard and Alcohol-Resistant Aqueous-Film-Forming Foam (AFFF) on Alcohol Fires
}

\author{
N. J. Alvares, H. W. Ford, and S. J. Priante
}

In late 1980, LLNL obtained reserves of gasohol as a means of fuel conservation for laboratory vehicles. To ensure that the Lab Fire Department (FD) had proper resources to combat potential gasohol spill fires, the Fire Science Group was authorized to test extinguishants in the FD inventory with regard to their effectiveness in extinguishing gasohol pool fires and their stability and endurance when layered over nonburning gasohol. The extinguishants tested were high-expansion foam, standard 6\% AFF, and alcoholresistant $6 \%$ AFFF; both experimental and commercially available aetation nozzles were used to apply them. The tests indicated that no advantage is gained by using alcoholresistant AFFF for either extinguishing or inerting.

\section{Introduction}

Fires on spills of flammable fluid are dynamically controlled by physical properties of the fluid, heat transfer, and atmospheric pressure. During fires, these processes are coupled such that the burting rate (rate of fuel consumption) is dominated by heat feedback from the flame. Essentiaily, burning rate is equal to rete of fuel evapora* tion $\left(R_{e}\right)$. When burning is steady, energy feedback from fire zone $\left(\dot{Q}_{f}\right)$ minus energy sinks and losses to surroundings ( $\dot{Q} \cup$ divided by the latent heat $(L)$ equals energy required for fuel evaporation or

$R_{\mathrm{t}}=\frac{\dot{Q}_{\mathrm{t}}-\dot{Q}_{\mathrm{L}}}{L}$.

To modify $R_{\mathrm{e}^{\prime}}$ extinguishing agents must tamper with $\dot{Q}_{1}$ or $\dot{Q}_{L} ;$ i.e., agents can block $\dot{Q}_{Q}$, increase $\dot{Q}_{L}$, and thus frustrate fuel evaporation. The action of foams and films during extinguish. ment operations interferes with fuel vapor release by three correlating mechanisms:

- Blocking radiative and convective heat tracsisier from llame to fuel surface (reducing $\dot{Q}_{\text {f }}$ ).

- Cooling the fuel and adjacent exposed surfaces (increasing $\dot{Q}_{\mathrm{U}}$.

- Providing a barrier atop the fuel to prevent vapor release $\left(R_{\mathrm{p}}\right)$.
For an agent to be effective it must be delivered faster than the fire can consume it by evaporation and losses; e.g. AFFF is applied most effectively if it is ejected as a low-expansion foam so that it will float on rather than penetrate the fuel surface. Flame and hot surfaces destroy bubble membranes, releasing water which sinks through fuel or evaporates in fire. Therefore, both foam properties and application procedures are critical to the effectiveness of extinguishing operations. Successful extinguishment reguires that agent application rate $\left(A_{1}\right)$ be greater than the theoretical a.nount of agent capable of covering the surface area of the fuel spill $\left(\lambda_{\nu}\right)$ because of agent destruction (D) by fire and heat:

$A_{\mathrm{r}}-A_{\mathrm{l}}=\int_{0}^{T_{\mathrm{r}}} \mathrm{D} d t$.

where $t_{p}$ is endurance time of agent loyer. The function $t_{p}$ is sensitive to thermal and environ. mental conditions and, with foams, interfacial effects. For example, application of foam to petroleum hydrocarbon is effective because water within foam membranes is immiscible in the petroleum fluid. However, in gasohol (10\% ethyl alcohol in gasoline) the affinity of the alcohal for water can result in the destruction of foam mem. branes and thus reduce or negate the effeciveness of the agent. 


\section{Tests}

Several tests were conducted to assess the stability and endurance of alcohol-resistant AFFF on gasohol pool fires contained in pans $3 \mathrm{ft}$ and

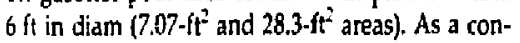
trol, standard (non-alcohol-resistant AFFF) was applied in parallel tests.

Initial tests involved application of foam to nonburning pools of gasohol. High-expansion foam provided na sealing protection on these pools; therefore we conducted no further tests of this extinguishant. For both alcchol-resistant and standard AFF, the endurance of the foam layer was greater than 15 minutes. No differences in appearance were noted during the application or testing periods.

Figure 1 shrws typical results of the extinguishment tests 1. in No. 9-small experimental nozzle applying aerated alcohol-resistant AFFF to a fully developed 6 -ft-diam pool of burning gasohol). Table 1 summarizes the times until control and extinguishment of these fires. (Control time is defined as the time when approximately $90 \%$ of the fire is extinguished.) To ensure that the fire attained steady-state burning we allowed it to bum for $1 \mathrm{~min}$ before initiating extinguishing procedures. During this period, the pan edges became very hot and destroyed the foam, resulting in substantial periods between control time and complete extinguishment. The last photo in Fig. 1 shows flamelets that persisted during this period.

\section{Conclusions}

LLNL no longer stocks gasohol as fuel for vehicles. Therefore, the practical utility of this report is moot. However, it is interesting that both standard and alcohol-resistant AFFF appeared to be nearly equally effective in exinguisting gasohol fires. If there is a significant price differential between the two formulations, our recommendation based on these test results would be to use the cheaper of the two.

Table 1. Control and extinguishment time for standard and alcohol-resistant 6\% AFFF applied to gasohoi fires.

\begin{tabular}{|c|c|c|c|c|c|}
\hline $\begin{array}{l}\text { Run } \\
\text { No. }\end{array}$ & $\begin{array}{c}\text { Extinguishment } \\
\text { time (s) }\end{array}$ & $\begin{array}{l}\text { Nozzle } \\
\text { size }\end{array}$ & $\begin{array}{l}\text { Pan } \\
\text { size }\end{array}$ & Type of AFFF & $\begin{array}{l}\text { Control } \\
\text { time (s) }\end{array}$ \\
\hline 1 & 17 & Small & Small & Standard & - \\
\hline 2 & 29 & Small & Small & Standard & - \\
\hline 3 & 23 & Small & Small & Standard & - \\
\hline 4 & 15 & Smalf & Small & Alcohol-resistant & - \\
\hline 5 & 15 & Small & Small & Alcohol-resistant & - \\
\hline 6 & 17 & Small & Small & Alcohol-resistani & - \\
\hline 7 & 163 & Small & Large & A lcohol-resistant & - \\
\hline 8 & 49 & Smal1 & Large & Alcohol-resistant & - \\
\hline 9 & $6 \mathrm{I}$ & Small & Large & Alcohol-resistan! & 25 \\
\hline 10 & 130 & Large & Lange & Standard & 32 \\
\hline 11 & 90 & Lirge & Large & Standard & 35 \\
\hline 12 & 120 & Large & Lame & Standard & 49 \\
\hline 13 & 73 & Latge & Large & Alcohol-jasistan! & 45 \\
\hline 14 & 90 & Small & Large & Standard & 35 \\
\hline 15 & 100 & Small & lane & Standard & 35 \\
\hline 16 & 60 & Ligge & Lage & Standand & 15 \\
\hline 17 & 86 & Large & Large & Standard & 25 \\
\hline \multicolumn{6}{|c|}{ "Expansion ratios: } \\
\hline \multirow{2}{*}{\multicolumn{2}{|c|}{$\begin{array}{l}\text { Small nozzle, standard AFFF } \\
\text { Small nozzle. aleahol+resistant AFFF }\end{array}$}} & $60: 1$ & & & \\
\hline & & $75: 1$ & & & \\
\hline \multicolumn{2}{|c|}{ Large nozzd wijndard AFFF } & $10: 1$ & & & \\
\hline \multicolumn{2}{|c|}{ Large nozzle, alcohol-tesistant AFFF } & $10: 1$ & & & \\
\hline
\end{tabular}



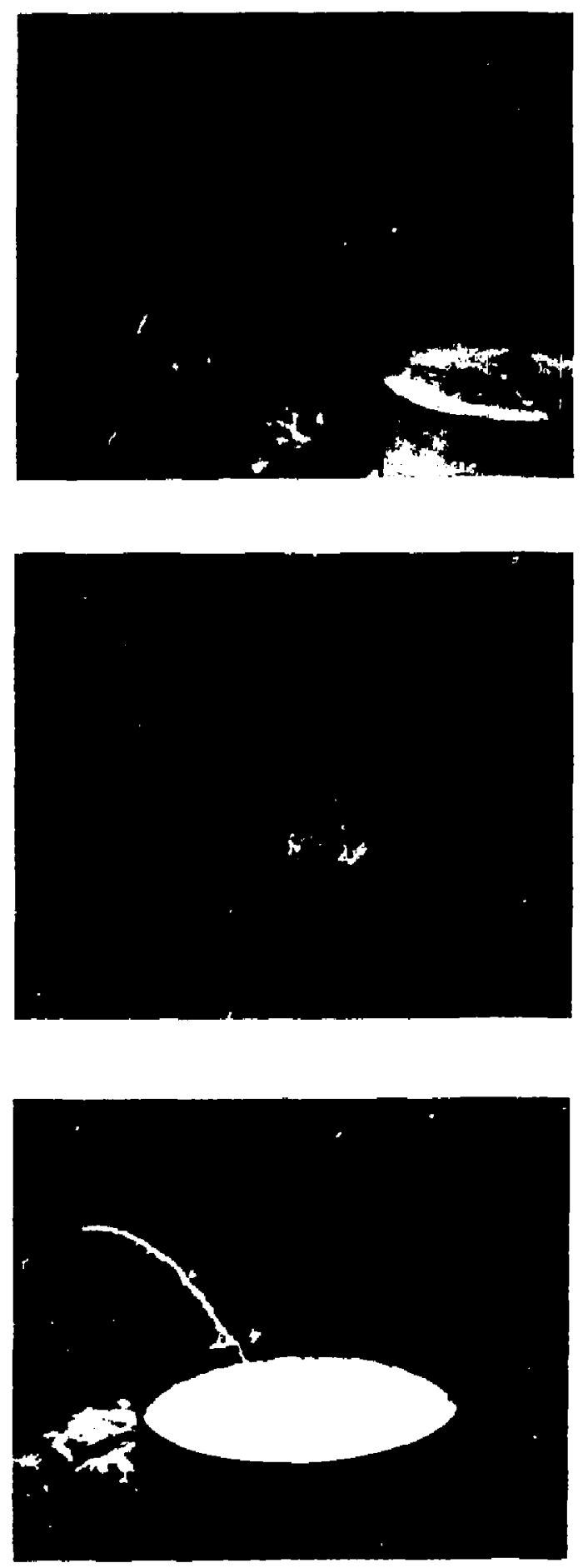

Figure 1. Alcohol-resistant AFFF applied to burning gasohol. 


\section{Technical Notes}




\title{
Determination of Explosives Using High-Performance Liquid Chromatography
}

\author{
R. D. Szidon
}

We have used high-performance liquid chromatography to measure trace levels of the explosives HMX, RDX, PETN, and TATB distributed as dust in working environments. As little as 1-3 $\mu \mathrm{g}$ of individual explosives on a filter paper swipe can be detected. Each explosive can be measured without interference from the others by appropriate selection of chromatographic conditions.

\section{Introduction}

Industral hygienists, toxicologists, and environmental scientists are increasingly interested in the analysis of explosives, because of mounting evidence that many explosives are mutagenic and/or carcinogenic in laboratory animals and that many aromatic nitro derivatives possess biological properties detrimental to animals and humans.'

High-performance liquid chromatograpiny (HPLC), coupled with a sensitive and selective detector, can be used for the analysis of trace amounts of both volatile and nonvolatile materials and is nondestructive in all cases where explosives have been studied by tnis approach. HPLC is conducted near ambient temperature. This is preferable to medium- or high-temperature gas chromatography, since most explosives will not surwive the thermal conditions required for their determination as gases.

We have used HPLC with ultraviolet detection to determine microgram anounts of $1,3,5,7$. tetranitro-1,3,5,7-tetrazacyclooctane (HMX), 1,3,5trinitro-1,3,5-triazacyclohexane (RDX), pentaerythritol tetranitrate (PETN), and 2,4,6-trinitro1,3,5-benzenetriamine (TATB) collected on filter paper swipes.

\section{Results}

The equipment used in this study consisted of a Hewlett-Packard 1084B liguid chromatograph uith a variable-wavelength uitraviolet detector, a variable-volume injector, and an automatic sampling system. Filter paper swipes were immersed in a suitable solvent and agitated in an ultrasonic cleanes to dissolve the explosives. Acetonitrile was used to dissolve HMX, RDX, and PETN, while dimethylformamide was used to dissolve TATB.

HMX and RDX were deternined simultaneousiy by elution from a bonded-phase RP-18 LiChrosorb column ( $25 \mathrm{~cm} \times 4.6 \mathrm{~mm}$ ) with a $60 \%$ water- $40 \%$ methyl alcohol mobile phase.? The ultraviolet detector was set at $230 \mathrm{~nm}$ for highest sensitivity. A typical chromatogram is shown in Fig. 1. Calibration curves obtained from standard solutions of HMX and RDX are given in Fig. 2. Detection limits are on the order of $1 \mu \mathrm{g}$ for HMX and $2 \mu \mathrm{g}$ for RDX.

PETN cannot be determined under these conditions because the eluting solvent, methyl alcohol, absorbs ultraviolet radiation at $200 \mathrm{~nm}$, the optimum wavelength for the determination of PETN. No attempt was made to determine TATB with this systern, because TATB is not soluble in the eluting solution.

PETN was determined by elution from the RP. 18 LiChrosorb column by using $40 \%$ water$60 \%$ acetonitrile as the solvent as shown in Fig. 3 . The ultraviolet detector was set at $200 \mathrm{~nm}$. This system also provides separation of PETN from HMX and RDX. The relationship between ultraviolet response and quantity of PETN is shown in Fig. $t$ t the detection limit is approximately $2 \mu \mathrm{g}$.

TATB can be eluted from a Chromosorb LC. $9 \mathrm{NH}_{2}$ column with a mixture of $1.5 \%$ 


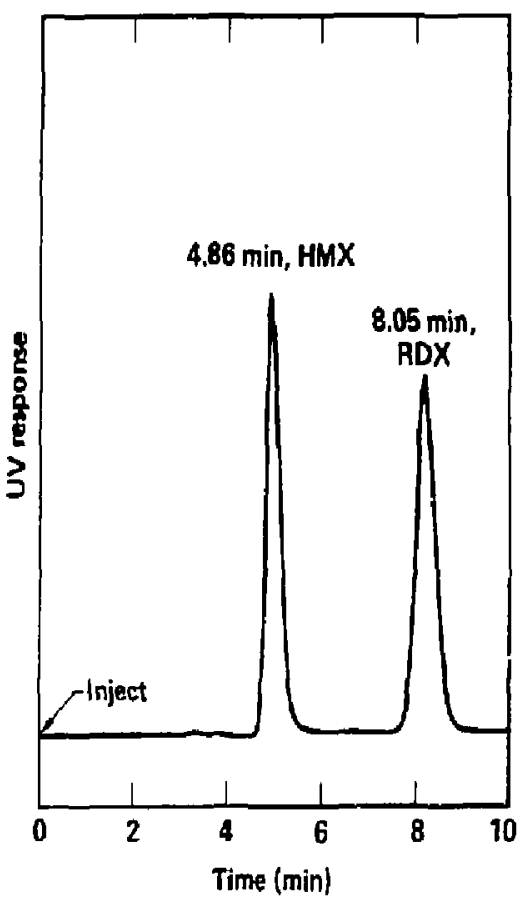

Figure 1. HPLC separation of HMX and RDX (column, RP-18 LiChrosorb; mabile phase, 60\% water-40\% methyl alcohol; UV delector, $230 \mathrm{nml}$.

dimethylformamide, $43 \%$ toluene, and $55.5 \%$ heptane.' Uttraviolet absorption at $355 \mathrm{~nm}$ is most sensitive for detection. A typical chromatogram of TATB in this system is shown in Fig. 5. A calibration curve is shown in Fig. 6; the detection limit for TATB is $3 \mu \mathrm{g}$.

\section{Sumatary}

HPLC with ultraviolet detection is useful for the rapid determination of trace quantities of the explosives HMX, RDX, PETN, and TATB. By groper selection of columns, eluting solvents, and detection wavelengths, each explosive can be measured without interference from the others.

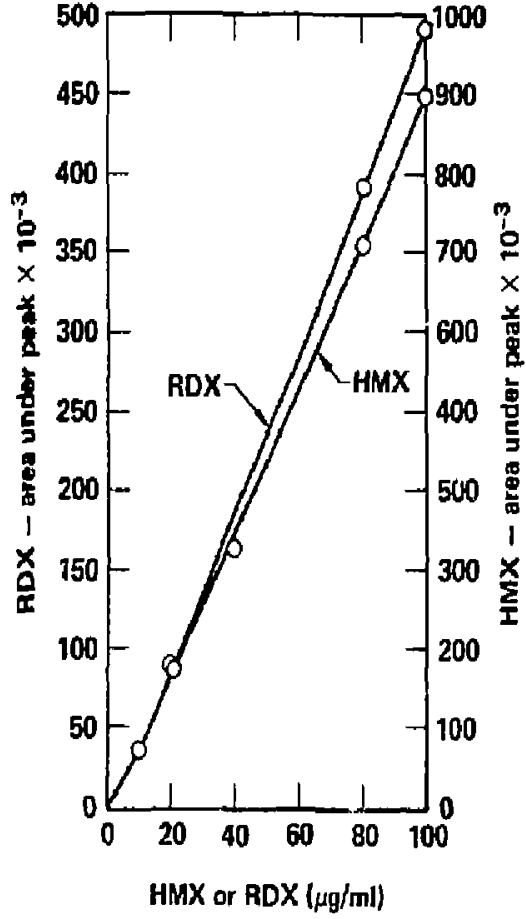

Figure 2 Calibration curves for $H M X$ and RDX by HPLC.

Such analyses are useful in the monitoring of working environments for these potentialiy harm. ful substances.

\section{References}

1. I. S. Krull and M. J. Camp, "Analysis of Explosives by HPLC," American Labornlury 12,63 (1980).

2. E. P. Meier, L. G. Taft, A. P. Graffeo, and T. B. Stanford, "The Determination of Selected Munitions and Their Degradation Products Using High Performance Liquid Chromatography," 4h loint Conffrente on Sensing of Environmental Pollutants, 1977, American Chemical Society (1978).

3. C. L. Schaffer, Assay of TATE by HPLC, Mason and Hanger-Silas Mason Co.r Inc. Amarillo, TX, MHSMP-78-65 (1978). 


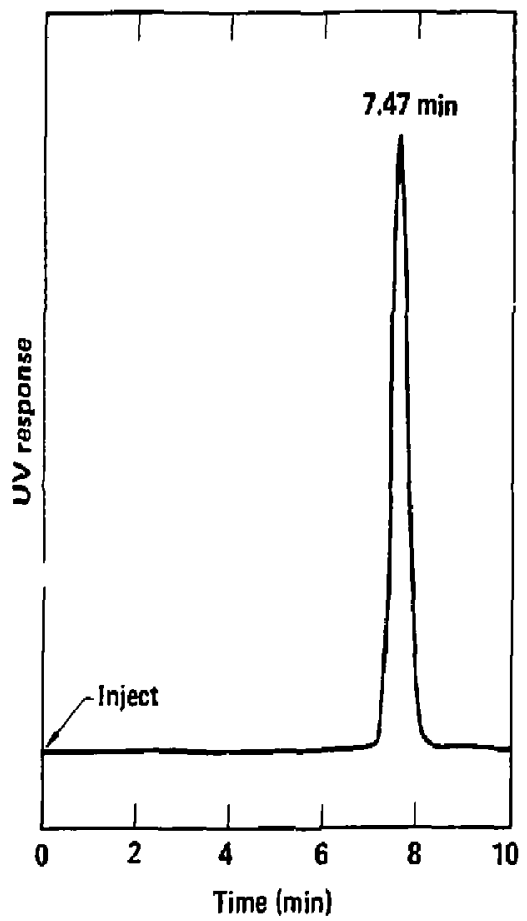

Figure 3. HPLC chromatogram of PETN (column, RP-18 LiChrosorb; mobile phase, 40\% water-60\% acetonitrile; UV detector, $200 \mathrm{~nm}$ ).

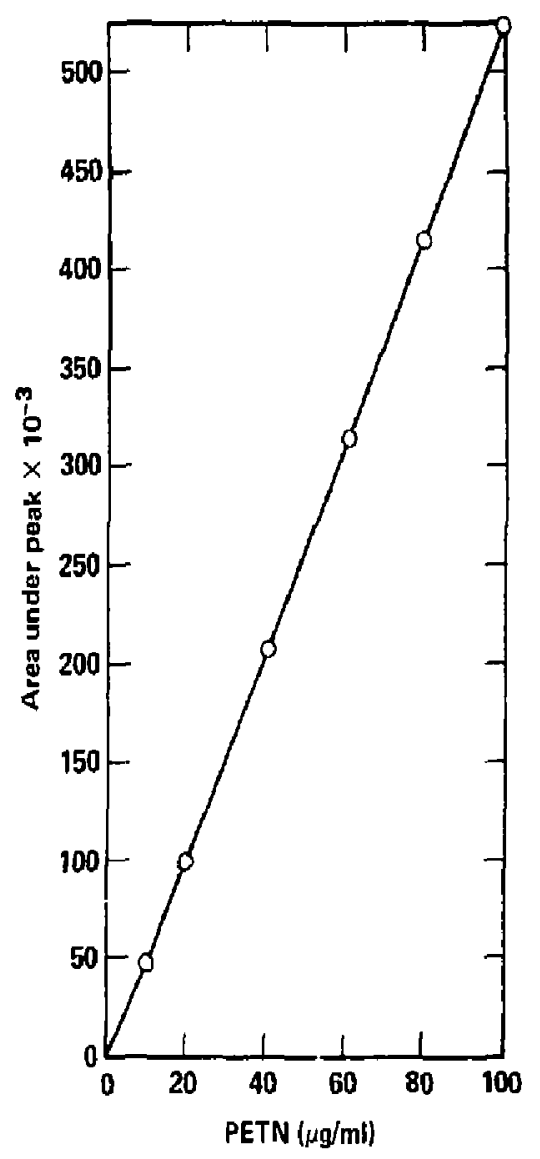

Figure 4. Calibration curve for PETN by HPLC. 


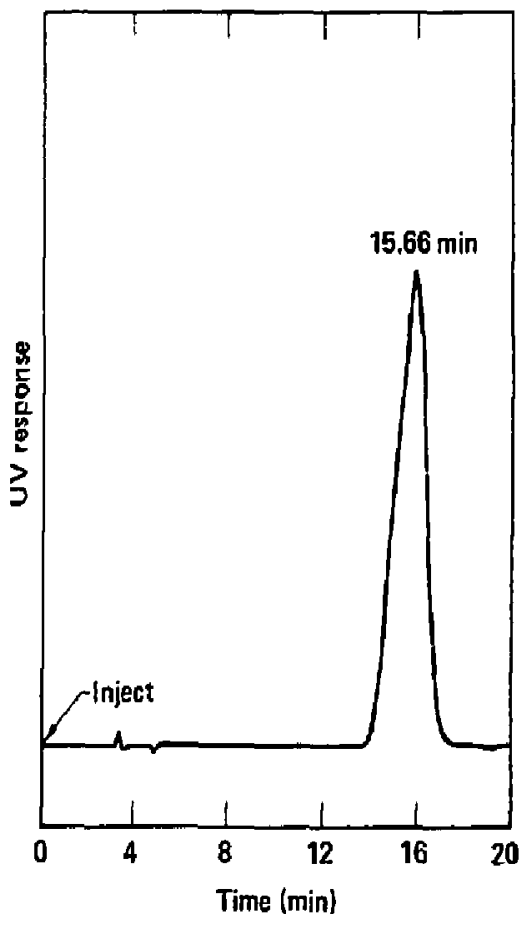

Figure 5. HPLC chromatogram of TATB (as)umn, Chromosotb LC-9 $\mathrm{NH}_{2}$; mobile phase, 1.5\% dimethylformamide . $43 \%$ tolutne- $55.5 \%$ heptane; UV detector, $355 \mathrm{~nm}$ ).

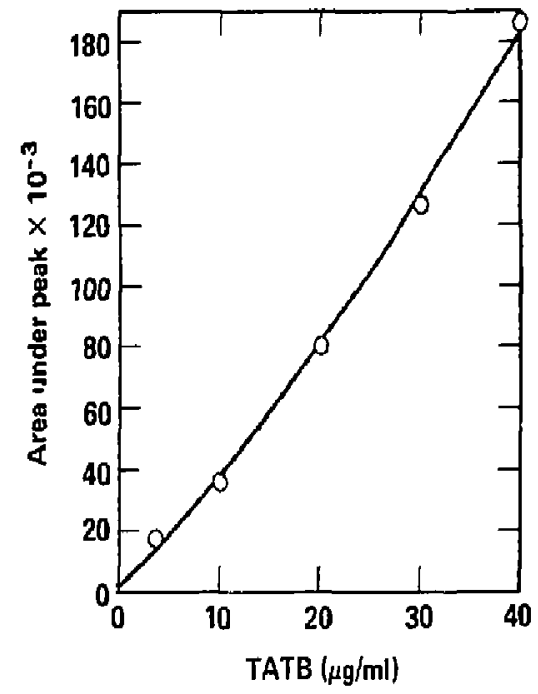

Figure 6, Calihration curve for TATB by HPLC. 


\title{
Self-Contained-Breathing-Apparatus Protection at High Work Rates
}

\author{
I. W. Stengel
}

More than 60 years ago when the U. S. Bureau of Mines was created, a sthedule for testing and approving breathing apparatus was developed for the mining industry. Their need was for long-duration (2- to 4-hour) apparatus for mine rescue. Out of that background evolved the national approval and certification testing of apparatus used throughout all industry; this is the testing done by the National Institute of Occupational Safety and Health (NIOSH). The technical specifications in current testing are still biased toward the reeds of the mining industry-for example, the moderate ventilation rate used is appropriate for long durations. We conducted tests that showed that the appropriateness of using a moderate work rate in testing equipment that is intended for short-duration work of high intensity (such as firefighting) is highly questionable.

\section{Standards}

The maximum work rate of the machine testing and the average human subject testing conducted by NIOSH conesponds to a minute volume (ventilation rate) of 40 standard liters per minute (SLPM).' By contrast, a NIOSH-funded rtudy determined that a mean minute volume of 58 SLPM was arhieved by actual firefighters at work (see Fig. 1). Failure to attain the necessary protection from a breathing apparatus in a fire atmosphere (immediately dangerous to life and health) can easily mean loss of control of the fire and resulting property loss, injury, or fatality. These are serious consequences which are beyond standard NIOSH laboratory testing. Yet these problems are faced daily, even houriy, in municipal fire departments throughout the United States.
A very basic problem for firefighters working at high ventilation rates is loss of protection. At some point (work level) and for one of many pos. sible reasons (e.g., improper fit or adjustment, growth of beard, sweaty facial skin, loss of proper shape of facepiece, etc.), a leakage of the facepiece will accur. The point at which this occurs is considered to be the limit of protection provided by that SCBA (self-contained breathing apparatus). The most protective of all SCBA designs is that which maintains a positive lacepiece pressure throughout the entive breathing cycle. This design is called "positive-pressure," because when a leakage occurs in the facepiece, it will occur outward. "Pressure-demand" apparatus will allow toxic atmosphere to Row into the facepiece during leakage. For that reason, positive-pressure SCBA is mandatory for the fire service. This position is

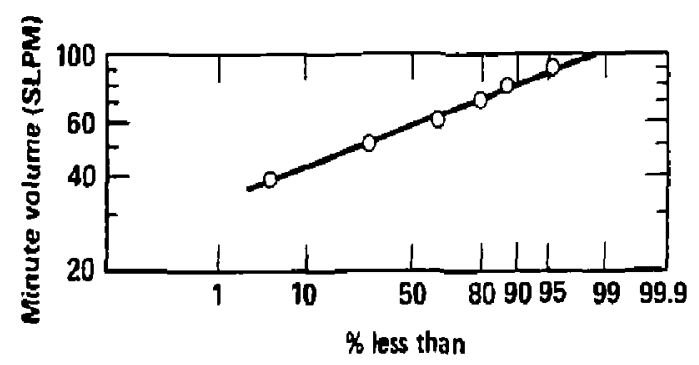

Figure 1. Minule volume of firefighters at work. 
supported by the Occupational Safety and Health Administration, the National Fire Protection Association, and the American National Standards Institute.

\section{Experiments}

The ability of a firefighter's SCBA to maintain positive facepiece pressure is directly related to the work raie. A review of the data from the NIOSH study ${ }^{2}$ indicated that approximately $98 \%$ of firefighters would be capable of sustaining a high work rate corresponding to a minute ventilation of 100 SLPM. Other studies have indicated that some firefighters axe capable of much higher work rates when tested under laboratory conditions. ${ }^{b}$ Figure 1 illustrates that fewer than $10 \%$ of fitefighters are adequately served by the 40-SLPM ventilation rate used by NIOSH. The median work rate would occur at ap? roximately 60 SLPM, and a $100-S L P M$ ventilation rate would protect greater than $95 \%$.

Therefore, preliminary tests were undertaken to determine whether the N!OSH-approved SCBA found in use in the fire service today are capable of maintaining positive facepiece pressure at 100 SLPM, NIOSH-approved SCBA were measured "ring the experimental set-up depicted in Fig. 2. Tesults of testing are depicted in Fig. 3. Data frum machine testing show that seven of 12 approved breathing apparatus are capable of maintaining positive pressure at a high wotk rate. Additionally, two apparatus tested from other countries were also able to pass this test. Maximum breathing resistances were also noted. Maximum resistance taken with the more important absolute value of the magnitude of the pressure change is a good indicator of perceived discomfort due to breathing resistance. The ideal product would have a high positive pressure to ensure protection, and a low peak resistance for comfort.

\section{Conclusions}

Added protection for the wearer can be gained by increasing the design work rates of breathing apparatus to maintain a minimum of 0.5 in. $\mathrm{H}_{2} \mathrm{O}$ positive facepiece pressure when sub. jected to a work rate corresponding to 100 SLPM. One-third of all apparatus tested can already meet this criterion. Another one-third may be able to meet it by minor adjustments or modification.

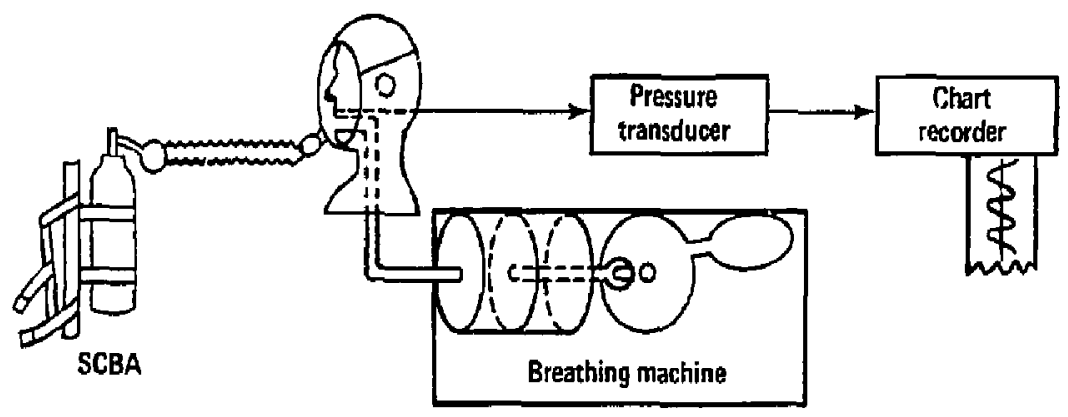

Figure 2. Diagram of SCBA lesting apparatus. 


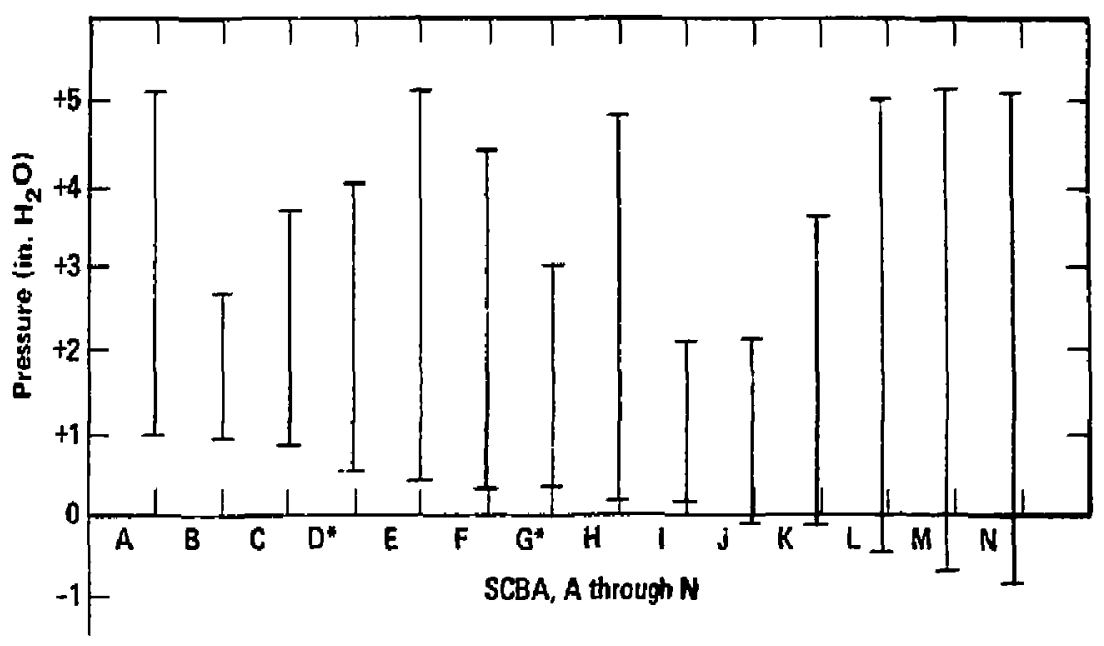

- Not aprowa

Figure 3. SCBA performance at a high work rate.

\section{References}

1. 30 Code of Federal Regulations Part 11H, "Respiratory Protective Devices; Tests for Permissibility."

2. W. A. Burgess et al., "Design Specifications for Respiratory Breathing Devices for Firefighters, " HEW Publication (NIOSH) No. 76-121 (September 1975).

3. OSHA Fire Brigade Standards, 29 CFR 1910.156.
4. "Pratices for Respiratory Protection for the Fire Service," ANSI 288.5.

5. Self-Contained Breathing Apparatus for the Fire Service, National Fire Protection Association (1981).

6. L. G. Myhre, R. D. Holden, F. W. Baumgardner, and D. Tucker, Physiological Limits of Fire 'Fighters, Tyndall AFB, FL, ESL-TR-79-06, AFESC (June 1979). 


\title{
RADIATION PROTECTION
}

\section{Neutron and Gamma-Ray Measurements at the LANL SHEBA Critical Assembly}

\author{
D. E. Hankins, R. V. Griffith, J. H. Thorngnte, and D. W. Rueppel
}

We recently performed some measurements on the SHEBA critical assembly at the Los Alamos National Laboratory to determine the leakage spectra and dose rates of neutrons and gamma rays at various distances from the assembly and through shields of steel and concrete.

\section{SHEBA}

The SHEBA critical assembly is a cleangeometry critical assembly employing tuel of $4.8 \%$ enriched uranium as the fluoride. It was constructed during 1980 to evaluate accidentalcriticality-alarm detectors tor enrichment plants. to provide radiation spectra and intensity measurements to benchmark calculations on a low. enrichment solution system, and to provide radiation fields to calibrate personnel dosimetry. The reactor vessel is a simple stainless steel cylindrical tank with a wall $6.35 \mathrm{~mm}(1 / 4$ in.) thick. A single safety rod aiong the axis provides shutdown without sacrificing cylindrical symmetry. Control is effected by varying the solution level through calibrated metering valves, To facilitate measurements out to $300 \mathrm{~m}$, SHEBA is housed in a thin metal shed outside of Kiva I at the Los Alamos Critical Assemblies Laboratory.

\section{Measurements}

Measurements were made at distances from 4.5 to $69 \mathrm{~m}$ from the assembly. A 5-1/4-in.-thick steel shield was positioned at 4 or $12 \mathrm{~m}$ from the assembly and concrete shields 8 and $16 \mathrm{in}$. thick were placed at 12 and $4 \mathrm{~m}$, respectively.

Neutron doses were determined using the 9-in.-5phere PNR-4 temmeter and from the readings of TLDs ( sphere. Thermal neutron doses were measured using the $\mathrm{BF}_{3}$ tube of the PNR-4 instrument and with pairs of ${ }^{6} \mathrm{Li}$ and ${ }^{7} \mathrm{Li}$ TLDs. We used albedo: neutron dosimeters of the "Hankins" type and ap- plied the 9- to 3-in--sphere ratio technique to evaluate the albedo readings. Gamma-ray dose measurements were made using TLDs located in air and on the phantoms. Two types of phantoms were used; the first was the head and torso section from a REMAB phantom (containing bones) and the second was the LLNL water-filled torso phantom. To provide input data to evaluate a solution criticality accident, saline solutions of $\mathrm{Na}_{2} \mathrm{CO}_{3}$ (sodium carbonate) were placed in both phantoms and the activity of the ${ }^{24} \mathrm{Na}$ was determined. Sulfur pellets $1-1 / 2$ in, in diameter were exposed on the phantoms and the ${ }^{32} \mathrm{P}$ activity was used to determine the fast neutron ( $>2.9 \mathrm{MeV}$ ) component of the neutron fluence. The ratio of the gamma dose in air to the gamma dose on the phantom and the ratio of $\gamma$ to $\mathrm{n}$ was calculated.

Neutron spectrum measurements were made with the NE-213 scintillator, and with multispheres over the full range from thermal to $20 \mathrm{MeV}$. A 0.5 -in. $\times 0.5$-in, "Lil scintillator was used in the multispheres. We obtained spectrum. weighted dose-equivalent values from the NE-213 and multisfher measurements for comparison with other techniques. Above $0.4 \mathrm{MeV}$, neutson energy spectra were measured with a 2 -in. $\times 2$-in. NE-213 scintillator used with a pulse-shape discriminator to suppress gamma-ray response. Measurements were made at two detector gains, covering the energy ranges $0.3102 \mathrm{MeV}$, and 1 to $12 \mathrm{MeV}$. A multisphere system composed of a 0.5 -in. $\times 0.5$-in. ${ }^{6}$ Lil detector with a cadmium shield and 3, 5-, B., 10-, and 12-in.-diameter spheres of polyethylene was used to measure the entire neutron energy spectra, but with poorer resolution than the NE-213 detector. 
Figure 1. SHEBA neutron spectra obtained with the NE-213 detector at $5 \mathrm{~m}$.

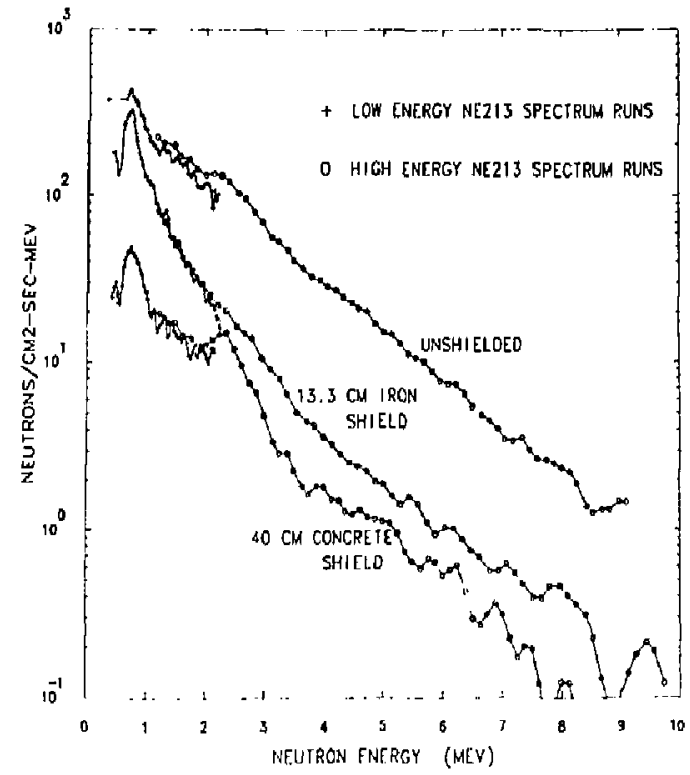

\section{Neutron Dose}

In order to take full advantage of the NE-213 resolution and the multisphere energy range, we began reducing the neutron data by unfolding the NE-213 response, using $\bar{a}$,rogram that differentiates the proton recoil response and corrects for detector characteristics such as nonlinear light outpit and multiple scattering. Figure 1 shows the neutron spectra obtained with the NE-213 detecior at $5 \mathrm{~m}$ from SHEBA with and without the shields. The NE-2l3 results were also an input parameter for the evaluation of the multisphere responses used to calculate the spectra below $0.3 \mathrm{MeV}$. Figure 2 presents a comparison of the full-range composite neutror spectrá thus ob. tained at $5 \mathrm{~m}$.

The results obtained in this study are given in Tables 1 through 4 . They have been normalized to an ion chamber rearing (used to determine the reactor power) of $0.1 \times 10^{-9} \mathrm{~A}(\sim 0.154 \mathrm{~W})$ for most of the dose measurements and to $0.5 x$ $10^{-7} \mathrm{~A}$ for the activations of $\mathrm{Na}$ and sulfur. All calibrations were to a bare ${ }^{752} \mathrm{Cf}$ neutron source or a ${ }^{137} \mathrm{Cs}$ gamma-ray source in the LLNL calibration facility.

Figure 3 shows the neutron dose rate as determined by the 9.in. sphere. Two points are shown at many of the distances-one obtained with TLDs placed inside the sphere, and the sec- ond with the $\mathrm{BF}_{3}$ tube. The decrease in the neutron dose rate for the unshielded (bare) assembly follows the inverse square relationship very closely. The concreie shield is a very effective shield, reducing the neutron dose rate at $5 \mathrm{~m}$ by almost an order of magnitude. The slope of the curve in Fig. 3 for the concrete shield is less than the inverse square curve. This is caused by neutron leakage around the shield as the distance from the shield is increased.

With the steel shield the decrease in dose rate is more rapid than inverse square. The rapid drop behind the steel shield must be caused by the en. ergy dependence of the 9-in. sphere, which overresponds to low-energy neutrons (by a factor of -7 at the $25-\mathrm{keV}$ iron cross section window). At larger distances from the shield, the number of these 25-keV energy neutrons is decreased by scatter and air absorption, causing the bend in curve shown in Fig. 3. At the larger distances the leakage around the shiein causes the curve to have a slope that is less than inverse square. However, even at $59 \mathrm{~m}$ the effect of the shield in reducing the neutron dose rate is still apparent. The rapid drop in neutron dose rate at small distances behind the steel shield is not seen in the gamma dose rate, which is discussed later.

There is reasonably good agreement bitween the remmeter, NE-213 scintillator, and multisphere results (see Tables 1 and 3). The NE-213 


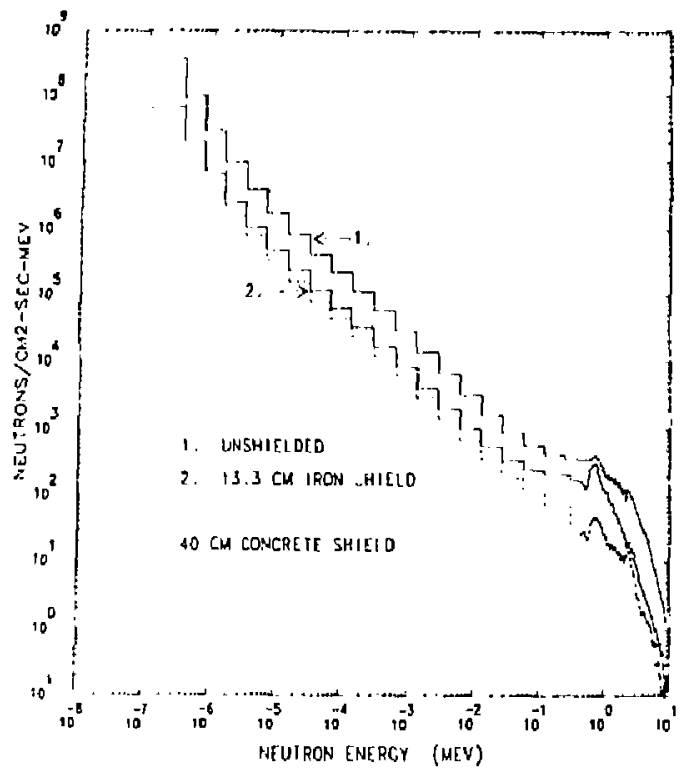

Figure 2. Comparison of SHEBA neutron spectra at $5 \mathrm{~m}$.

scintijlator Jesults are slightly lower for the steeland concrete + shielded data and the multisphere results are low at $14 \mathrm{~m}$. The multisphere results are also lower than the remmeter results at $69 \mathrm{~m}$. The NE-213 scintillator has a lower energy threshold of $400 \mathrm{keV}$ and its readings were expected to be low when compared to an instrument sensitive to all neutron energies.

The ratio of the 9- to 3 -in. spheres given in Table 1 decreases as the distance from the bare assembly is. Teases, indicating that a gradual softening of tise spectrum is occarring (High 9. to 3 -in ratios are obtained from fast spectra and low ratios from low-energy spectra.) The results behind the steel shield indicate that the spectrum is softening very rapidly as the distance from the shield is increased. At the langer distances the 9to 3 -in. ratios appear to be merzing at a ratio of around 0.3 but data at greater distances were not obtained. It is reasonable to assume the ratios would be the s' ile at greater distances.

The themal neutron dose rates measured with the bare probe from the PNR-4 instrument and with TLDs are plotted as a function of distance trom the assembly in Fig. 4 . There is an unexplained difference in the instrurent and TLD readings; the TLDs are higher for the bare and steel-shieided assembly and lower behind the concrete shield. The thermal neutron dose rates from the bare assembly and behind the concrete

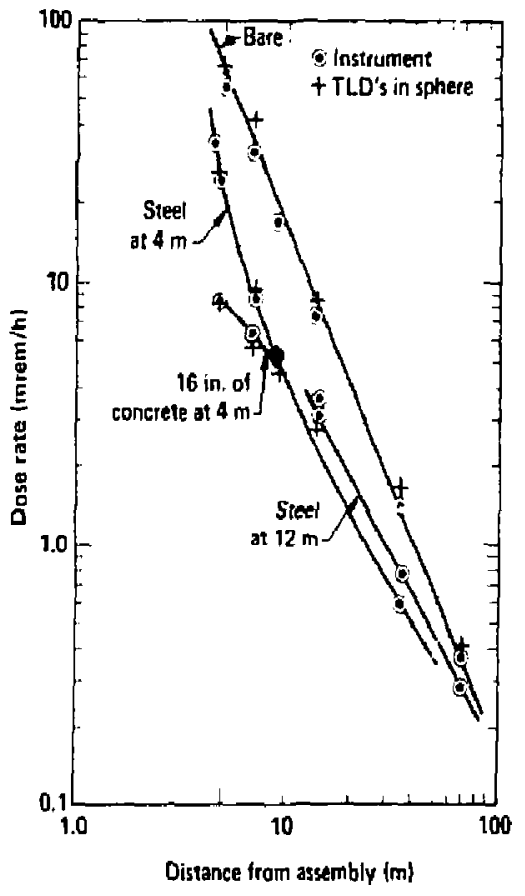

Figure 3. Neutron dose rates determined with the 9-int-sphere remmeter as a funation of distance from the assembly. Measurements were made with (1) the $\mathrm{BF}_{3}$ probe and (2) the ${ }^{6} \mathrm{~L} f$ and ${ }^{7} \mathrm{Li}$ TLDs in the sphere. 
Table 1. Neutron dose rates obtained with the 9-in.-sphere remmeter and the thermal theutron results obtained at the SHEBA critical assembly.

\begin{tabular}{|c|c|c|c|c|c|c|c|c|c|c|c|c|c|}
\hline \multirow{4}{*}{$\begin{array}{l}\text { Shicld } \\
\text { and shield } \\
\text { distance }\end{array}$} & \multirow{4}{*}{$\begin{array}{c}\text { Distance } \\
\text { from } \\
\text { assembly } \\
\text { (1n) }\end{array}$} & \multirow{3}{*}{\multicolumn{2}{|c|}{$\begin{array}{l}\text { Dose rale, 9-in. } \\
\text { sphere (mrem/h) }\end{array}$}} & \multirow{3}{*}{\multicolumn{2}{|c|}{$\begin{array}{l}\text { Katio of 9- to } \\
\text { 3-in. spheres }\end{array}$}} & \multirow{2}{*}{\multicolumn{4}{|c|}{ Pose ralc, thermal neueran (meem $/ h$ ) }} & \multicolumn{4}{|c|}{ F thermal neutrons } \\
\hline & & & & & & \multicolumn{2}{|c|}{ On phanlaim } & & & \multirow{2}{*}{\multicolumn{2}{|c|}{ In air }} & \multicolumn{2}{|c|}{ On phantom } \\
\hline & & & & & & In dir & & $\begin{array}{l}\text { REMAB } \\
\text { phantom }\end{array}$ & $\begin{array}{l}\text { LENL } \\
\text { phantom }\end{array}$ & & & $\begin{array}{l}\text { REMAB } \\
\text { phantom }\end{array}$ & $\begin{array}{c}\text { CLNi } \\
\text { phantom }\end{array}$ \\
\hline & & Instrument & TL.0s & Instrument & TLOS & Insirument & TLE & & TLD & Instrument & TL.D & & TLD \\
\hline \multirow{6}{*}{$\begin{array}{l}\text { Steel } \\
\text { at } 4 \mathrm{~m}\end{array}$} & 4.5 & 34.5 & & 0.68 & & 0.067 & & & & 0.19 & & & \\
\hline & $\mathbf{5 . 0}$ & 24.2 & 24, 8 & 0.56 & 0.61 & 0.069 & 0.088 & 0.19 & 0.29 & 6.30 & 0.36 & 0.78 & 1.04 \\
\hline & 7.0 & 8.80 & 9.44 & 0.45 & 0.43 & 0.070 & 0.090 & & 0.19 & 0.01 & 0.95 & & 3.96 \\
\hline & 9.0 & 5.35 & 4.72 & 0.42 & 0.32 & 0.056 & 0.067 & & 0.14 & 1.06 & 1.42 & & 2.99 \\
\hline & 14 & 3.09 & & 0.32 & & 0.049 & & & & 1.60 & & & \\
\hline & 35 & 0.58 & & 0.31 & & 0.012 & & & & 2.03 & & & \\
\hline \multirow[t]{6}{*}{ Bare } & $\mathbf{s}$ & 57.2 & 66.4 & 0.59 & 0.61 & $\mathbf{0 . 3 5}$ & 0.51 & 1.06 & 1.24 & 0.61 & 0.77 & 1.59 & 1.86 \\
\hline & 7 & 30.9 & 38.3 & 0.59 & 0.66 & 0.20 & 0.22 & & 0.68 & 0.66 & 0.58 & & 1.79 \\
\hline & 9 & 17.1 & & 0.56 & & 0.11 & & & & 0.66 & & & \\
\hline & 14 & 7.64 & P.59 & 0.57 & 0.59 & 0.057 & 0.068 & & D.20 & 0.75 & 0.80 & & 2.32 \\
\hline & .75 & 1.43 & 1.66 & 0.46 & & 0.014 & & & & 1.01 & & & \\
\hline & 69 & 0.37 & 0.38 & D.38 & & 0.005 & & & & 1.22 & & & \\
\hline \multirow{3}{*}{$\begin{array}{l}\text { Sieel } \\
\text { 21 } 12 \mathrm{~m}\end{array}$} & 14 & 3.56 & 2.82 & 0.39 & & 0.045 & & & & 1.27 & & & \\
\hline & 35 & 0.80 & & 0.28 & & 0.016 & & & & 1.98 & & & \\
\hline & 69 & 0.29 & & 0.34 & & 0.0047 & & & & 2.61 & & & \\
\hline $\begin{array}{l}\text { sin. of } \\
\text { concrete } \\
\text { d } 12 \mathrm{~m}\end{array}$ & 14 & 2.69 & 2.42 & 0.33 & & 0.056 & & & & 2.09 & & & \\
\hline \multirow{3}{*}{$\begin{array}{l}16 \text { in. al } \\
\text { concrete } \\
+14 \mathrm{~m}\end{array}$} & 5 & 8.73 & 8.55 & 0.39 & 0.40 & 0.21 & D.14 & 0.28 & 0.32 & 2.40 & 2.21 & 3.26 & 3.79 \\
\hline & 7 & 6.53 & 5.71 & 0.30 & 0.30 & 0.14 & 0.11 & & 0.23 & 2.09 & 1.95 & & 4.08 \\
\hline & 9 & 2.92 low & 5.22 & 0.38 & 0.35 & 0.042 low & 0.082 & & 0.17 & 1.48 & 1.57 & & 3.22 \\
\hline
\end{tabular}


Table 2 Albedo neutron dosimeter and gamma-ray measurements made at the SHEBA critical assembly.

\begin{tabular}{|c|c|c|c|c|c|c|c|c|c|c|c|c|c|c|c|}
\hline \multirow{3}{*}{$\begin{array}{l}\text { Shield } \\
\text { and shield } \\
\text { distance }\end{array}$} & \multirow{3}{*}{$\begin{array}{l}\text { Distance } \\
\text { from } \\
\text { assembly } \\
\text { (m) }\end{array}$} & \multicolumn{6}{|c|}{ Albedo ncutron dosimeters } & \multicolumn{8}{|c|}{ Gamma ray } \\
\hline & & \multicolumn{2}{|c|}{$\begin{array}{l}\text { Calibration factor } \\
\text { using TLEs in 9-in.- } \\
\text { sphere doses } \\
\end{array}$} & \multicolumn{2}{|c|}{$\begin{array}{c}\text { Dose rate } \\
\text { using inst } 9 / 3 \\
\text { ratio (mrem } / \mathrm{h} \text { ) }\end{array}$} & \multicolumn{2}{|c|}{$\begin{array}{l}\text { Dose rste } \\
\text { using TLD } 9 / 3 \\
\text { Tatio }(\mathrm{mrem} / \mathrm{h}) \\
\end{array}$} & \multirow{2}{*}{$\begin{array}{l}\text { TLDs } \\
\text { in air } \\
\{\mathrm{mk} / \mathrm{h}\}\end{array}$} & \multicolumn{2}{|c|}{$\begin{array}{l}\text { TLDs nn } \\
\text { phiantom }\end{array}$} & \multicolumn{2}{|c|}{$\begin{array}{l}\text { Personnel TLD } \\
\text { badges on phantom }\end{array}$} & \multicolumn{2}{|c|}{$\begin{array}{l}\text { Ratio of TLD on } \\
\text { phantom to } \\
\text { in air }\end{array}$} & \multirow{2}{*}{$\begin{array}{l}\text { Ratio of gamma } \\
\text { (in dir) to } \\
\text { neutron (9-in.- } \\
\text { sphere TLD) }\end{array}$} \\
\hline & & $\begin{array}{l}\text { REMAB } \\
\text { phantom }\end{array}$ & $\begin{array}{c}\text { TLNL } \\
\text { phantom }\end{array}$ & $\begin{array}{l}\text { FEMAE } \\
\text { pharton }\end{array}$ & $\begin{array}{c}\text { LLN1 } \\
\text { phantom }\end{array}$ & $\begin{array}{l}\text { REMAB } \\
\text { phantom }\end{array}$ & $\begin{array}{c}\text { LENL } \\
\text { phanton }\end{array}$ & & $\begin{array}{l}\text { REMAB } \\
(\mathrm{mK} / \mathrm{h})\end{array}$ & $\begin{array}{l}\text { I.ENL. } \\
(\mathrm{mR} / \mathrm{h})\end{array}$ & $\begin{array}{l}\text { REMAB } \\
(\mathrm{mR} / \mathrm{h})\end{array}$ & $\underset{(m R / h)}{\operatorname{LLNL}}$ & $\frac{\text { in a }}{\text { REMAB }}$ & & \\
\hline \multirow[t]{6}{*}{ Sieel at $4 \mathrm{~m}$} & 4.5 & & & & & & & & & & & & & & \\
\hline & 5.0 & 0.55 & 0.61 & 17.8 & 19.8 & 19.5 & 21.7 & 0.42 & $0.5 \mathrm{~B}$ & 0.61 & 0.60 & 0.64 & 1.38 & 1.44 & 0.017 \\
\hline & 7.0 & & 0.96 & & 9.26 & & 9.49 & 0.35 & & 0.46 & & 0.43 & & 1.29 & 0.037 \\
\hline & 9.0 & & 1.37 & & $5.2^{\circ}$ & & 3.85 & 0.21 & & 0.30 & & 0.32 & & 1.43 & 0.044 \\
\hline & 14 & & & & & & & & & & & & & & \\
\hline & 35 & & & & & & & & & & & & & & \\
\hline \multirow[t]{5}{*}{ Bare } & 5 & 0.87 & 0.86 & 78.4 & 77.7 & $\mathbf{8 1 . 7}$ & B1.0 & 5.42 & 6.32 & 6.05 & 6.54 & 5.71 & 1.17 & 1.12 & 0.082 \\
\hline & $\begin{array}{l}7 \\
9\end{array}$ & & 0.79 & & 32.8 & & 47.6 & 2.47 & & 3.31 & & $\mathbf{3 . 2 0}$ & & 1.34 & 0.064 \\
\hline & 14 & & 0.96 & & 10.9 & & 11.2 & $0.6 \mathrm{t}$ & & 0.81 & & 0.75 & & 1.34 & 0.071 \\
\hline & 35 & & & & & & & & & & & & & & \\
\hline & 69 & & & & & & & & & & & & & & \\
\hline \multirow[t]{3}{*}{ Steel alt $12 \mathrm{~m}$} & 14 & & & & & & & & & & & & & & \\
\hline & 35 & & & & & & & & & & & & & & \\
\hline & 69 & & & & & & & & & & & & & & \\
\hline $\begin{array}{l}B \text { in. of } \\
\text { concrete at } 12 \mathrm{~m}\end{array}$ & 14 & & & & & & & & & & & & & & \\
\hline \multirow{3}{*}{$\begin{array}{l}16 \mathrm{in} \text {. of } \\
\text { concrete at } 4 \mathrm{~m}\end{array}$} & 5 & 0.96 & 0.99 & 6.15 & 5.5.4 & 7.40 & 7.69 & 0.69 & 0.81 & 0.86 & 0.84 & 0.85 & 1.18 & 1.25 & 0.081 \\
\hline & 7 & & 1.57 & & 7.66 & & 5.85 & 0.42 & & 0.67 & & 0.62 & & 1.57 & 0.074 \\
\hline & 9 & & 3.29 & & 6.75 & & 5.22 & 0.29 & & 0.42 & & 0.38 & & 1.44 & 0.056 \\
\hline
\end{tabular}


Table 3. Reoulb obtainea with the multiphere neutron inatrument and the NE-213 detector at the SHEDA critical membly.

\begin{tabular}{|c|c|c|c|c|c|c|c|c|}
\hline \multirow[b]{2}{*}{$\begin{array}{l}\text { Shited } \\
\text { and shiejd } \\
\text { disunce }\end{array}$} & \multirow{2}{*}{$\begin{array}{l}\text { Diwlesce } \\
\text { from } \\
\text { (mes) }\end{array}$} & \multicolumn{6}{|c|}{ Molliephere } & \multirow[b]{2}{*}{$\begin{array}{c}\text { NE-213 } \\
\text { dew nute } \\
\text { (arew/h) }\end{array}$} \\
\hline & & $\begin{array}{c}\text { Totol flox } \\
\left(\mathrm{a} / \mathrm{cm}^{2} \cdot \mathrm{s}^{-1}\right)\end{array}$ & 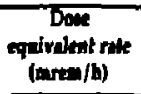 & $\begin{array}{c}\text { Kermen nite } \\
\left(\mathrm{et} / \mathrm{g} / \mathrm{g}^{-1} \cdot \mathrm{h}^{-1}\right)\end{array}$ & $\begin{array}{l}\text { Elemeal } 57 \\
\text { dowe rate } \\
\text { (tad/h) }\end{array}$ & 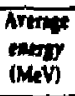 & Total & \\
\hline \multirow[t]{6}{*}{ Steel at $1 \mathrm{~m}$} & 1.5 & & & & & & & \\
\hline & 5.0 & 401 & 23.5 & 0.194 & 0.00251 & 0.532 & 0.317 & 20,9 \\
\hline & 7.0 & & & & & & $(0.121)^{b}$ & \\
\hline & 9.0 & & & & & & $(0.0603)^{\prime}$ & \\
\hline & 14 & & & & & & & \\
\hline & 35 & & & & & & & \\
\hline \multirow[t]{6}{*}{ Ane } & 5 & 1107 & 68.9 & 0.557 & 0.0175 & 0.69 & 0.921 & 6.2 \\
\hline & 7 & & & & & & $(2,531)^{b}$ & \\
\hline & 9 & & & & & & & \\
\hline & 14 & 148 & 7.04 & 0.0570 & 0.0000000 & 0.499 & 0.0912 & 9.2 \\
\hline & 35 & & & & & & & \\
\hline & 69 & & & & & & & \\
\hline \multirow[t]{3}{*}{ Stel at $12 \mathrm{n}$} & 14 & & & & & & & \\
\hline & 35 & & & & & & & \\
\hline & 69 & 7.18 & 0.212 & 0.00167 & 0.0000278 & 0.255 & 0.00276 & \\
\hline $\begin{array}{l}g \text { in. of } \\
\text { concrete at :2 m }\end{array}$ & 14 & & & & & & & \\
\hline \multirow{3}{*}{$\begin{array}{l}16 \text { in. of } \\
\text { concrete at } 4 \mathrm{~m}\end{array}$} & 5 & 210 & 7.34 & 0.0570 & 0.000923 & 0.350 & 0.186 & 5.9 \\
\hline & 7 & & & & & & $(0.124)^{k}$ & \\
\hline & 9 & & & & & & $(0.114)^{b}$ & \\
\hline
\end{tabular}

- Bure aseer bly and siet shield exposures were 20 midt; concrete shield exposure was to thin.

${ }^{\circ}$ Calculated on the basis of 9-in,-sphere (TCD) results at these distances.

Tabje 4. Sulfur and sodium activation results obtained from the SHEBA critical assembly (normalized to $0.5 \times 10^{-7} \mathrm{~A}$ ).

\begin{tabular}{|c|c|c|c|c|c|c|c|c|c|}
\hline \multirow{2}{*}{$\begin{array}{l}\text { Shield } \\
\text { and shitid } \\
\text { distance }\end{array}$} & \multirow{2}{*}{$\begin{array}{l}\text { Distanse } \\
\text { from } \\
\text { asembly } \\
\text { (m) }\end{array}$} & \multicolumn{2}{|c|}{$\begin{array}{c}\text { Sulfur fluence } \\
\left(\mathrm{n} / \mathrm{cm}^{2}\right)\end{array}$} & \multicolumn{2}{|c|}{$\begin{array}{l}\text { Sodium activity } \\
\text { (pCi/mg) }\end{array}$} & \multicolumn{2}{|c|}{$\begin{array}{l}\text { Sodium activation/ } \\
\text { rad (kerma) } \\
\text { (pCi/mg) }\end{array}$} & \multirow{2}{*}{\multicolumn{2}{|c|}{$\begin{array}{l}\text { Ratio of sulfur } \\
\text { fluence to } \\
\text { sodjum activation }\end{array}$}} \\
\hline & & $\begin{array}{l}\text { REMAB } \\
\text { phantom }\end{array}$ & $\begin{array}{c}\text { LLNL } \\
\text { phasiom }\end{array}$ & $\begin{array}{l}\text { REMA } \\
\text { phantom }\end{array}$ & $\begin{array}{c}\text { LLNiL } \\
\text { phantqu }\end{array}$ & $\begin{array}{l}\text { REMĀB } \\
\text { phaniom }\end{array}$ & $\begin{array}{l}\text { ILNT } \\
\text { phanlom }\end{array}$ & & \\
\hline Slrel at 4 ml & $\begin{array}{l}4.5 \\
5.0 \\
7.0 \\
9.0 \\
114 \\
35\end{array}$ & $7.0 \times 10^{6}$ & $\begin{array}{l}6.1 \times 10^{6} \\
3.0 \times 10^{6} \\
23 \times 10^{6}\end{array}$ & 3.45 & $\begin{array}{l}3.50 \\
1.59 \\
1.15\end{array}$ & 10.9 & $\begin{array}{l}11.0 \\
13.1 \\
19.1\end{array}$ & $2.03 \times 10^{\mathrm{H}}$ & $\begin{array}{l}1,24 \times 10^{12} \\
1,88 \times 10^{12} \\
200 \times 10^{12}\end{array}$ \\
\hline Bare & $\begin{array}{r}5 \\
7 \\
9 \\
14 \\
35 \\
69\end{array}$ & $7.1 \times 10^{7}$ & $\begin{array}{l}5.8 \times 10^{7} \\
3.3 \times 10^{7} \\
1.1 \times 10^{7}\end{array}$ & 9.85 & $\begin{array}{l}9.88 \\
5.81\end{array}$ & 10.7 & $\begin{array}{l}10.7 \\
10.9\end{array}$ & $7.21 \times 10^{12}$ & $\begin{array}{l}5.87 \times 10^{12} \\
5.68 \times 10^{12} \\
9.56 \times 10^{12}\end{array}$ \\
\hline Sleel af $12 \mathrm{~m}$ & $\begin{array}{l}14 \\
35 \\
69\end{array}$ & & & & & & & & \\
\hline $\begin{array}{l}2 \ln \text { of } \\
\text { concrete at } 12 \mathrm{~m}\end{array}$ & 14 & & & & & & & & \\
\hline $\begin{array}{l}\text { If in. of } \\
\text { concrete at } 4 \mathrm{~m}\end{array}$ & $\begin{array}{l}5 \\
9\end{array}$ & $7.6 \times 10^{4}$ & $\begin{array}{l}7.6 \times 10^{4} \\
5.2 \times 10^{4} \\
2.7 \times 10^{4}\end{array}$ & 353 & $\begin{array}{l}3.30 \\
2.92 \\
2.28\end{array}$ & 19.0 & $\begin{array}{l}17.7 \\
23.5 \\
20.0\end{array}$ & $2.15 \times 10^{12}$ & $\begin{array}{l}230 \times 10^{12} \\
1.79 \times 10^{12} \\
1.18 \times 10^{12}\end{array}$ \\
\hline
\end{tabular}




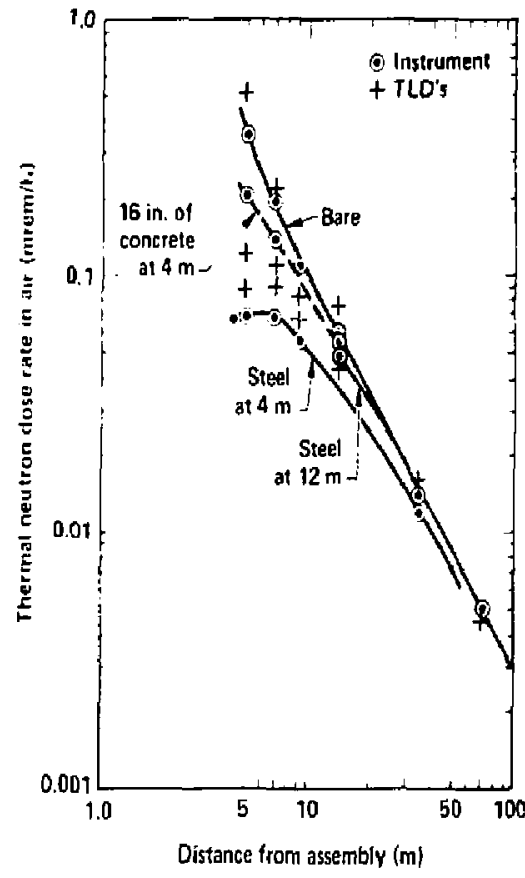

Figure 4. Thermal neutron dose rates as a function of distance from the assembly. Measurements were made with (1) the bare $\mathrm{BF}_{3}$ probe from the PNR-4 remmeter and (2) ${ }^{6} \mathrm{Li}$ and ${ }^{7}$ Li TLDs.

are almost equal. The curve for the steel-shielded assembly peaks at a distance of about $6 \mathrm{~m}$ from the assembly. At the larger distances all the curves appear to merge.
When the TLDs are placed on a phantom the thermal neutron dose is increased by fast neutrons moderated to thermal in the phantom and by incident thermal neutrons reflected by the phantom. The readings of TLDs exposed on a phantom increased by a factor of $\sim 3$ for the bare assembly and a factor of $\sim 2$ for the concrete- and steelshielded assembly. There is a difference in the thermal response from the different phantoms; the Remab phantom has slightly lower readings than the LLNL phantom. The percentage of the total neutron dose (determined by the 9-in. sphere) that is contributed by thermal neutrons is given in Table 1.

Figure 5 shows the results obtained from the albedo neutron dosimeters plotted as a function of the 9- to 3-in. ratio. The ratios used in this figure were those obtained using TLDs in the spheres, which differed only slightly from the instrument results. The calibration factors were obtained by dividing the albedo dosimeter readings ('Li minus ${ }^{7} \mathrm{Lj}$ ) by the neutron dose determined using the TLDs placed inside the 9-in. sphere. The line drawn on the figure is the standard curve used to evaluate albedo neutron dosineters based on the 9- to 3 -in.-sphere technique. The points shown on Fig, 5 fall close to the curve, indicating that the 9 to 3-in.-sphere technique can be used accurately with this assembly shielded or unshielded.

The dose rates obtained from the albedo nettron dosimeters are given in Table 2 . Two evaluations were made with each albedo reading, one with the 9- to 3-in. ratio determined using TLDs inside the 9-and 3-in. spheres and the second with the 9- to 3-in. ratio determined using the $\mathrm{BF}_{3}$ probe in the spheres. We also used both the

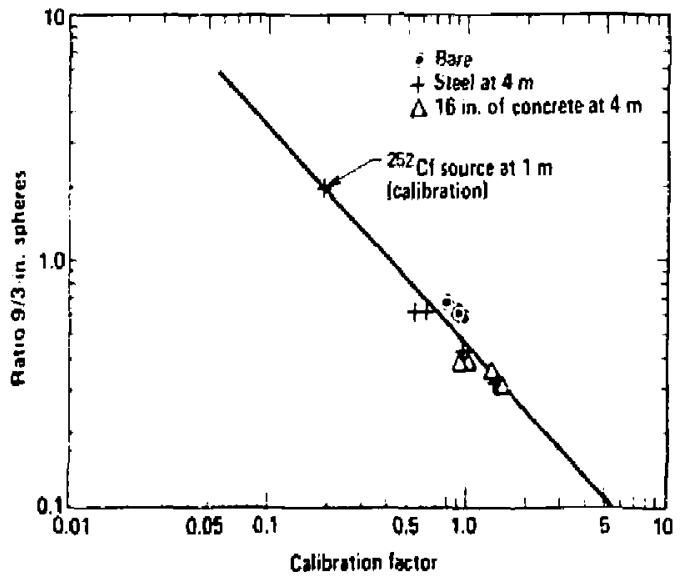

Figure 5. Albeds neutron dosimeler calibration factors as a function of the ratio of the 9- to the 3-in. sphere. 
Remab and ULNL-type phantoms at the 5-m distance, giving us four dose determinations at these points. The curve shown in Fig. 5 was used to determine the doses. A bare ${ }^{252} \mathrm{C} f$ source was used for calibration of the albedo dosimeters. When the results are compared with the neutron doses shown in Fig, 3, we find agreement within about $25 \%$. In Fig. 5 , points that lie above the standard curve cause the neutron dose evaluation to be high, and points below the curve cause the doses to be low This is shown in Table 2, where the bare assembly results are high and the steel- and concrete-shielded results are slightly low. No significant differences in the results obtained with the Remab or LLNL phantoms ware found, indicating that either phantom can be used in future studies.

\section{Gamma-Ray Dose}

The gamma-ray dose rates measured by TLDs exposed in air as a function of distance from the assembly are shown in Fig. 6. The dose rates measured by TLDs on the phantom are higher than the dose rates in air (averaging about 30 to 35\%; see Table 4). This increase is caused by reutron capture in the phantom, which produces gamma rays. Comparing Fig. 4 with Fig. 3 , we find the relative positions of the curves for the bare and concrete-shielded assembly to be the same. but the curve for the steel-shielded assembly is lower on Fig. 6 and has a different shape. The steel is obviously providing appreciable gammaray shieldaing.

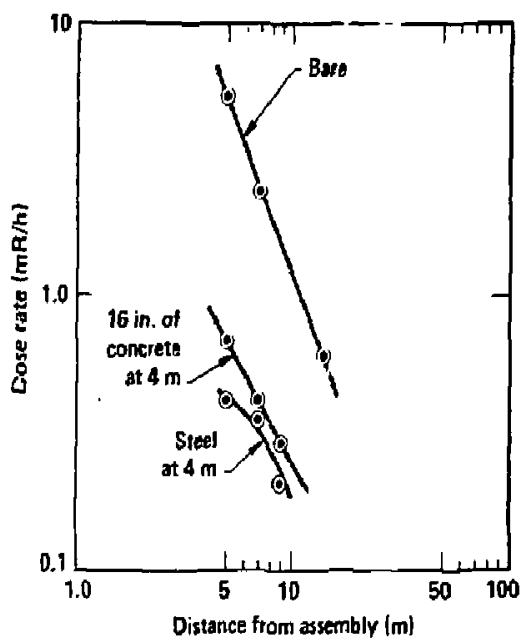

Figure 6. Gamma-ray dose rates measured in air as a function of distance from the assembly.

\section{Sulfur and Sodium Activation}

The fast neutron fluences $(>2.9 \mathrm{MeV})$ determined by using the sulfur pellets are given in Table 4. There is no significant difference in the results obtained with the sulfur pellets located on either of the two types of phantoms.

The sodium activation of the saline solution in the phantons is shown in Fig. 7. The curves for
Figure 7. Activation of the $\mathrm{Na}$ solution in two types of phantons 25 a function of distance from the assembly.

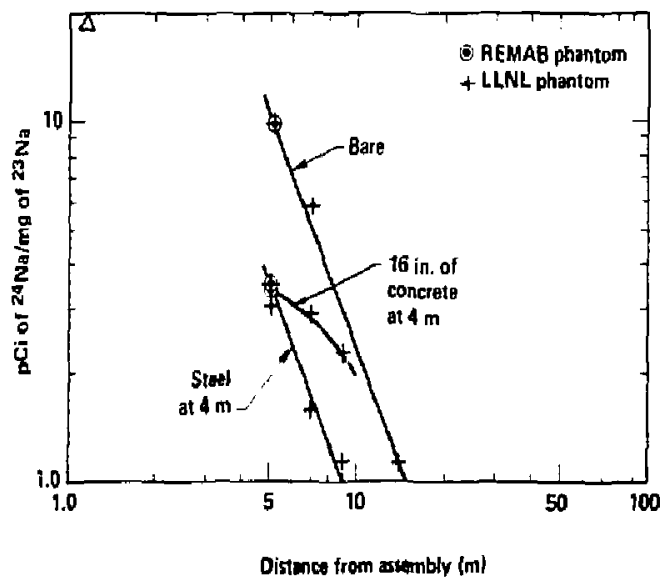




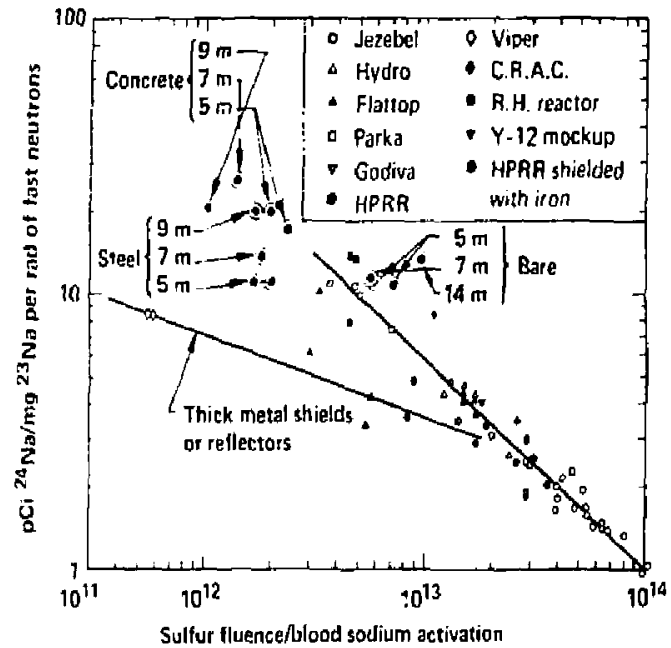

Figure 8. Curves used to delermine the dose received in a criticality accident, based on the ac. tivation of the blood and hair (sulfur fluence). The new points obtained in this study are indicated. the bare and steel-shielded assembly have about the same shapes as shown in Fig. 3 for the total neutron dose, but the slope for the steel-shielded curve in Fig. 7 is differeni and follows closely an inverse square relationship. The concrete-shielded results in Fig. 7 are higher than their relative position in Fig. 3. The relative positions of the sodium activation curves in Fig.7 are not the same as those for either the thermal neutron dose rates shown in Fig. 4 or the fast neutron dose rates shown in Fig. 3 , indicating that sodium activation is from a composite of all neutron energies.

The results from the sodium activation and sulfur fluence were plotted on the curve used to determine criticality-accident doses by using only blood and hair activations." The results are shown in Fig. 8. For this assembly all the points lie near

-D. E. Mankins, "Dosimetry of Criticality Accidents Using Activations of the Blood and Hait." Healif Physics 38, 529 (1980) the top of the figure, indicating that there is considerable sodium activation per rad of fast neutron dose, which makes detection of small doses possible. The sulfur activation is low, however, because the number of $>2.9-\mathrm{MeV}$-energy neutrons leaking from this assembly is less than for metal assemblies. This would make detection of the sulfur activation in the hais difficulf for low doses and the evaluation of these low doses correspondingly less accurate, if the hair and blood activation method were used. The concrete-shielded points lie beyond the curve and the previously published curve can now be extended to include these results. The bare assembly points are above the curve but within the scatter of data previously obtained. The 14-m bare point is questionable and could be from counting statistics of the blood and sulfur samples. If this point is correct, it would be interesting in a future study to determine what is happening at larger distances. The steel-shielded points lie between the curves as expected, except for the $9 . m$ point which fell on the upper curve. 


\title{
Additional Calibrations of the PTB Beta Sources
}

\author{
D. E. Hankins
}

The Hazards Control Calibration Facility has a set of the secondary standard beta-ray sources calibrated by the West German equivalent to our National Bureau of Standards. The sources are usually referred to as the "PTB" sources (the abbreviation for the Physikalisch-Technische Bundesanstalt at Braunschweig, Germany).* We have expanded their usefulness to us by making additional calibrations to cover a wider range of dose rates.

\section{Beta Energies}

The set of sources consists of two ${ }^{90} \mathrm{Sr}$ sources $\left(E_{\max } 2.270 \mathrm{MeV}\right), \mathrm{a}^{204} \mathrm{Tl}\left(E_{\max } 0.766 \mathrm{MeV}\right)$, and : ${ }^{1+7} \mathrm{Pm}$ source $\left(E_{\max } 0.224 \mathrm{MeV}\right.$ ). (By convention, a ${ }^{90} \mathrm{ST}_{\mathrm{T}}$ - ${ }^{D} \mathrm{Y}$ source is referted to as ${ }^{90} \mathrm{Sr}$ and the energy understood to be $2.270 \mathrm{MeV}$. In fact, the $\mathrm{Sr}$ and $Y$ are in equilibrium and the $2.270 \mathrm{MeV}$ is the energy of the $Y$ beta.) These sources were selected to give beta spectra of low, medium, and high energies. The sources came to us with limited, but extremely accurate, calibrations. Only one calibration point is given for the ${ }^{20-1} \mathrm{Tl}$, the ${ }^{1.77} \mathrm{Pm}$, and the small ${ }^{90} \mathrm{Sr}$ source, and three calibration points at various distancos are given for the large ${ }^{90} \mathrm{Sr}$ source. The large ${ }^{97} \mathrm{St}$ source is used unfiltered, bare, but the other sources are used with filters or "flatteners" which are used to flatten the beam from the source over an area where a reasonably sized probe would be exposed fairly unifomly.

The maximum beta energy for the sources is not the theoretical values given above (taken from nuclear tables). The spectra from the PTB sources of ${ }^{90} \mathrm{Sr}$ and ${ }^{204} \mathrm{Tl}$ are lower than the theoretical value, which is caused in part by absorbers of 50 and $20 \mathrm{mg} / \mathrm{cm}^{2}$, respectivoly; used to seal the spurce. In addition, air attenuation, probe window thickness, and the effect of the flatteners all reduce the beta energies.

The ${ }^{117} \mathrm{Pm}$ source has a contaminant of ${ }^{1-16} \mathrm{Pm}$ (beta $E_{m s} 0.78 \mathrm{keV}, 4.4-\mathrm{y} \mathrm{T1} / 2$ ) which confuses the beta energy determination. Although this contaminant is small, it results in the observed effective energy for the flattened source at $20-\mathrm{cm}$ dis.

\footnotetext{
- Artually, the sourtes were made in England by Amersham, ralibrated at the PTB. and sold by the Ceman firm Buchler.
}

tance being slightly higher than the $E_{m s x}$ of ${ }^{147} \mathrm{Pm}$. This source is sealed with a $5-\mathrm{mg} / \mathrm{cm}^{2}$ cover and at $20 \mathrm{~cm}$ of air $\left(\sim 25.9 \mathrm{mg} / \mathrm{cm}^{2}\right)$ very few of the ${ }^{117} \mathrm{Pm}$ betas from the source are deterted.

Thus the beta encrgies from the sources (1) are lower than those given in the tables except for the ${ }^{14 i} \mathrm{Pm}$ source, (2) vary detectably as a function of distance from the source, and (3) are low'et if the flatteners are used.

\section{Measurements}

In using the sources, we found that the calibration points given by the PTB were too limited to cover the wide ranges of dose rates we desired. We decided to expand the usefulness of these sources by making measurements at several distances without the flatteners using our extrapolation chamber ${ }^{\dagger}$ (purchased from Monitor Radiation Corp.. Santu Barbara, CA). One advantage was that we would have information with the small ${ }^{90}$ Sr source with the same energy spectra as the large ${ }^{90} \mathrm{Sr}$ (at the same distance) at dose rates that are different by approximately a factor of 25 .

The dose rates obtained with the extrapolation chamber are given in Table 1 . The effect of the flatteners on the dose rates is to reduce the dose rates from ${ }^{90} \mathrm{Sr}$ and ${ }^{204} \mathrm{Tl}$ by $36 \%$ and for $117 \mathrm{Pm}$ by a factor of four. Note also the large decrease in the $\mathrm{Pm}$ dose rate when the detector is moved from 11 to $20 \mathrm{~cm}$ (a factor of $\sim 11$ ). This rapid drop in dose rate makes accurate measurements difficult since small measurement errors

\footnotetext{
'Sce W. ). Price, Nuctear Radintan Detirtron, 2nd Ed (MicGipu-Hill Book Co. New York. NY, 1958).
} 
Table 1. Dose rates (rads $/ h)^{2}$ at various distances from the PTB sources, measured with ar, axtropoLation chamber.

\begin{tabular}{|c|c|c|c|c|c|}
\hline \multirow[b]{2}{*}{ Source } & \multicolumn{5}{|c|}{ Distance from source $(\mathrm{cm})$} \\
\hline & $\overline{11}$ & 20 & 30 & 50 & 100 \\
\hline $\begin{array}{l}\text { Large }{ }^{\$ 5} \mathbf{r}, \\
\text { no flatlener }\end{array}$ & 176 & & & 8.87 & 2 is \\
\hline $\begin{array}{l}\text { Stmall }{ }^{\infty} b_{r}, \\
\text { flaflenter } \\
\text { no flattener }\end{array}$ & 6.69 & 0.606 & 0.947 & 0.333 & 0.0764 \\
\hline $\begin{array}{l}\text { Ifut } \\
\text { flatlenter } \\
\text { no flattener }\end{array}$ & 0.910 & & $\begin{array}{l}0.0677 \\
0.1064\end{array}$ & 0.0290 & \\
\hline $\begin{array}{l}\text { 14: } \mathrm{Pm}, \\
\text { flattener } \\
\text { no flattener }\end{array}$ & 3.24 & $\begin{array}{l}0.0729 \\
0.287\end{array}$ & & & \\
\hline
\end{tabular}

- Measured on 3/17/82.

become very important. The decrease in dose rate of the ${ }^{90} \mathrm{Sr}$ source with distance is slightly more sapid than inverse square. The ${ }^{204} \mathrm{~T}$ source decrease is significantly more rapid than calculated by using the inverse square rule.

We compared our results with the PTB calibration points in Table 2 . Our results were generally in good agreement with the PTB values except for the "it" $\mathrm{Pm}$ source, where we are $16.5 \%$ high. This could be error from distance measurement or other factors. The PTB values are probably more accurate than our values and should be used when possible.

\section{Conversions}

To convert the air dose rates in Tables 1 and 2 into tissue rads, conversion factors of $1.111,1.139$, and 1.150 are given by the PTB for ${ }^{90} \mathrm{Sr},{ }^{204} \mathrm{TI}$, and ${ }^{1{ }^{7}} \mathrm{Pm}$, respectively. These factors are given only for the calibration points they measured and there is no indication as to how much these would vary at other locations. I doubt they change by more than a percent or two, and using these values for the other points should not result in a significant eтror.

To determine the depth dose at $7 \mathrm{mg} / \mathrm{cm}$ (dead layer of skin thickness) the PTB gives attenuation factors that are different for each measurement point. These values vary from 1.070 to 1.041 for ${ }^{90} 5$. The values for $\left.{ }^{204} \mathrm{~T}\right]$ and ${ }^{147} \mathrm{Pm}$ are 0.955 and 0.20 , respectively. The values $>1.0$ for ${ }^{90} \mathrm{Sr}$ ate caused by the buildup factor's being greater than absorption, but for ${ }^{204} \mathrm{Tl}$ and ${ }^{147} \mathrm{Pm}$ the ab. sorption in the skin exceeds the buildup factor and the dose at a depth of $7 \mathrm{mg} / \mathrm{cm}^{2}$ is lower, particularly for ${ }^{147} \mathrm{Pm}$.

Table 2 Comparison of measured vs reported dose rates in air (rads/h) from the PTB beta sources.

\begin{tabular}{|c|c|c|c|c|}
\hline Source & $\begin{array}{c}\text { Distance } \\
(\mathbf{c m})\end{array}$ & Measured value & PTB reported value' & $\approx$ Difference \\
\hline \multirow[t]{3}{*}{ Lorge ${ }^{*} g_{1}$} & 11 & 176 & 175 & +0.6 \\
\hline & 30 & & 23.9 & \\
\hline & 50 & 8.67 & 8.5 & +3.9 \\
\hline $\begin{array}{c}\text { Small }{ }^{40} \mathrm{Sr} \\
\text { ftattener }\end{array}$ & 30 & 0.606 & 0.591 & +25 \\
\hline${ }^{104} \mathrm{Tl}$, & & & & \\
\hline flattener & 30 & 0.0677 & $0 . \Gamma 20$ & -6.0 \\
\hline${ }^{17} \mathrm{Pm}$ & & & & \\
\hline flallenter & 20 & 0.0729 & 0.0626 & +16.5 \\
\hline
\end{tabular}

Correcled for decay 10 3/17/82. 


\section{Probability of Interaction and Energy Deposition of Neutron-Induced Recoil Protons in a Cell Plasma Membrane}

\section{T. Prevo and T. Straume}

The germ cells (oocytes) in female mice are known to be unusually sensitive to killing by radiation. ${ }^{1}$ Fifty percent are killed by 7 rads of gamma rays. It is of interest both radiobiologically and for radiation protection purposes to identify the radiosensitive target in these cells. This has recently been studied by Straume ${ }^{2}$ who presents evidence that the target is the oocyte's plasma membrane. In this paper we describe calculations that validate those made by Straume. His calculations use published microdosimetric data (event frequency) obtained for a small tissue sphere (mouse-oocyte dimensions) to convert to a tissue shell with the dimensions of the oocyte's plasma membrane.

\section{Calculations}

One can calculate the probability of recoil protons depositing energy in the cell membrane because of neutron interactions in the cell if one assumes a spherical model of the cell and restricts the calculation to protons of one energy.

The spherical cell is shown in Fig. 1. The probability that a recoil proton will deposit energy in the membrane tecause of a neutron interaction in the cell is given by

$P=\frac{P_{1} V_{1}+P_{2} V_{2}+P_{3} V_{3}+P_{4} V_{i}}{V_{\text {tot }}}$.

where $P_{1}, P_{2}, P_{3}$, and $P_{4}$ are the probabilities that interactions in the volumes $V_{1}, V_{2}, V_{3}$ and $V_{4}$ will result in energy deposition in the membrane, $V_{1}$ is the innermost sphere of radius $R_{f}-R$ and for which $P_{1}=0$, since protons originating more than a distance $R$ away from the membrane cannot de. posit energy in the membrane. Protons originating in the membrane $\left(V_{3}\right)$ will all deposit energy in the membrane and thus $P_{3}=1$. The situation in $V_{2}$ and $V_{4}$, which are within range of the membrane, is somewhat more complicated. For these Jegions the probability that the proton will deposit energy in the membrane depends upon the point position at which the proton is created. For a proton produced at a distance $r$ from the origin and for which $R_{1}-R \leq r \leq R_{1}$, the probability is given by'

$$
\frac{\Omega}{4 ! 1}=\sin ^{3} \frac{a}{2}=\frac{1-\cos a}{2} \text {. }
$$

where $\alpha$ is shown in Fig. 2. From Fig, 2 we can see that

$$
\begin{array}{r}
\cos \alpha=\frac{R_{1}-r-Z}{R}=\frac{R_{1}-r-R_{1}(1-\cos \theta)}{R} \\
=\frac{R_{1} \cos r-r}{R},
\end{array}
$$

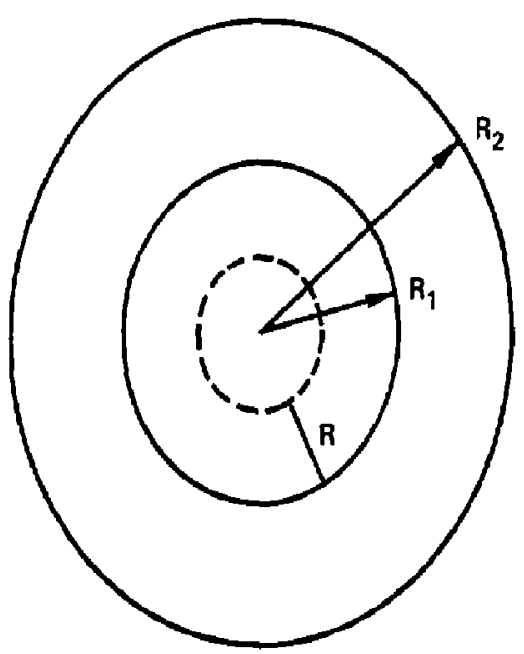

Figure 1. Spherital model of cell. $R_{1}$ and $R_{-2}$ are the inner and outer radii of the membrane. $R$ is the range of a recoil proton. 


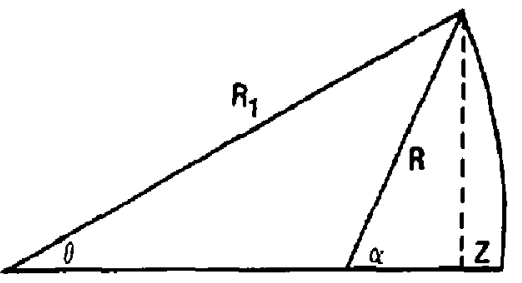

Figure 2. Geometric relations for tell for Eq. (2).

and since

$\cos \theta=\frac{\dot{r}+R_{i}^{2}-R^{2}}{2 r R}$.

then

$\cos a=\frac{r^{2}-R_{1}^{2}-R^{2}}{2 r R}-\frac{r}{R}$.

and

$P_{:}=\frac{n}{4 I I}=\frac{1}{2}\left(1+\frac{r}{2 R_{1}}-\frac{R_{1}^{2}-R^{2}}{2 r_{n_{1}}}\right)$

$P_{2}=\frac{\int P_{2} d r}{\int d v}$

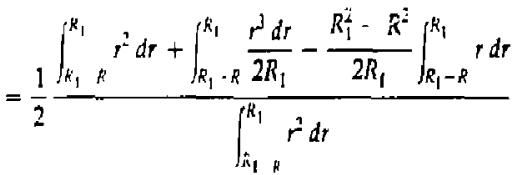

$=\frac{1}{2}\left\{1+\frac{3}{8 R_{1}} \frac{\left(R_{1}^{4}-\left(R_{1}-R\right)^{4}\right\}}{R_{1}^{3}-\left(R_{1}-R\right)^{3}}\right.$

$\left.-\frac{3\left(R_{1}^{2}-R^{2}\right)}{4 R_{1}} \frac{\left(R_{1}^{2}-\left(R_{1}-R\right)^{2}\right]}{R_{1}^{3}-\left(R_{1}-R\right)^{3}}\right\}$

For a proton produced at a distance $r$ from the origin and for which $R_{2} \leq l \leq R_{2}+R$, the probability is given by

$\frac{n}{4 n}=\sin ^{2} \frac{\alpha}{2}=\frac{1-\cos \alpha}{2}$, where $\alpha$ is shown in Fig. 3. From Fig. 3 we see that

$$
\begin{gathered}
\cos \alpha=\frac{x}{R}=\frac{r-R_{2} \cos \theta}{R}=\frac{r}{R}-\frac{r^{2}+R_{2}^{2}-R^{2}}{2 r R} \\
\begin{aligned}
P_{1}=\frac{1}{2}\left(1-\frac{r}{R}+\frac{r^{2}+R_{2}^{2}-R^{2}}{2 r R}\right) \\
=\frac{1}{2}\left(1-\frac{r}{2 R}+\frac{R_{1}^{2}-R^{2}}{2 r R}\right)
\end{aligned}
\end{gathered}
$$

$=\frac{1}{2} \frac{\int_{R_{2}}^{R_{2}-k} r^{2} d r+\int_{R_{2}}^{R_{2}-R} \frac{r^{3} d r}{2 R}-\frac{R_{2}^{2}-R^{2}}{2 R} \int_{R_{2}}^{R_{2}+R} r d r}{\int_{R_{2}}^{R_{2}+R^{2}} r^{2} d r}$

$=\frac{1}{2}\left\{1-\frac{3\left[\left(R_{2}+R\right)^{4}-R_{2}^{4}\right]}{8 R^{\lceil}\left(R_{2}+R^{3}\right)^{3}-R_{2}^{3}}\right.$

$\left.+\frac{3\left(R_{2}^{2}-R^{2}\right)\left[\left(R_{2}+R\right)^{2}-R_{2 !}^{2 !}\right]}{4 R\left[\left(R_{2}+R\right)^{3}-R_{2}^{3}\right]}\right\}$

\section{Results}

A Monte Carlo cade was written which also calculates the probabilities for energy áeposition for $(n, p)$ reactions inside and outside of a spherica] cell as well as the average energy deposition in the plasma membrane. The resuits for proton energies from 0.043 to $0.430 \mathrm{MeV}$ are given in Table 1. The proton ranges were obtained by using $\log -\log$ interpolation of the values given for water in ICRU Report 16. The results are based on ten batches of $10^{5}$ protons each. The results are in good agreement both with those reported by Straume ${ }^{2}$ for $0.215-\mathrm{MeV}$ protons and with calculations based on Eqs. (2) and (3).

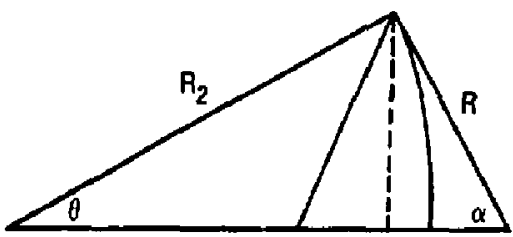

Figure 3. Geometric relations for cell for Eq. (3). 
Table 1. Proton energy (E) deposition and energy deposition probabilities (P) in the cell membrane.

\begin{tabular}{|c|c|c|c|c|c|c|}
\hline \multirow[b]{2}{*}{$\mathrm{E}(\mathrm{MeV})$} & \multirow[b]{2}{*}{ Range luml } & \multirow[b]{2}{*}{$E_{d e p}(M e V)$} & \multicolumn{2}{|c|}{$P_{\text {insalde }}$} & \multicolumn{2}{|c|}{$P_{\text {ontulde }}$} \\
\hline & & & Cälc & MC & Cals & $\overline{\mathrm{MC}}$ \\
\hline 0.043 & 0.663 & $0.00098 \pm 0.00006$ & 0.278 & 0.279 & 0.225 & 0.224 \\
\hline 0.086 & 1.136 & $0.00159 \pm 0.00011$ & 0.300 & 0.302 & 0.209 & 0.208 \\
\hline 0.129 & 1.597 & $0.00228 \pm 0,00014$ & 0.327 & 0.328 & 0.194 & 0.193 \\
\hline 0.172 & 2.089 & $0.00276 \pm 0.00011$ & 0.359 & 0.357 & 0.182 & 0.178 \\
\hline 0.215 & 2.643 & $0.00302 \pm 0.00015$ & 0.393 & 0.394 & 0.167 & 0.164 \\
\hline 0.258 & 3.350 & $0.00328 \pm 0.00015$ & 0.445 & 0.446 & 0.152 & 0.147 \\
\hline 0.301 & 4.094 & $0.00329 \pm 0.00016$ & 0.510 & 0.508 & 0.138 & 0.131 \\
\hline 0.344 & 4.670 & $0.00337 \pm 0.00014$ & 0.577 & 0.579 & 0.124 & 0.116 \\
\hline 0.387 & 5.676 & $0.00328 \pm 0.00018$ & 0.654 & 0.657 & 0.109 & 0.103 \\
\hline 0.430 & 6.509 & $0.00310 \pm 0.00017$ & 0.736 & 0.733 & 0.099 & 0.091 \\
\hline
\end{tabular}

Monte Corlo.

\section{References}

1. R. L. Dobson and T. C. Kwan, "The Tritium RBE at Low-Level Exposure-Variations with Dose, Dose Rate, and Exposure Duration," Curr. Top. Radiat. Res. Q. 12, 44-62 (1979).

2. T. Straume, "Biological Effectiveness of Neutron Irradiation on Animals and Man," PhD thesis, University of Califorria, Davis, CA (1982).

3. H. H. Rossi, "The Role of Microdosimetry in Radiobiology," Radiat. Environ. Biopirys. 127, 29-40 (1979). 


\title{
Calibration of the PNR-4 Neutron Remmeter for Weapons-Like Spectra
}

\author{
C. T. Prevo
}

There is an exror in measuring neutron dose rates with a neutron remmeter because of the differences in the spectral shapes of the field being measured and the calibration source. Errors as large as $30 \%$ can result if a PuBe neutron source was used for calibration. We performed a set of calculations to demonstrate that for the type of neutron sources measured in LLNL's Intrinsic Radiation Facility, ${ }^{252} \mathrm{CF}$ is preferable to either Am-Li or PuBe neutron sources for calibration.

The theoretical calibration factor-(counts/ $\mathrm{min}) /(\mathrm{mrem} / \mathrm{h})$-for operational and calibration spectra were calculated using the codes DOSE and DOSEM, which were written for the CDC-7600. DOSE calculates the theoretical spectrumweighted response using a TARTNP calculated response function, shown in Fig. 1 and given in Table 1. TARTNP is a Monte Carlo coupled neutron-photon transport code.' DOSEM does the same calculation as DOSE, except that 30 group MORSE-calculated spectra are used. MORSE is also a Monte Carlo coupled neutron-phaton transport code."

The calibration factors and spectral correction factors are shown in Table 2. It was assumed in each case that the instrument had beerl calibrated with ${ }^{252} \mathrm{Cf}$.
Ideally, one would like the calibration factors to be small. $A$ dose variance of

$$
\sigma^{2}=\sum_{i=1}^{30}\left(D W_{1}-D C\right)^{2}
$$

where

$D W_{1}=$ the dose rate of the $1^{\text {th }}$ group of a MORSEcalculated neutron spectrum

and

$D C_{1}=$ the dose rate of the $i^{\text {th }}$ group of the calibration sousce,

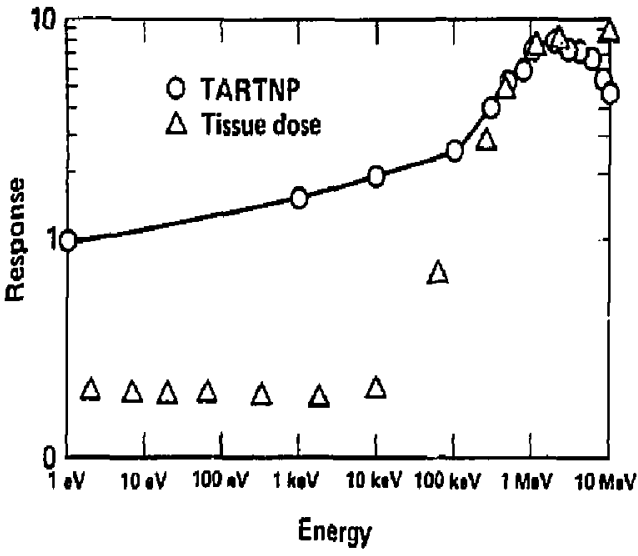

Figure 1. PNR-4 response and tissue dose response as a function of energy.
Table 1. PNR-4 response calculated by TARTNP.

\begin{tabular}{cc}
\hline $\begin{array}{c}\text { Energy } \\
\text { (MeV) }\end{array}$ & $\begin{array}{c}\text { Response } \\
\text { (counts/n) }\end{array}$ \\
\hline $2.5 \times 10^{-8}$ & $2.95 \times 10^{5}$ \\
$1.0 \times 10^{-8}$ & $3.57 \times 10^{5}$ \\
$1.0 \times 10^{-5}$ & $5.82 \times 10^{-5}$ \\
$1.0 \times 10^{-2}$ & $7.50 \times 10^{-5}$ \\
$1.0 \times 10^{-1}$ & $9.32 \times 10^{-5}$ \\
$3.0 \times 10^{1}$ & $1.53 \times 10^{-4}$ \\
$5.0 \times 10^{-1}$ & $2.07 \times 10^{4}$ \\
$.0 \times 10^{-1}$ & $2.24 \times 10^{-4}$ \\
1.0 & $2.78 \times 10^{-4}$ \\
2.0 & $3.06 \times 10^{-4}$ \\
2.2 & $3.27 \times 10^{-4}$ \\
3.0 & $2.82 \times 10^{-4}$ \\
4.0 & $2.72 \times 10^{4}$ \\
6.0 & $2.51 \times 10^{-4}$ \\
8.0 & $2.04 \times 10^{-4}$ \\
10.0 & $1.73 \times 10^{-4}$ \\
14.0 & $1.5 \times 10^{-4}$ \\
\hline
\end{tabular}


was used to compare $\mathrm{Am}-\mathrm{Li}$, ${ }^{252} \mathrm{Cl}$, and PuBe as calibration sources for the W48, W68, and W84. The results are shown in Table 3 . For the three cases calculated, the variance was minimum for the ${ }^{252} \mathrm{Cf}$. This indicates that the dose spectrum for the W48, W68, and W84 more nearly matches that of ${ }^{252} \mathrm{Cr}$ than that of Am-Lj or PuBe.

Table 2. Theoretical calibration factors for PNR-4 for various neutron spectra.

\begin{tabular}{lcc}
\hline Source & $\begin{array}{c}\text { Calibration } \\
\text { factor }\end{array}$ & $\begin{array}{c}\text { Spectral correction } \\
\text { factor }\end{array}$ \\
\hline${ }^{\text {Am-Li }}$ & 62.6 & 0.848 \\
${ }^{25 f}$ & 53.1 & 1.00 \\
Pub $^{6}$ & 51.8 & 1.025 \\
PuBe $^{c}$ & 44.9 & 1.183 \\
PuBe $^{6}$ & 43.2 & 1.229 \\
W48 $_{\text {W63 }}$ & 55.5 & 0.957 \\
W84 & 55.6 & 0.955 \\
\hline
\end{tabular}

"Neutron dose results based on instrument calibration with ${ }^{242} \mathrm{Cf}$ need to be multiplied by this factor.

b 30 group spectra were used by Intrinsic Radiation as input for MORSE.

'NBS spertrum.
Table 3. Dose variances of weapon dose spectra for various calibration sources.

\begin{tabular}{cccc}
\hline Weapon & Am-Li & ${ }^{252} \mathrm{CF}$ & PuBe \\
\hline W48 & 1795 & 827 & 833.8 \\
W68 & 1900 & 128 & 772 \\
W84 & 147 & 36 & 1600 \\
\hline
\end{tabular}

\section{References}

1. E. F. Plechaty and J. R. Kimlinger, "TAKTNP: A Coupled Neutron-Photon Monte Carlo Transport Code," Lawrence Livermore National Laboratory, Livermore, CA, UCRL. 50400, Vol. 14 (1976).

2. T. P. Wilcox, "MORSE-L, A Special Version of the MORSE Program Designed to Solve Neutron, Gamma and Cospled Neutron-Gamma Penetration Problems," memorandum (Sept. 1, 1972). 


\title{
A Single-Calculation Comparison of MORSE76L and ANISN
}

\author{
C. I. Prew and J. C. Fishe"
}

Previously, ANISN was used to calculate the dose rates at $1 \mathrm{~m}$ for ${ }^{252} \mathrm{Cr}$ in various moderators in cell A of the calibration facility. The cell is $12.2 \mathrm{~m}$ long, $9.14 \mathrm{~m}$ wide, and $7.32 \mathrm{~m}$ from basement to ceiling. Since ANISN is a one-dimensional discrete-ordinates code, it cannot be used to address issues involving asymmetry in the geometry such as the hole in the moderator and the walls of the cell. MORSE is a two-dimensional Monte Carlo radiation-transport code and is well suited for accounting for the effects due to asymmetry.

The first issue raised was: how well do MORSE and ANISN agree in their determination of the dose rates for the same problem? ${ }^{152} \mathrm{Cl}$ in a 15- $\mathrm{cm} \mathrm{D}_{2} \mathrm{O}$ sphere was picked for the comparison. The same energy group structure, crosss sections. geumetry, and isotopic compusitions were used for both problems. The isotopic composition of the concrete is given in Table 1. Tne 30 group spectra are given in columns three and four of Table 2 and are shown in Figs. 1-3. Running the MORSE problem with 10 batches of $10^{4}$ neutrons each produced a $1.0 \%$ standard deviation on the dose rate at $1 \mathrm{~m}$. This dose rate is $1.9 \%$ greater than predicted by ANISN. This is really excellent agrement between the two codes.

Table 1. Isotopic composition of the concrete walls.

\begin{tabular}{cc}
\hline Jsolope & Aloms/barn-cm \\
\hline$H$ & 0.01386 \\
$C$ & 0.01200 \\
$O$ & 0.01582 \\
Nd & 0.00100 \\
Mg & 0.00011 \\
Al & 0.00174 \\
Si & 0.01063 \\
K & 0.00046 \\
$C_{A}$ & 0.00152 \\
Fe & 0.00035 \\
\hline
\end{tabular}

The second is te raised was: what percent of the flux ard dose is below the cadmium cutof? Lsing $0.4 \mathrm{eV}$ as the cutoff energy, MORSE predicts that $27.9 \%$ of the flux and $4.40 \%$ of the dose is below the cadmium cutoff, compared to $29.3 \%$ and $4.83 \%$ predicted by ANISN. We did an addjtional calculation to determine what percent of the dose and flux density at $1 \mathrm{~m}$ is due to retum from the room. This was accomplished to: rerun. ning the problem with ${ }^{25} \mathrm{Cf}$ in the $15-\mathrm{cm} \mathrm{D}_{2} \mathrm{O}$ sphere; however, this time the room air and walls were replaced with a racuum. The difference be tween the two runs gave that portion due to room retum.

The results were a $5.6 \%$ retum for the dose and $19.9 \%$ retum on the flux density. Table 2 gives the vacuum-differential spectrum as well as the fluence-to-dose-equivalent conversion factors used for all the calculations. These rem/n-cm values are those used in the original ANISN calculations,?

\section{References}

1. R. V. Griffith et al., "Mult-technique Characterization of Neutron Fields from Muderated ${ }^{152} \mathrm{Cl}$ and ${ }^{334}$ PuBe Sources," Wational and international Standardisation of Radiation Dosimatry. Vol. 1l, IAEA-SM-222/14.

2. Protection Aganst Neutron Radiation. NCKP Report No. 38 (1971). 
Table 2. The differential spectra for ${ }^{252} \mathrm{Cf}$ in $15-\mathrm{cm} \mathrm{D}_{2} \mathrm{O}$ sphere $\left(\mathrm{m} / \mathrm{cm}^{2}-\mathrm{MeV}\right)$.

\begin{tabular}{|c|c|c|c|c|c|}
\hline Group & E Tap & ANISN & MORSE & MORSE - Vacuum & $\mathrm{rem} / \mathrm{n}-\mathrm{cm}^{2}$ \\
\hline 1 & $18.000 \mathrm{MeV}$ & 0 & 0 & 0 & $4.278 \mathrm{E}-08^{4}$ \\
\hline 2 & 15.612 & 0 & 0 & 0 & $4,241 E-08$ \\
\hline 3 & 13.541 & $8.52 \mathrm{AE}-10$ & $8.690 \mathrm{E}-10$ & 8.893E-10 & $4.209 \mathrm{E}-0 \mathrm{~B}$ \\
\hline 4 & 11.745 & $2722 \mathrm{E}-09$ & 2.809E-09 & $2.803 E-09$ & $4.146 \mathrm{E}-0 \mathrm{~B}$ \\
\hline 5 & 10.187 & $7.571 E-09$ & $7.939 \mathrm{E}-09$ & $7.445 E-08$ & $4.985 E-08$ \\
\hline 6 & 8.835 & $1.606 \mathrm{E}-08$ & $1.686 \mathrm{E}-08$ & $1.717 \mathrm{E}-0 \mathrm{~B}$ & $4.085 E-08$ \\
\hline$i$ & 7.663 & 2884E-08 & $3.034 \mathrm{E}-08$ & $3,009 E-0 B$ & f.095E-08 \\
\hline B & $6.6+7$ & 4.967E-09 & $5.342 E=-09$ & $5.139 \mathrm{E}-0 \mathrm{~B}$ & $4.085 E-00$ \\
\hline 9 & 5.765 & 7.793E-08 & $7.991 \mathrm{~J}-08$ & $7.927 \mathrm{E}-0 \mathrm{~B}$ & $4.085 \mathrm{E}-04$ \\
\hline 10 & 5.000 & 1.162E-07 & $1.194 E-07$ & $1.219 \mathrm{E}-07$ & $4.085 E-08$ \\
\hline 11 & 4.205 & 1.469E- 07 & $1.551 E-07$ & $1.545 \mathrm{E}-03$ & $4.005 E-08$ \\
\hline 12 & 3.536 & $2.017 \mathrm{E}-07$ & 2099E-07 & $2.105 E-07$ & $4.016 \mathrm{E}-0.06$ \\
\hline 13 & 2.973 & $3.032 \mathrm{E}-07$ & $3.109 \mathrm{E}-07$ & $3.121 \mathrm{E} \cdot 07$ & $3.968 E-06$ \\
\hline 14 & 2500 & $3.470 \mathrm{E}-07$ & $3.551 E-07$ & 3.566E-07 & $3.968 E-08$ \\
\hline 15 & 1.988 & $3.013 \mathrm{E}-07$ & 3.165E-07 & $3.091 \mathrm{E}-07$ & 3.6BSE-0S \\
\hline 16 & 1.581 & $2946 \mathrm{E}-07$ & $3.120 \mathrm{E}-07$ & $2.892 \mathrm{E}-107$ & $3.779 \mathrm{E}-08$ \\
\hline 17 & 1.257 & $2574 \mathrm{E}-07$ & 2679E-07 & $2.465 E-07$ & $3.429 E-08$ \\
\hline 18 & 1,000 & $3.026 \mathrm{E}-07$ & $3.36 \mathrm{IE}-07$ & $2882 \mathrm{E}-07$ & $2053 E-09$ \\
\hline 19 & 0.841 & \$.355E-07 & $+.658 E-07$ & $4.256 E-07$ & $2769 \mathrm{E}-0 \mathrm{~B}$ \\
\hline 20 & 0.707 & $5.054 \mathrm{E}-07$ & 5.4"6E-07 & $3.099 \mathrm{E}-0$ ? & $2.395 E-08$ \\
\hline 21 & 0.595 & $5.457 \mathrm{E}-0^{\circ}$ & $5.8+8 E-07$ & $5.539 E-07$ & $2973 \mathrm{E}-68$ \\
\hline 22 & 0.500 & $7.473 \mathrm{E} \cdot 07$ & $8.020 \mathrm{E}-07$ & $7.241 \mathrm{E}-07$ & $1.502 E-08$ \\
\hline 23 & 0.224 & 2.498E-06 & 2592E-06 & $2469 \mathrm{E}-06$ & $8.170 \mathrm{E}-08$ \\
\hline 24 & 0.100 & $1.198 E-05$ & $1.20 \mathrm{tE}-05$ & 1.139E-05 & $25 \pi 2 E-09$ \\
\hline 25 & $1261 \mathrm{keV}$ & $8.963 \mathrm{E}-05$ & 8.943E-05 & 8.053E-05 & $1,002 E-109$ \\
\hline 26 & 1.54 & $6.144 \mathrm{E}-0$. & $6.001 E-04$ & $5.343 \mathrm{E}-04$ & $1,068 E-09$ \\
\hline 27 & $200 \mathrm{eV}$ & $5.305 E-03$ & $3.229 \mathrm{E}-03$ & $4.591 \mathrm{E}-03$ & $1.157 E-09$ \\
\hline 26 & 25.7 & 3. $\$ 3 C E-02$ & $3.3635-02$ & $2.815 E-02$ & $1.218 E-09$ \\
\hline 29 & 3.18 & 2.39?E-01 & $2.352 \mathrm{E}-01$ & $3.772 \mathrm{E}+00$ & $1.068 \mathrm{E}-09$ \\
\hline \multirow[t]{2}{*}{30} & 0.50 & $7.300 \mathrm{E}-00$ & $6.851 E-00$ & $3.772 \mathrm{E}-00$ & $1.06 \mathrm{SE}-09$ \\
\hline & 0.0001 & & & & \\
\hline
\end{tabular}

'E-08 denates $\times 10$ ', etc. 


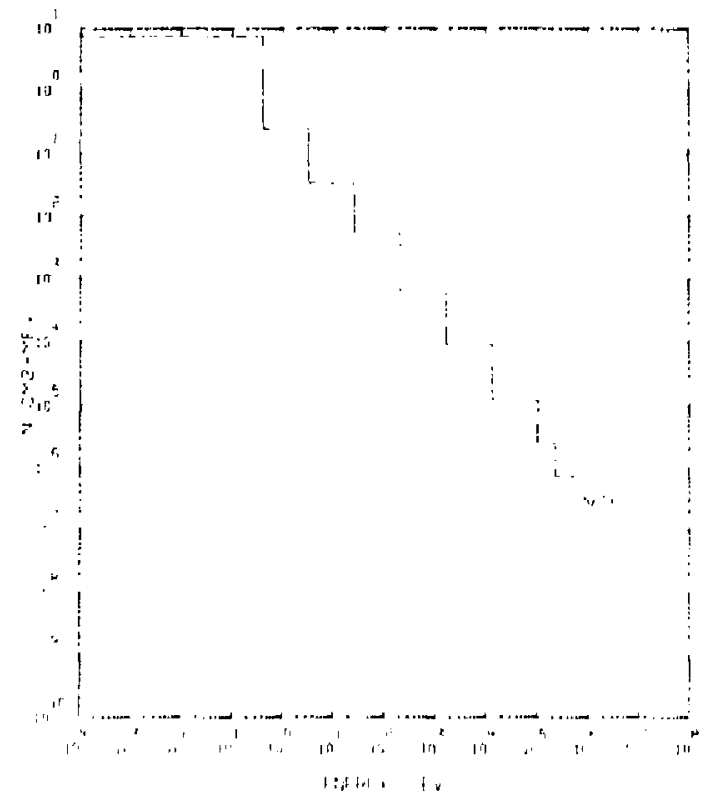

Figure 1. ANISN differential spectra for ${ }^{252} \mathrm{C} f$ in $15-\mathrm{cm} \mathrm{D}_{2} \mathrm{O}$ sphere in air.

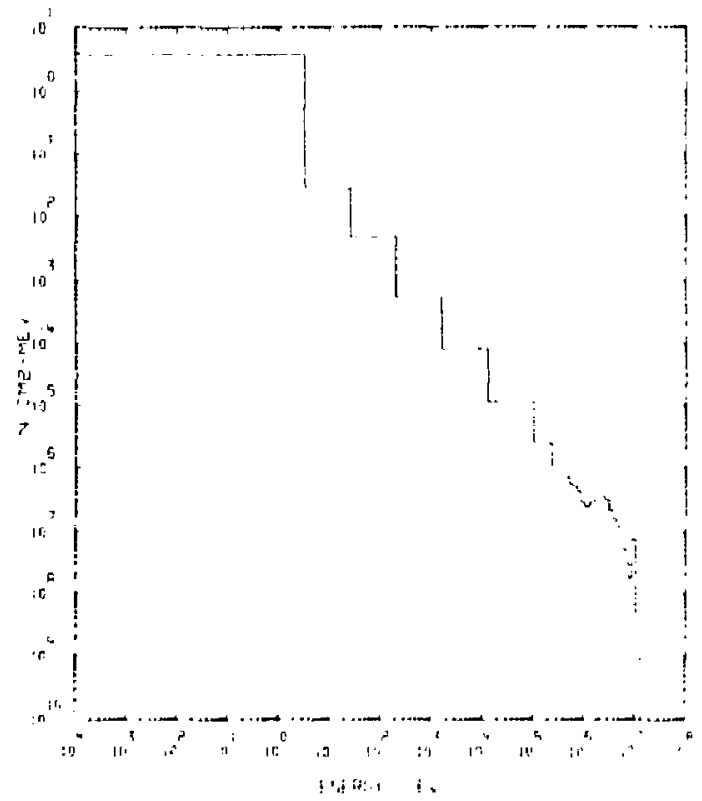

Figure 2. MORSE differential spectra for ${ }^{252} \mathrm{Cf}$ in $15-\mathrm{cm} \mathrm{D}_{2} \mathrm{O}$ sphere in vacuum. 


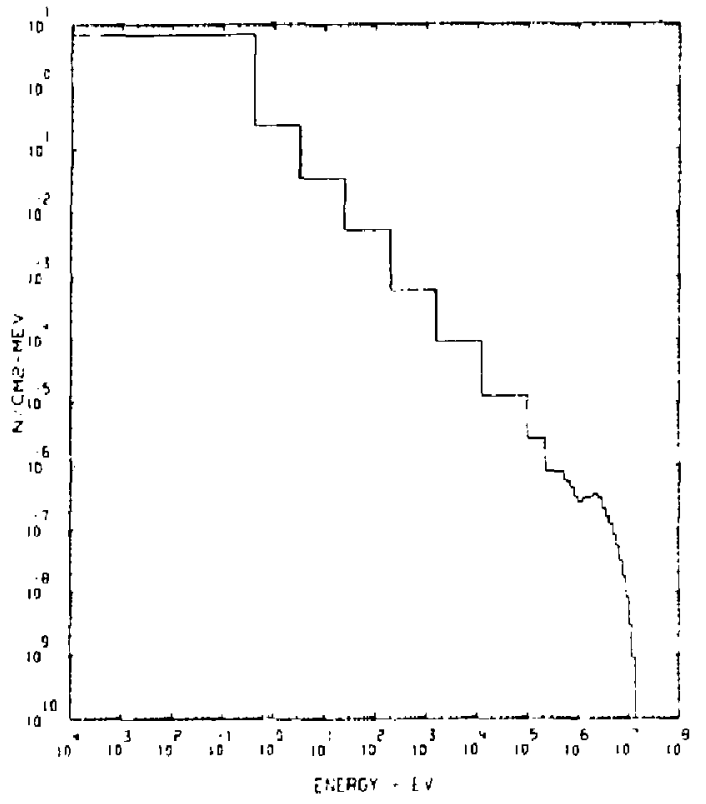

Figure 3. MORSE differential spectra for ${ }^{252} \mathrm{Cf}$ in $15 \cdot \mathrm{cm} \mathrm{D}_{2} \mathrm{O}$ sphere in air. 


\title{
Effective Absorption Thickness of the ${ }^{7}$ Li TLD for Beta Particles
}

\author{
D. E. Honkins
}

To cvaluate the reading of a thermoluminescence dosimeter (TLD) exposed to beta particles, a correction must be made for the absorption of the beta particles in the TLD material. This absorption results in the TLD's being irradiated nonuniformly and, for veri-liw-energy beta, the front surface of the TLD may be highly exposed and the back part mat not be exposed at all. Calibrations of TLDs are usually made to ${ }^{17} \mathrm{C} s$ gamma rays which irradiate the entire TLD uniformly. The correction for beta absorption requires that the thickness of the TLD and the energy of the beta be known. In place of the beta energy, (me can use the absorption curve results from aluminum if they are available. In both casess, however, the effective thickness of the TLD relative to aluminum, which is the standard for beta studies, is required. The "Beta Particle Range Energy Curve" given in the Rialmlycical Hoalfh Handlwol" is for aluminum (although this isn't stated in the book and the curve is often misused for other materialst. We determined the effective thickness of sur TL.Ds relative to aluminum.

\section{Introduction}

The thickness of materials used for beta shielding is usually stated in $\mathrm{mg} / \mathrm{cm}^{2}$ rather than in $\mathrm{cm}$. in.. mils, etc. This is because beta particles are absorbed very nearly the same for a given thickness in $\mathrm{mg} / \mathrm{cm}^{2}$ regardless of the type of material. However, there are fairly significant differences at low $-Z$ materials, such as lithium, and reasonably large deviations from aluminum are found.

At LLNL we use 35 -mil-thick ' $\mathrm{Li}$ in our personnel badges. The TLDs are $1 / 8 \times 1 / 8$ in, and weigh $-6.238 \mathrm{~g}$ each. The absorption thickriess for $1 \mathrm{~cm}^{2}$ of the TLD material is calculated to be $236 \mathrm{mg} / \mathrm{cm}^{2}$. This is considerably thicker than the value we determined below using absosption measurements.

\section{Measurements}

We compared the absoption of the 'Li TLD material with that of aluminum foilsi using two ${ }^{401} \mathrm{Sr}\left(E_{\mathrm{max}} 2.27 \mathrm{MeV}\right)$ and a ${ }^{204} \mathrm{Tl}\left(E_{\mathrm{max}} 0.766 \mathrm{MeV}\right)$

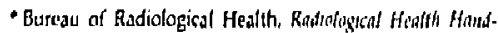
honk. U.S. Dupt. of HEW. Puhlic Health Service, Rockville, MD.
}

beta sources. We used the Eberline RO.7 for the large ${ }^{\text {(1) }} \mathrm{Sr}$ source at 11 and $30 \mathrm{~cm}$, and the pancake proke for the small ${ }^{4 /} \mathrm{S}$ 的 and the ${ }^{3 / 4} \mathrm{Tl}$ sources. The small ${ }^{41} \mathrm{Sr}$ and ${ }^{201} \mathrm{Tl}$ sources were used with beam flatteners (see the article on "Additional Calibrations of the PTB Beta Source" in this report). We found no significant variation that could be attributed to differerices in beta source energies or the use of different types of instruments.

Because the probe size of the RO.7 and the pancake probe is large compared with the size of the TLD array that we were going to use (see below), we used a small hole $(-5 / 16$-in.-diam) drilled in a $1 / 4$-in.-thick Al disk placed over the front of the probe of the two instruments. A series of 10 mil Al foils was used to obtain an absosption curve for aluminum, which is plotted in Fig. 1.

Twenty-five of the TLDs urere positioned in a $5 \times 5$ array with their edges touching to form a $5 / 8 \times 5 / 8$ in. block of TLDs, which was held together by wrapping with I-mil Al foil. Three of these TLD blocks were prepared and measurements made with each to ensure that no leakage between chips was occurring. The relative reading of the instruments was determined with the TLDs placed over the hole. The readings are indicated in Table 1 and by the boxes in Fig. 1 . 


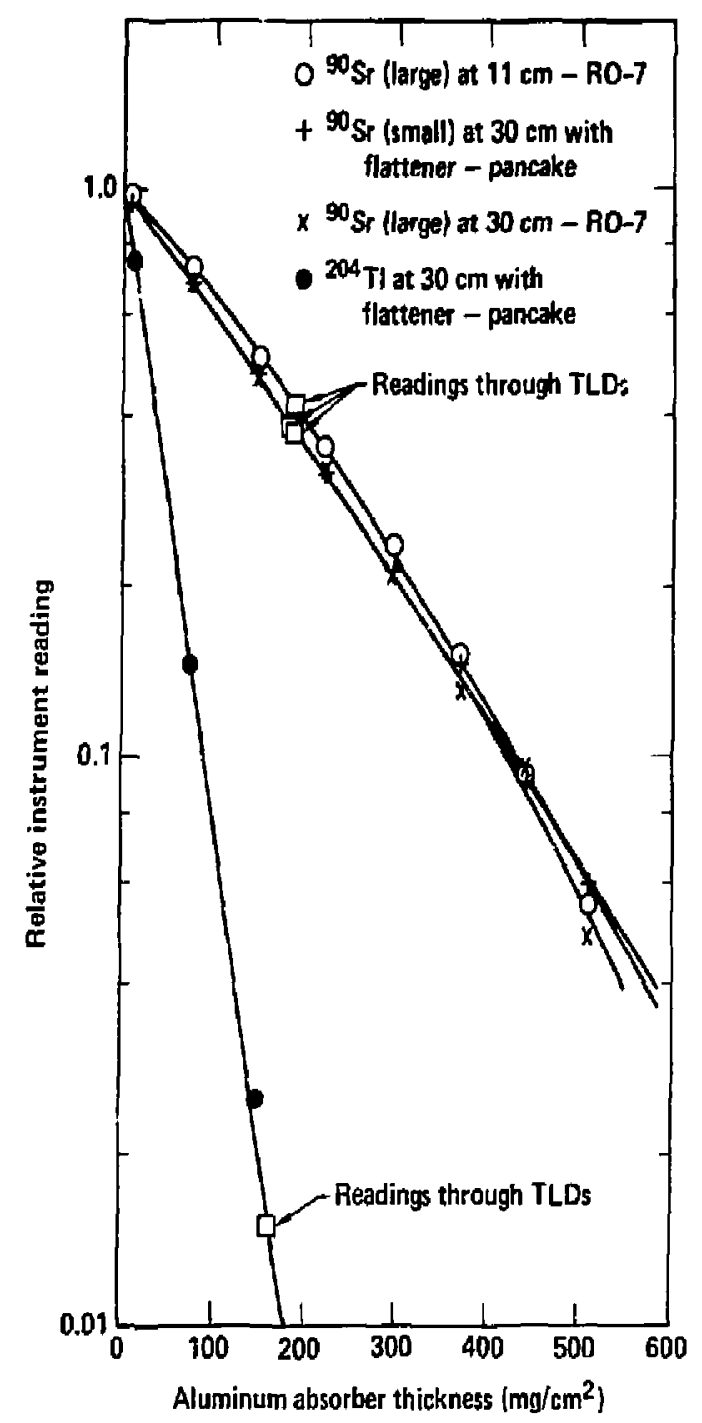

Figure 1. Effective absorption thickness of ${ }^{7} \mathrm{Li}$ TLDs (35-mil).

Results

The effective thickness of the TLD matertal and two layers of Al foil $\left(9.6 \mathrm{mg} / \mathrm{cm}^{2}\right)$ was found to be between 180 and $190 \mathrm{mg} / \mathrm{cm}^{2}$ when the ${ }^{x / 5}$ sources were used, and $160 \mathrm{mg} / \mathrm{cm}^{2}$ when the ${ }^{204} \mathrm{Tl}$ source was used. The count rates with the $\left.{ }^{21} \mathrm{~T}\right]$ source were small and the results correspondingly less accurate than the ${ }^{90} 5 \mathrm{r}$ results. 1 recommend that a value of $175 \mathrm{mg} / \mathrm{cm}^{2}$ be usgd as the effective thickness of our ${ }^{7} \mathrm{Li}$ TLD material for betas when $\mathrm{Al}$ is used as the reference material. This value applies only to the TLD material; other absorbers in front of the TLD must be considered separately. 
Tabie 1. Relative bela reading of instruments shielded by one thickness of "Li TLD material (35-mil), and the effective thickness (compared with aluminum).

\begin{tabular}{|c|c|c|c|c|}
\hline Instrument & Source & $\begin{array}{c}\text { Distance } \\
\text { (cm) }\end{array}$ & $\begin{array}{l}\text { Relative } \\
\text { instrument } \\
\text { seading }\end{array}$ & $\begin{array}{l}\text { Effective } \\
\text { absorption } \\
\text { thickness' } \\
\text { (mg/cms) }\end{array}$ \\
\hline RO-7 & ${ }^{*}$ Sr llarget & 30 & 0.386 & 180 \\
\hline $\mathrm{RO}-7$ & $\omega_{\text {Sp (large) }}$ & 11 & 0.116 & 190 \\
\hline Pancake & ${ }^{\infty} \mathrm{Sr}$ (smalli) with flattener & 30 & 0.375 & 185 \\
\hline Pancake & ${ }^{20} \mathrm{TI}$ with flallener & 30 & 0.015 & 160 \\
\hline
\end{tabular}

'includes $9.6 \mathrm{mg} / \mathrm{cm}^{2}$ of Al foil.

These results indicate that 'Li TLDs absorb less of the beta energy than do comparable thicknesses (in $\mathrm{mg} \mathrm{y}^{-}$') of aluninum. When calculaking the corteaticn for the energy absorbed in a TLD to determis'e the reading expected from a TLD or vice versa, the effective absorption thick. ness should be used. If the calculations are based on absorption curves from the Radiological Health Hamthunk or from measurements of beta absorption in aluminum, the effective TLD thickness of $175 \mathrm{mg} / \mathrm{cm}^{2}$ must be used. An example of this cor- rection was a measurement we recently made of the beta- and gamma-dose rates of the Godiva IV Critical Assembly at LANL, We used TLDs to measure the dose rates anld corrected their readings for self-absorption using the information from an absorption clirve obtained at the Assembly with aluminum foils. If we had used the actual rather than the effective Al thickness, the final evaluated beta-dose rate would have been significantly greater tha, the actual dose rate. 


\title{
Evaluation of the Fire Properties and Potential Safety Hazard of Building 431's Exterior Wall Panels
}

\author{
H. K. Hasegawa, K. Staggs, S. J. Priante, and I. A. Sharry
}

We have performed tests on samples of exterior wall panels from Bldg. 431 at LLNL to determine the fire properties-the potential flamespread and resultant smoke generation-of the coating material (a felt and asphalt composite). These tests will also be used to assess the potential hazard to life if the panels are exposed to a fire. This information will help the Fire Protection Engineering Group to evaluate the proposed expansion plans for Bldy. 431 and to determine appropriate countermeasures to protect life and property.

\section{Introduction}

The coating material has been applied to cor. rugated steel panels. We considered two fite exposure scenarios: (1) an "outside-in" exposure that would subject the exterior side of the panel (coated side) to flame, and (2) an "inside-out" live that would expose the interior side funcoated side) to flame. These two exposures would enable us to evaluate the fire and smoke response of the coating as a result of direct flame impingement and also of indirect heating. Our goals were:

- Define an appropriate and realistic exposure fire.

- Perform two large-scale fire experiments and monitor the following;

1. Time to ignition.

2. Rate and extent of namespread.

3. Smoke generation (qualitative).

4. Combustion-gas composition and rate of acid ion generation.

5. $\mathrm{O}_{2}, \mathrm{CO}, \mathrm{CO}_{2}$, and hydrocarbon concentrations.

6. Mass loss rate of burning coating.

7. Temperatures-

a. Both exposed- and unexposedface temperatures on panels.

b. Throughout the test cell.

8. Thermal fluxes.

\section{Survey of Fire-Exposure Studies}

We performed the following survey to ensure that we defined an appropriate and realistic fire exposure to evaluate the fire response of the panel coating material. Since energy conservation has gained increasing importance, fire research activity dealing with exterior walls has rapidly increased. The primary reason for this stepjed-up activity was the appearance of a number of exterior wall systems intended to reduce thermal transfer by using various thicknesses of foamed plastics. Many of these foamed plastics presented a considerable fire hazard if not protected by an appropriate fure-resistant coating or barrier.

One of the primary scenarios investigated for exterior fire spread was flames extending out of a fully inyolved compartment window and imping. ing on the exterior wall finish above the window. A number of research organizations performed room-bumout experiments to characterize this thermal assault through a window on the exterior of the enclosure. Table 1 compares the results of experiments at the Building Research Institute (BRI) in Japan, Underwriters Laboratonies (UL), and Stanford Research Institute (SRI), International. BRI and UL used wood cribs in similar-size compartments for the various fuel loads listed. The SRI results are taken from experiments using a fuel oil bumer to produce the various fire exposures. Actually, the $\mathrm{SRI}$ apparatus was designed to simulate fire intensities developed in both real-life situations and exemplar compartment bums (e.g. those by BRI and UL) to evaluate the fire performance of traditional exterior wall treatments.

Figures 1 and 2 show isotherms of tlames extending out of the windows of the experimental compartment fires. They illusirate the difference 
(a)

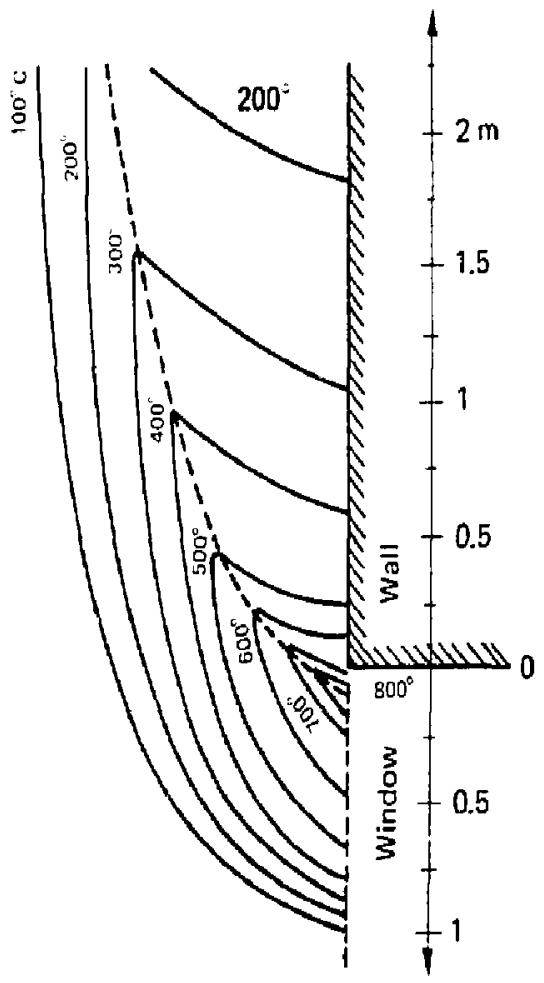

(b)

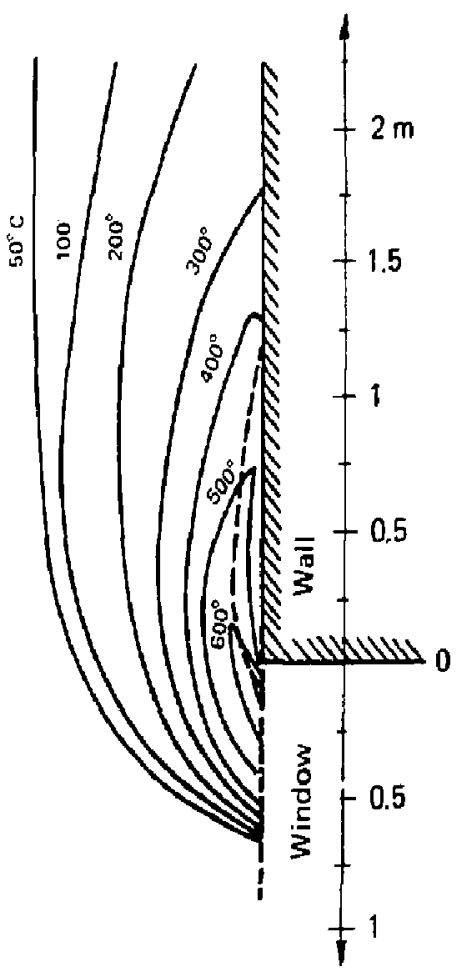

Figure 1. Study of convection currents created by fires of large area (from Ref. 1).

in flame characteristics as a result of varying room size, fuel loading, and window opening factor $\left(\begin{array}{c}A, \bar{H} \\ i_{1}\end{array}\right)$." The flame in Fig. la had a fuel loading of $41 \mathrm{~kg}$ of wood per $\mathrm{m}^{2}$ of floor area, or $12 \mathrm{~kg} / \mathrm{m}^{2}$ of total surface bounding the room with a window opening factor of $0.028 \mathrm{~m}^{1 / 2}(167 \mathrm{~cm}$ high $\times 91 \mathrm{~cm}$ wide). Figure $1 \mathrm{~b}$ corresponds to a fire loading of $40 \mathrm{~kg}$ of wood per $\mathrm{m}^{2}$ of floor area, or $10 \mathrm{~kg} / \mathrm{m}^{2}$ of total surlace area and a window opening factor of $0.060 \mathrm{~m}^{1 / 2}(1 \mathrm{~m}$ high $\times 3 \mathrm{~m}$ wide). Figure 2 summarizes the results of 30 tests in which the fuel load was varied from $24,4 \mathrm{~kg} / \mathrm{m}^{2}\left(5 \mathrm{lb} / \mathrm{ft}^{2}\right)$ of floor to $97.6 \mathrm{~kg} / \mathrm{m}^{2}\left(20 \mathrm{lb} / \mathrm{ft}^{2}\right)$ and window opening sizes from $0.61 \mathrm{~m}$ wide by $1.82 \mathrm{~m}$ high $101.82 \mathrm{~m}$ wide by $2.44 \mathrm{~m}$ high.

- $A$ = total window area of room, $H=$ height of window: $A_{1}=$ total ares of the surfaces bounding the room.

\section{Exposure Fire Calibration}

Excluding the one for $20 \mathrm{lb} / \mathrm{ft}^{2}$ and $1.0 \mathrm{gpm}$. the experimental fuel loads and resultant temperature profiles in Table 1 are sealistic fire exposures for exterior walls. Therefore, simulating selected temperatures from the table with our burner would provide an ignition source with enough energy to produce a fairly severe fire exposure with a flame height short enough $(-1 \mathrm{~m})$ to monitor flame spread due to the burning of the coating material.

On the basis of the temperature ranges in Table 1 at the 1-ft. and 4-ft heights, we opted for average temperatures of between $400^{\circ} \mathrm{C}$ and $600^{\circ} \mathrm{C}$ and between $200^{\circ} \mathrm{C}$ and $400^{\circ} \mathrm{C}$, respectively. We used a $0.89-\mathrm{m} \times 1.98$-m sheet of 1.27 . cm gypsum wallboard as the calibration panel to characterize the exposure fire. In order to find a proper gas-flow setting for the desired fire, a 

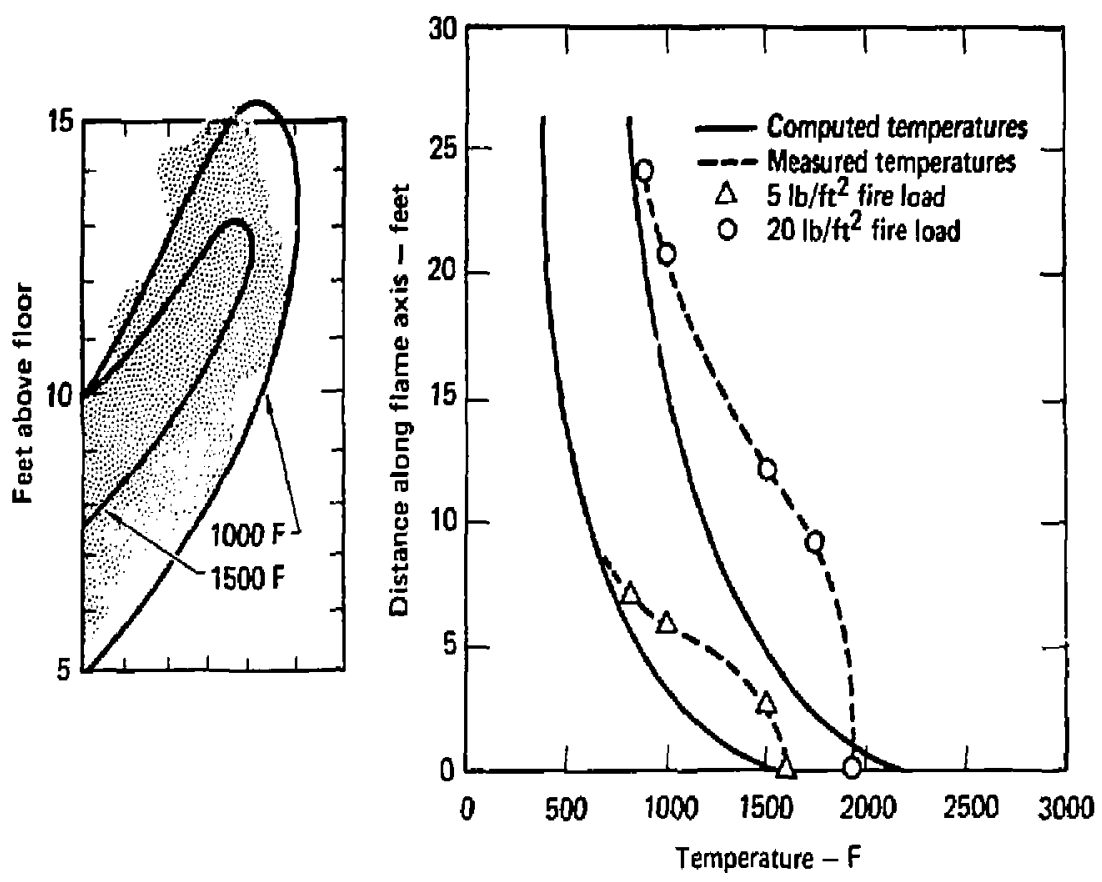

Figure 2 The projection of flames from buming buildings (from Ref. 2).

multi-nozzled bumer was ignited for a short duration to produce a flame pattern on the panel which would indicate where to locate thermocouples and heat-flux gauges.

The calibration procedure was to ignite the burner and adjust the ratural gas fow until a satisfactory flame height was established, at which point the gas flow was noted. Then the various temperatures and fluxes produced by this gasflow rate were monitored and recorded. This procedure was repeated until we achieved the combination of the flame height $(-1 \mathrm{~m})$ and temperatures at the $1-\mathrm{ft}$ and $4 \mathrm{ft}$ heights we defined for the igrition source. We weie able to time

Table 1. Comparison of room-burnout experiments.

\begin{tabular}{|c|c|c|c|c|c|c|c|c|}
\hline & \multicolumn{8}{|c|}{ Fuel load } \\
\hline & \multicolumn{2}{|c|}{$\mathrm{BRI}^{d}$ (wood) } & \multicolumn{2}{|c|}{ UL'b (wood) } & \multicolumn{4}{|c|}{ SRI' (gasoline) } \\
\hline & $85 \mathrm{Jb} / \mathrm{f}^{2}$ & $8.2 \mathrm{lb} / \mathrm{ft}^{2}$ & $5 \mathrm{lb} / \mathrm{ft}^{r}$ & $20 \mathrm{lb} / \mathrm{ft}^{2}$ & $0.25 \mathrm{gpm}$ & $0.5 \mathrm{Bpm}$ & $0.75 \mathrm{gpm}$ & $1.0 \mathrm{gpm}$ \\
\hline $\begin{array}{l}\text { Tolal flame } \\
\text { extension above windows (fi) }\end{array}$ & 5 & 5.75 & 5 & & 2 & 4 & 6 & B \\
\hline $\begin{array}{l}\text { Temperalure }\left({ }^{\circ} \mathrm{C}\right) \\
1 \mathrm{fl} \text { above window }\end{array}$ & 500 & 500 & 540 & 980 & 270 & 620 & 680 & 790 \\
\hline $\begin{array}{l}\text { Tempersture } \\
\text { ift above window }\end{array}$ & 300 & 400 & 400 & 870 & 100 & 310 & 560 & 750 \\
\hline $\begin{array}{l}\text { Tempersture } \\
6 \text { a doove window }\end{array}$ & 200 & 200 & 340 & 705 & 125 & 210 & 260 & 310 \\
\hline
\end{tabular}

- gullding Rewearch Indil ute, Japan.

- Undenwriters Laboraloriet.

'Staniord Research Institute.

Above top edge of window 
our gas flow to produce a source fire with a flame height about $1 \mathrm{~m}$ and temperatures of approximately $500^{\circ} \mathrm{C}$ at $1 \mathrm{ft}$ and $250^{\circ} \mathrm{C}$ at $4 \mathrm{ft}$. These levels fit the criteria we abstracted from Table 1 fairly well.

\section{Experimental Setup}

The experimental apparatus shown in Fig. 3 was designed for the performance of large-srale vertical cable burns but was well suited for this experimental program. As it tumed out, we were provided with panel samples which were coated on hoth sides; therefore, we could evaluate the panel response to both fire scenarios (outside-in and inside-out) with the same experiment. Figure 4 shows the test panel configuration along with the location of both exposed-and unexposed.face thermoxouples and the burner. Because the actual wall panel was $2 \mathrm{ft}$ wide, we added a $2-\mathrm{ft}-2 \mathrm{-in}$. wide $(0.66-\mathrm{m})$ corrugated aluminum panel on each side (see Fig. 4) to prevent flames from wrapping around the edges of the test specimer.

The panel configuration was then suspended from the test frame by a cable which was attached to a load cell to monitor dynamic mass loss from the burming of the panel coating. In addition to the above, in monitored and recorded the following:

- Temperatures-

1. Throughout the test cell.

2. Intet and exhaust air temperatures.

3. Exposed- and unexposed-face temperatures on panel.
- Ventilation rate.

- Heat fluxes (calorimeters) at several locations, approximately $30 \mathrm{~cm}$ from the panel.

- Gas analyzers-

1. Oxygen depletion.

2. $\%$ Carbon dioxide.

3. \% Carbon monoxide.

4. \% Hydrocarhons.

5. Combustion-gas acid ion concentration.

- Videotape and 35-mm photographs.

\section{Results}

The natural gas flow to the bumer was set to produce the exposure fire defined in the calibration burns, and the bumer ignited. The panel was continually exposed to the ignition source for $660 \mathrm{~s}(11 \mathrm{~min})$ in ' $\mathrm{h}$ very little, if any, fize contribution from the coating matejial. Figure 5 shows the experiment at the point of greatest flameheight and Fig. 6 illustrates the post-test condition of the panel. The char pattern on the panel is primarily an imprint of the exposure fire, indicating that the material did not contribute to flamespread. The non-burning of the coating is strongly substantiated by Fig. 7, which is a composite plot of the exposed-face temperatures. Note that, once the exposure flame stabilizes, the temperatures flatten out and remain constant for the duration of the test, which indicates that no combustion of the coating occurred. The back-face temperatures were about $45 \%$ of the exposed-face temperatures (on the average). Finally, most sensors monitoring

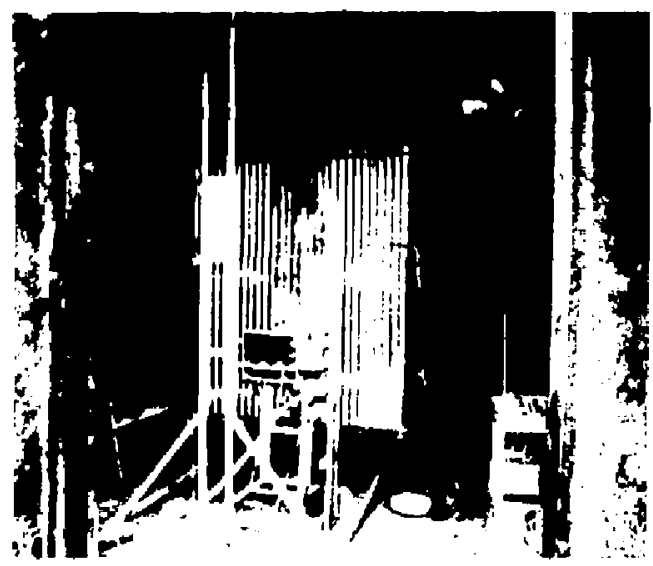

Figure 3. Photograph of experimental apparatus. 


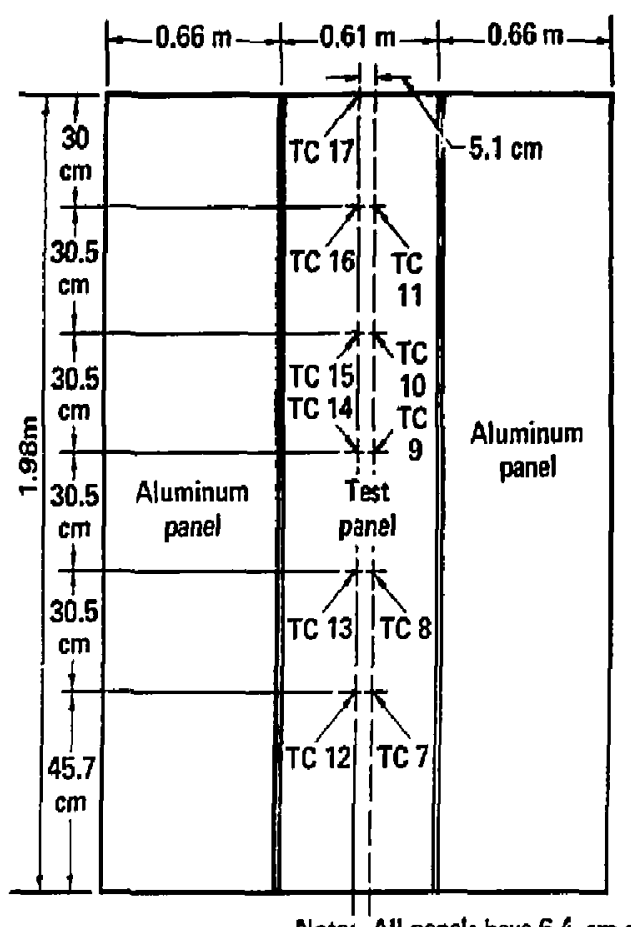

Note: All panels have $6.4-\mathrm{cm}$ corrugations

Front view

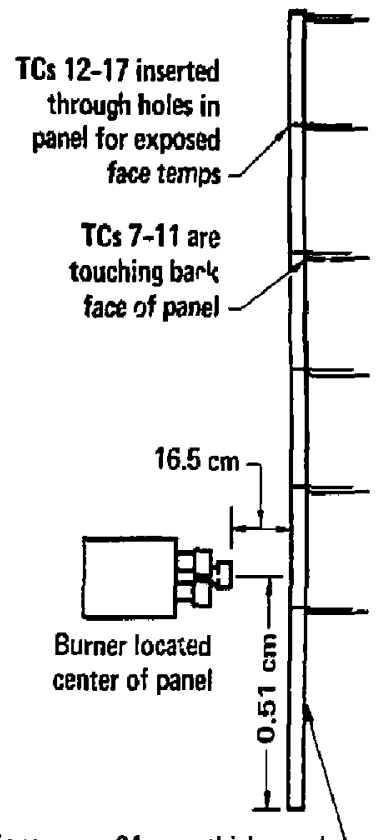

64-mm-thick panel

Side view

Figure 4. Building 431 test panel, showing locations of thermocouples (TCs).

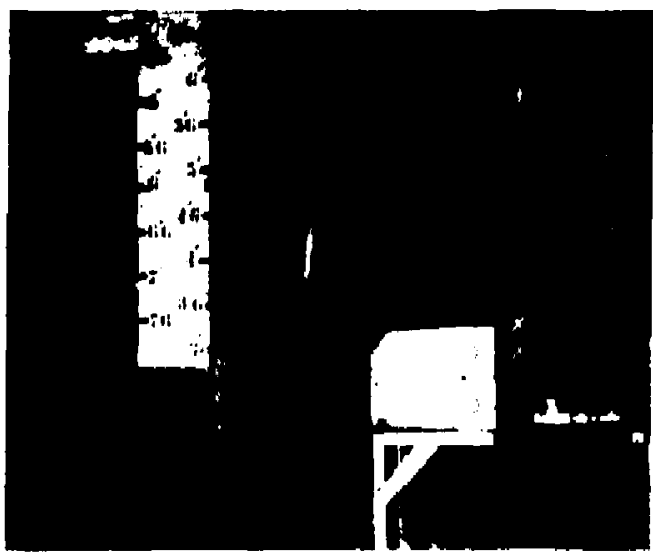

Figure 5. Pholograph of latter stage of experiment. 


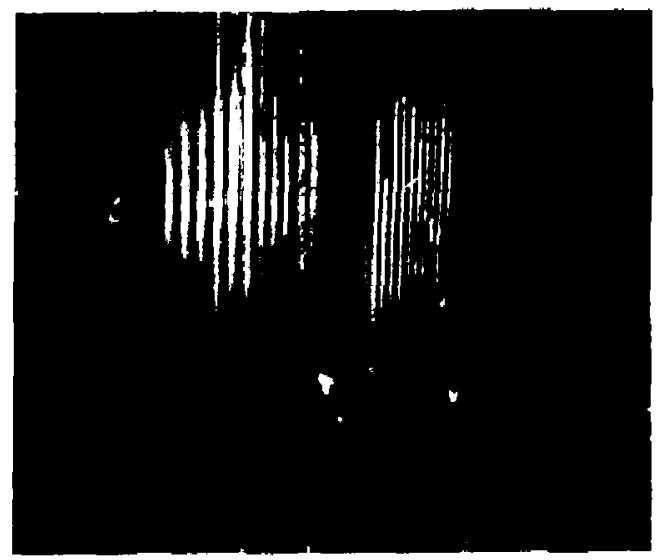

Figure 6. Post-test char pattern on panel.

test-cell air temperatures recorded only a minor rise above ambient conditions. Other significant data were as follows:

- In correspondence with the temperature data, incidert heat fluxes were very low.

- At a forced ventilation rate of 550 liters $/ \mathrm{s}$ there was no detectable oxygen depletion.

- Similarly, there was no mass loss recorded by the load cel].

- Carbon monoxide, carbon dioxide, and hydrocarbon readings were at pre-test levels.

Furthermore, analysis of the combustion products for acid components such as $\mathrm{HCl}$ and formaldehyde rendered negative results.

\section{Analysis of the Coating Material}

Thermogravimetric analysis (TGA) was perlormed on a portion of the sample to determine the $\%$ volatiles, initial degradation temperature, gross degradation temperature, and \% ash remaining. A 4.52-mg sample was placed in the TGA apparatus in an air atmosphere, and temperature was programmed at $20^{\circ} \mathrm{C} / \mathrm{min}$ from room temperature to $800^{\circ} \mathrm{C}$. Rosults were as follows:

$\begin{array}{ll}\text { \% volatiles } & -0.5 \% \text { at } 125^{\circ} \mathrm{C} \\ \text { Onset of degradation } & 260^{\circ} \mathrm{C} \\ \text { Onset of gross degradation } & 390^{\circ} \mathrm{C} \\ \% \text { ash } & 60 \% \text { at } 750^{\circ} \mathrm{C}\end{array}$

A sample was prepared for GC-MS analysis by nuning an appsoximately 20 -mg sample in the
TGA apparatus up to the final degradation temperature $\left.(80)^{\circ} \mathrm{C}\right)$, cooling the unit to room temperature, and washing down the furnace tube assembly with $10 \mathrm{ml}$ of methylene chloride io remove the pyrolyzed product. This samplecollection procedure was repeated because there was little evidence of pyrolysis products on the fumace tube after the first run.

The methylene chloride-sample mixture was then concentrated down to low volume $(\sim 0.5 \mathrm{ml})$, and a $4-\mu \mathrm{l}$ aliquot was injected onto the $\mathrm{GC}$ column for component separation. The GC condithons were as follows:

$\begin{array}{ll}\text { Column } & \begin{array}{l}25-\mathrm{ft} \text { fused-silica methyl } \\ \text { silicon fluid capillary }\end{array} \\ \text { Starting temperature } & 50^{\circ} \mathrm{C} \\ \text { Temperature ramp } & 10^{\circ} \mathrm{C} / \mathrm{min} \\ \text { Final temperature } & 230^{\circ} \mathrm{C}\end{array}$

The separated components then went directly into the mass spectrometer, where earh compound underwent fragmentation by high-energyelectron impact. The spedific chemical patterns of each component produced by the fragmentation were then stored on a computer disk.

The stored information on each compound was then compared against approximately 40,000 compounds on a library tisk and the 10 best "hits" from the library search were printed out. The "hits" were then subjected to an additional computer program which compares individual mass peak numbers between the sample and the library "hits." Table 2 lists compounds in the panel insulation identified using this method. 


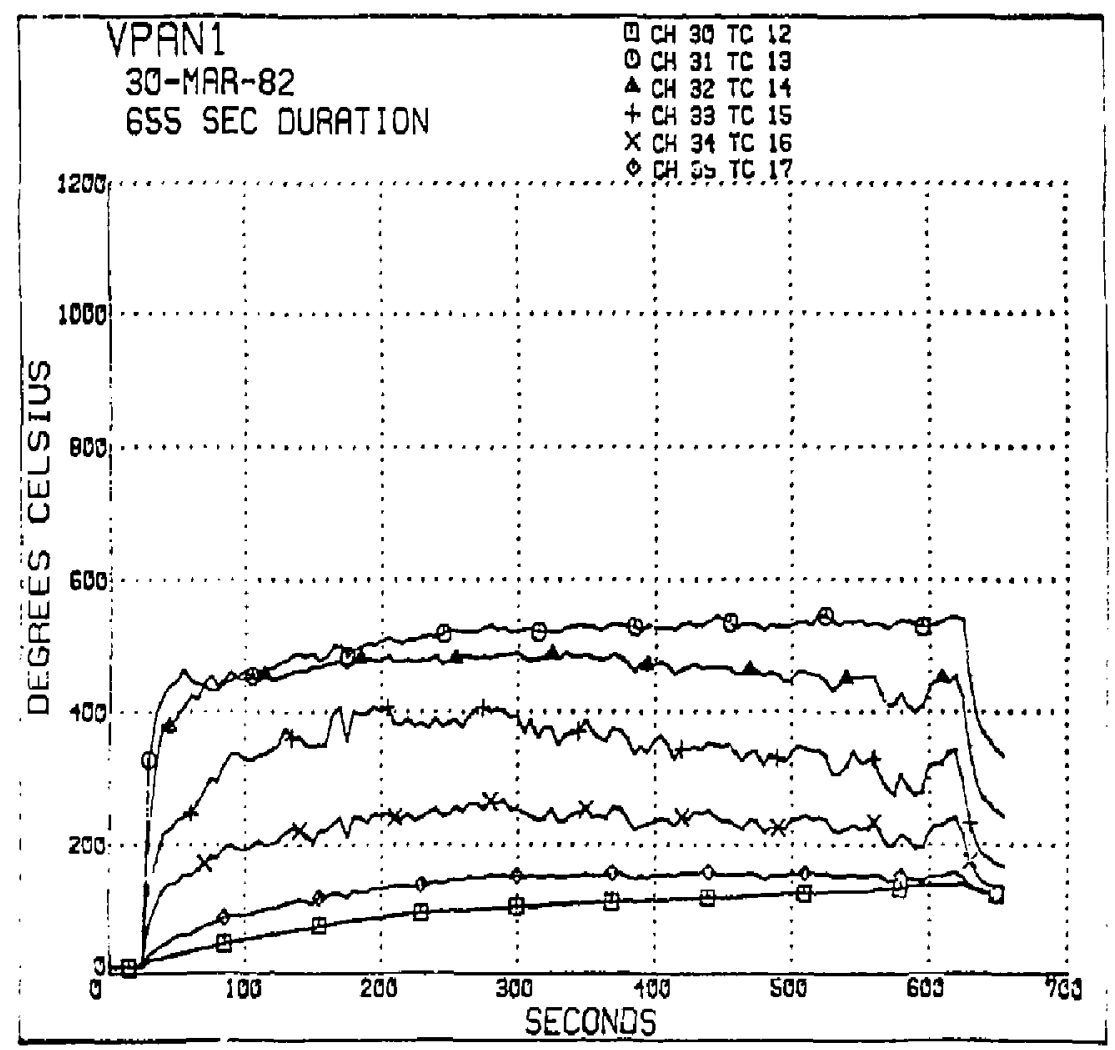

Figure 7. Exposed face temperatures.

Table 2. Analysis c.. degradation products.

\begin{tabular}{|c|c|c|c|c|c|c|c|c|}
\hline \multirow[b]{2}{*}{ Degradation products } & \multirow{2}{*}{$\begin{array}{c}\text { Flash } \\
\text { point }\left({ }^{\circ} \mathrm{C}\right)\end{array}$} & \multirow{2}{*}{$\begin{array}{l}\text { lgnition } \\
\text { point }\left({ }^{\circ} \mathrm{C}\right)\end{array}$} & \multirow{2}{*}{$\begin{array}{l}\text { Boiling } \\
\text { point }\left({ }^{\circ} \mathrm{C}\right)\end{array}$} & \multirow{2}{*}{$\begin{array}{c}\text { Water } \\
\text { soluble? }\end{array}$} & \multirow{2}{*}{$\begin{array}{l}\text { Extinguishung } \\
\text { method }\end{array}$} & \multicolumn{3}{|c|}{ NFPA hazafd identification } \\
\hline & & & & & & Health & Flammability & Reartivity \\
\hline $\begin{array}{l}\text { 2,2-diethyl-1,3- } \\
\text { propanediol }\end{array}$ & 102 & - & 160 & Yes & Aicohol foam & 2 & $:$ & 0 \\
\hline Phthalic acid & 168 & - & 289 & - & - & 0 & & 0 \\
\hline Phttalic anhydride & 152 & 570 & 284 & No & $\mathrm{H}_{2} \mathrm{O}$ or foam & $2^{2}$ & $1^{\mathrm{b}}$ & o \\
\hline 1-ejcosanol & - & - & - & - & - & - & - & - \\
\hline Nonadecanol & - & - & - & - & - & - & - & - \\
\hline 2L, 4D-dimethyl heptanol & - & - & - & - & - & - & - & - \\
\hline Octyl acetate & 71 & 268 & 199 & No & - & 2 & 2 & 0 \\
\hline Bela hetol-nitro octane & - & - & - & - & - & - & - & - \\
\hline $\begin{array}{l}\text { 1,2-epoxy-2,4-dimethyl } \\
\text { pentane }\end{array}$ & - & - & - & - & - & - & - & - \\
\hline
\end{tabular}

- Chemical is hazardous when inhaled, but self-contained apparatus will protect against inhalation.

"Chemiral must be preheated to ignite. Water may cause frolhing if it gets below the surface of the liquid and turns to sleam. 


\section{Conclusions}

On the basis of the preceding test methods and the sample provided us, we concluded that the coating on the pane/s from Bldg. 431 would not contribute to the fire or generate any significant quantities of smoke. Because of this negative result we attempted to ignite the coating by cutting holes through the panel with an acetylene torch. The material did ignite into small flamelets around the holes, but would extinguish shortly after removal of the torch.

It shouid be noted that the preceding results were from the specific panel supplied us. Vari- ables such as coating-mix variations, coating depth, etc. could influence the flammability of the panels.

\section{References}

1. S. Yokoi, "Study of Convection Currents Created by Fires of Large Areas," International Symposium on the Use of Models in Fire Research, Wastinglon, 1961, pp. 130-147.

2. L. G. Seigel, "The Projection of Flames from Burning Buildings," Fire Technology 5 (February 1969). 


\section{Publication Abstracts}


G. R. Endres, J. M. Aldrich, L. W. Brackenbush, L. G. Faust, R. V. Griffith, and D. E. Hankins, Veutron Dosimetry at Commercinl Nuclear Plants, Nuclear Regulatory Commission, NUREG/CR1769 (1981): Battelle Pacific Northwest Labordtories, Richiand, WA, PNL-3585 (1981).

A series of measurements of neutron energy spectra, neutron dose-equivalent rates, and personnel neutron dosimeter responses taken at six commercial nuclear power plants are discussed in detail. Results $\therefore$ i neutron spectral measurement indicate average or effective neutron energies helow $200 \mathrm{keV}$ at all locations :tudied inside containment of pressurized water reactor (PWR) power plants. The neutron energies were somewhat higher near containment penetrations at a boiling water reactor (BWR) power plant. Neutron spectra were obtained using multisphere and ${ }^{3} \mathrm{He}$ proportional counter spectrometer svstems. Graphs of all unfolded spectra from both measurement systems are presented.

Dose-equivalent rates were determined. where possible, both from the multisphere spectra and from event-size spectra measured with a tissue-equivalent proportional counter (TEPC). There is generally good agreement hetween the two techniques (within about 20\%), although quality factors $Q$ derived from the two types of spectra are quite different.

Results obtained from neutton track emulsion type A (NTA film), polycarbonate track etch and CR-39 plastic, and thermoluminescence (TLD albedo) personnel dosimeters are presented. In the neutron spectra found in reactor containment, the NTA film and polycarbonate track etch dosimeters failed to respond above the levels needed for positjve indication of dose. The CR-39 track etch dosimeters showed a low response (50\% or less) when calibrated with ${ }^{232} \mathrm{Cf}$ neutron sources. Thermoluminescence-albedo dosimeters showed a very high response but require spectral corrections for proper interpretation.

D. Hankins, Beta-Energy-Respouse Determination of the RO.7 Survey Instrument, Lawrence Livermore National Laboratory, Livermore, CA, UCID19484 (1982).

We obtained an RO-7 instrument from the Eberline Instrument Corporation to use in a study of the beta dose rates from the Godiva IV Critical Assembly at Los Alamos. We have performed a limited evaluation of the insintinent and have de. termined its energy dependence for beta particles.
D. Hankins, Evaluation of Neutron Dose Received by Periolmel al the LLNL, Lawrence Livermore National Laboratory, Livermore, CA, UCID-19385 (1982).

This report was prepared to document the techniques being used to evaluate the neutron exposures received by personnel at LLNL. Two types of evaluations are discussed, covering the use of the routine personnel dosimeter and of the albedo neutron dosimeter. Included in the repart are field survey results which were used to determine the calibration factors being applied to the dosimeter readings. Calibration procedures are discusised and recommendations are made on caljsistion and evaluation procedures.

D. Hankins, "Neutron and Gamma-Ray Dose Measurements at the Los Alamos Critical Assembly-SHEBA." presented at ANS meeting, Nov. 1981, San Francisco, CA; Nuclear News 24, No. 12 (1981). (Abstract only)

D. Hankins, Personnt! Neutron Dosimetry, presented at INPO Radiological Protection Seminar, April 5, 1982, Houston. TX (Institute of Nuclear Power Operations, 1820 Water Place. Atlanta. GA); Lawrence Livermore National Laboraion; Livermore, CA, UCRL-88131 (1982).

D. Hankins, "Personnel Neutron Dosimetry Studies at the Lawrence Livermore National Laboratory," Eighth DOE Workshop on Persormel Neutron Dosimetry, fune 18-19, 1981, Louisville. K"', Lawrence Livermore National Labotatory, Livermore, CA, UCRL-86170 (1981); Battelle Pacific Northwest Laboratories, Richland, WA, PNL-SA9950 (1981).

M. W. Nathans, Duties and Responsibilities of Employcrs and Employces under OSH Acts and the Industrial Hygienist, presented at Annual American Industrial Hygiene Conference, Cincinnati, $\mathrm{OH}$, June 6-11, 1982.

The Occupational Health and Safety At imposes, inter alia, upon employers the duty to comply with standards promulgated under the Act, and to furnish employment and workplaces free Irom recognized hazards that may cause death or serious ham to employees (29 U. S. C. 654). Employees have a duty to follow the law and the rules as they apply to them. Similar clauses are found in many state statutes. 
Court and OSHRA decisions concerning these "duty clauses" affect the mutual relationaship between an employer and the industrial hygienist or safety engineer, because they indicate the role of these professionals in the statutory scheme.

The primary issues of interest are the meaning of "recognized hazard" in the genteral duty clause, and what is required of an employer to enable him to avoid or defend a citation successfully. Following the standard of knowledge in the industry is not necessarily sufficient; an employer maybe held to a higher standard. An employer must discover and eliminate feasibly preventable hazards. The standard is the precautions a conscientious safety expert would take. These include the prevention of foreseeablc employee misconduct by adequate safety training and enforcement of the work rules.

We have found no case law dealing specifically with an employer's remedies against an expert who makes a mistake which results in the employer's being cited. Such remedies would depend on whether the expert is an independent contractor or an employee. If the latter, the enployer has probably only one recourse: fire the "culprit." If the former, an action for negligence may be taken, in which the employer may seek to recover all his provable damages approximately (i.e., legally) caused by the substandard performance of his consultant. The employer would have to prove, however, that thc expert has failed to meet the standard of expertise that prevails in the community. An action on the contract for breach of wartanty may be taken only if the contract contains an express warranty.

C. T. Prevo, Neutron and Gamma Radiation Transport Problems Solved Using TARTNP and MORSE Codes, presented at Ninth DOE Workshop on Personnel Dosimetry; Lawrence Livermore National Laboratory, Livermore, $\mathrm{CA}$. CONF-820668 (1982).

TARTNP and MORSE are Monte Carlo sodes currently used at LLNL to solve neutron and gamma radiation transport problems in Health Physics. They are useful in a personnel neutron dosimetry program for the calculation of dose rates, spectra, and detector responses for various neutron source and detector configurations. Examples include the response function of the PNR-4 remmeter and spectra from various sources and moderators in the LLNL calibration facility.

R. A. da Roza, C. A. Cadena-Fix, G. J. Carlson, K. E. Hardis, and B. J. Held, Reproducibility of Respirator Fit as Measured by Quantitative Fitting Tests, Lawrence Livermore National Laboratory, Livermore, CA, UCRL-87244 (1982).

The Occupational Safety and Health Adminstration (OSHA) is promulgating new health standards in which quantitalize respirator fitting is iequired. However, there has been controversy and confusion in the past few years regarding respirator fitting methods and their effectiveness. Members of the LLNL's Hazards Control Department employ a quantitative chamber to fit facepieces to users of respiratory protective devices. We are reporting the results of a study to determine the variability in protection factors obtained for multiple facepiece fittings, with particular emphasis on the protection fail/pass limits.

On the basis of this work, the following statistical statements can be made regarding the protection that would be afforded by a facepiece properly fitted to the user:

- The probability density function for the fit cbtained by one individual wearer with a given facepiece is well described by a log-normal cistribution.

- The geometric standard deviation for the above distribution varies widely among individtals and facepieces, making it necessary to measure it for each wearer/facepiece combination.

- A risk-plot method can be used to calculate the exposure risk to a wearer.

J. W. Stengel, Eniaronmental Testing of Escape Brealling Apparatus, presented at Twelfth Intersocietal Conference on Environmental Systems, San Diego, $C A$, July 19-21, 1982; Lawrence Livemore National Laboratory, Livermore, CA, LCRL.87580 (1982). 